Flavia Costa Nunes Machado

\title{
Análise do jitter com agulha concêntrica em pacientes com miastenia gravis autoimune adquirida
}

Tese apresentada à Faculdade de Medicina da Universidade de São Paulo para obtenção do titulo de Doutor em Ciências

Programa de Neurologia

Orientador: Prof. Dr. Paulo Eurípedes Marchiori Coorientador: Prof. Dr. João Aris Kouyoumdjian

São Paulo 
Dados Internacionais de Catalogação na Publicação (CIP)

Preparada pela Biblioteca da

Faculdade de Medicina da Universidade de São Paulo

Creprodução autorizada pelo autor

Machado, Flavia Costa Nunes

Análise do jitter com agulha concêntrica em pacientes com miastenia gravis autoimune adquirida / Flavia Costa Nunes Machado. -- São Paulo, 2016.

Tese(doutorado)--Faculdade de Medicina da Universidade de São Paulo Programa de Neurologia.

Orientador: Paulo Eurípedes Marchiori.

Coorientador: João Aris Kouyoumdjian.

Descritores: 1.Eletromiografia 2.Miastenia gravis 3.Neurofisiologia 4.Junção neuromuscular 5.Transmissão sináptica 6.Músculos

USP/FM/DBD-083/16 
Dedico esta tese ao meu marido Luís Otávio Sales Ferreira Caboclo, meu maior incentivador, minha referência intelectual, meu ponto de equilíbrio emocional, meu amor. Dedico também às minhas princesas Marina e Laura, de quem tenho muito orgulho e são a certeza da nossa continuidade. 



\section{AGRADECIMENTOS}

Agradeço ao meu orientador Prof. Dr. Paulo Eurípedes Marchiori pela confiança, motivação e ensinamentos que permitiram a execução deste trabalho.

Agradeço ao meu coorientador Prof. Dr. João Aris Kouyoumdjian por compartilhar comigo seus conhecimentos, sempre presente e disponível nos momentos cruciais desta trajetória e, sobretudo, por sua amizade.

Agradeço ao Prof. Dr. Erik Stålberg, um exemplo a ser seguido, por sua acolhida calorosa em Uppsala, por seu incentivo e por despertar minha paixão pelo tema deste trabalho.

Agradeço a todas as pessoas que de alguma forma contribuíram para este trabalho, por meio de seus músculos, cérebros ou corações.

Agradeço aos amigos, familiares, colegas e pacientes por me permitirem analisar a microfisiologia de seus músculos, disponibilizando tempo e certa dose de coragem.

Agradeço ao meu avô, Álvaro de Lima Costa, por me ensinar ainda pequena, a grandeza da semiologia do sistema nervoso.

Agradeço à minha mãe, Suzana Costa Nunes Machado, e ao meu pai, Gerlado Nunes Machado Júnior (in memoriam), por proporcionarem a melhor formação intelectual e moral, e indicarem o caminho para alcançar meus objetivos.

Agradeço especialmente ao meu marido, Luís Otávio Sales Ferreira Caboclo, pelo suporte emocional e pela participação ativa em todas as etapas 
deste trabalho, com sugestões, críticas, correções, tornando-se um "especialista" em jitter.

Agradeço também às minhas filhas, Marina e Laura, por terem se comportado durante as muitas horas que estive fisicamente ausente de suas vidas. 
"Todas as vitórias ocultam uma abdicação."

Simone de Beauvoir (1908 - 1986) 



\section{SUMÁRIO}

Lista de Siglas

Lista de Abreviaturas

Lista de Símbolos

Lista de Figuras

Lista de Tabelas

Resumo

Abstract

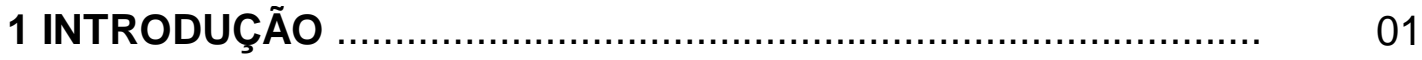

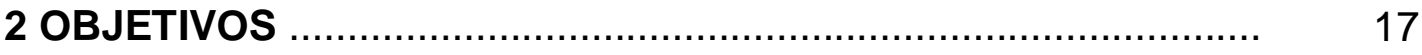

2. Objetivo geral .................................................................. 19

2.2 Objetivos específicos .............................................................. 19

3 REVISÃO DA LITERATURA ............................................. 21

3.1 Fisiologia da transmissão neuromuscular ............................... 23

3.2 Estimulação repetitiva ....................................................... 24

3.3 Jitter neuromuscular ................................................... 27

3.4 Técnicas de análise do jitter e critérios de anormalidade ............ 33

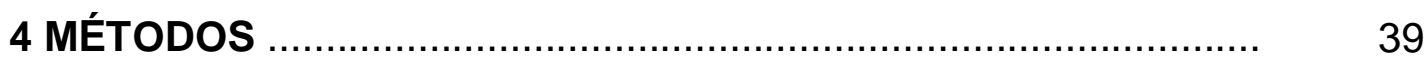

4.1 População do estudo ............................................................ 41

4.1.1 Grupo Controle ............................................................. 41

4.1.1.1 Critérios de inclusão ...................................................... 41

4.1.1.2 Critérios de exclusão .................................................. 42

4.1.2 Grupo miastenia gravis forma generalizada ......................... 42

4.1.2.1 Critérios diagnósticos de inclusão ...................................... 42

4.1.2.2 Critérios de exclusão ...................................................... 43

4.1.3 Grupo miastenia gravis forma ocular .................................. 43

4.1.3.1 Critérios diagnósticos de inclusão ...................................... 43

4.1.3.2 Critérios de exclusão .......................................................... 44

4.2 Procedimentos ............................................................ 44

4.2.1 Análise do jitter com aguda concêntrica .............................. 45 
4.2.2 Estimulação repetitiva e eletroneuromiografia ........................ 47

4.2.3 Dosagens de ac-AChR e ac-MuSK ................................... 47

4.3 Análise estatística .......................................................... 48

4.3.1 Definição dos valores normativos ..................................... 48

4.3.2 Análise descritiva em relação aos grupos .............................. 48

4.3.3 Análise de sensibilidade e especificidade - curvas ROC ........ 48

5 RESULTADOS ……......................................................... 51

5.1 Grupo controle .............................................................. 53

5.2 Grupo pacientes (MGG e MGO) ….............................. 55

5.2.1 Grupo miastenia gravis forma generalizada .......................... 55

5.2.2 Grupo miastenia gravis forma ocular ................................. 58

5.3 Análise descritiva em relação aos grupos ................................ 60

5.4 Análise de sensibilidade e especificidade - curvas ROC ............ 63

6 DISCUSSÃO .................................................................. 67

7 CONCLUSÕES ............................................................. 81

REFERÊNCIAS …..................................................... 85

APÊNDICES

Apêndice 1 - Aprovação do Comitê de Ética da Faculdade de Medicina da USP

Apêndice 2 - Aprovação do Comitê de Ética do Fleury Medicina e Saúde

Apêndice 3 - Termo de consentimento informado

Apêndice 4 - Protocolo preenchido para o grupo controle

Apêndice 5 - Protocolo preenchido para o grupo pacientes 


\section{LISTA DE SIGLAS}

FAMERP Faculdade de Medicina de São José do Rio Preto, São José do Rio Preto, São Paulo

FMUSP Faculdade de Medicina da Universidade de São Paulo

HC Hospital das Clínicas 


\section{LISTA DE ABREVIATURAS}

AC

agulha concêntrica

ac-AChR $^{\star} \quad$ autoanticorpo antirreceptor nicotínico de acetilcolina

$\mathrm{ACh}$ acetilcolina

AChR $^{\star} \quad$ receptor nicotínico de acetilcolina

ac-MuSK anticorpo antimúsculo específico tirosina quinase

AFU agulha de fibra única

ASC área sob a curva

CV

técnica de contração voluntária

dp

desvio padrão

EA

técnica de estimulação axonal

ENMG eletroneuromiografia

EMGFU eletromiografia de fibra única

EMGFU-JAC eletromiografia de fibra única - jitter com agulha concêntrica

ER

estimulação repetitiva

IDI

interdischarge interval - intervalo entre descarga

IPI

interpotential interval - intervalo entre potencial

JNM* junção neuromuscular

LRP4 lipoproteína de baixa densidade

MCD mean consecutive difference - média das diferenças

consecutivas

MG miastenia gravis

MGFA Myasthenia Gravis Foundation of America

MGFAa MGFA classificação atual, no momento do estudo

MGFAp MGFA pior classificação na história da doença

MGG miastenia gravis generalizada

MGO miastenia gravis ocular

MIPI mean interpotential interval - média do intervalo entre potencial

MSD mean sorted data - média dos dados classificados

OOc Orbicularis Oculi

PA $^{*} \quad$ potencial de ação 
PA-AFU* potencial de ação aparentemente de fibra única

PAMC potencial de ação muscular composto

PPT* potencial de placa terminal

ROC Receiver Operating Charachteristic Curve

VRF velocity recovered function- função de recuperação da

velocidade

* No plural as siglas estão escritas como: ac-AChRs, AChRs, JNMs, PAs, PA-AFUs, PPTs, Em expressões nas quais as siglas são consagradas na literatura manteve-se a sigla em inglês, e ao lado, as respectivas traduções para o português 


\section{LISTA DE SÍMBOLOS}

$\begin{array}{ll}\mathbf{c m} & \text { centímetro } \\ \mathbf{H z} & \text { hertz } \\ \mathbf{k H z} & \text { quilohertz } \\ \mathbf{m m} & \text { milímetro } \\ \mathbf{m m}^{2} & \text { milímetro quadrado } \\ \mathbf{m s} & \text { milissegundo } \\ \mathbf{m V} & \text { milivolt } \\ \mathbf{n m} & \text { nanometro } \\ \mathbf{s} & \text { segundo } \\ \mathbf{\mu s} & \text { microssegundo } \\ > & \text { maior que } \\ < & \text { menor que } \\ \geq & \text { maior ou igual a } \\ \% & \text { porcento } \\ / & \text { por }\end{array}$




\section{LISTA DE FIGURAS}

Figura 1 Representação esquemática da unidade motora e do registro dos potenciais de ação de fibras musculares individuais. Duas fibras musculares $\left(M_{1}\right.$ e $\left.M_{2}\right)$ inervadas por um axônio que se divide no ponto $B$ em duas fibras nervosas terminais $\left(N_{1}\right.$ e $\left.N_{2}\right)$. $O$ eletrodo $(E)$ registra um par de potenciais de ação, um de $M_{1}$ e outro de $M_{2}$. O intervalo de tempo entre os dois potenciais de ação das fibras musculares varia em descargas consecutivas (o jitter), por causa das diferenças no tempo de transmissão nas duas vias, entre $B$ e E, sobretudo na transmissão sináptica na placa motora terminal $\left(\mathrm{MEP}_{1} \mathrm{e}\right.$ $\left.M E P_{2}\right)$. Calibração: $2 m V$ e $500 \mu s$.

Figura 2 Áreas de registro relativas para o pico do potencial de ação da unidade motora, para as agulhas de fibra única, concêntrica e monopolar.

Figura 3 Exemplos de pares de potenciais de ação aparentemente de fibra única (PA-AFU), registrados com ativação voluntária do músculo Orbicularis Oculi, com eletrodo de agulha concêntrica. Traçados vistos no modo de sobreposição de 10 descargas consecutivas, todos com valores normais de jitter. Calibração: $0,3 \mathrm{mV}$ e $0,5 \mathrm{~ms}$ por divisão

Figura 4 Exemplos de potenciais de ação registrados com eletrodo de agulha concêntrica, com ativação voluntária do músculo Orbicularis Oculi, vistos no modo de varredura de descargas consecutivas. A) potencial de ação com evidência de somação no pico; pico mal definido com marcações variáveis, não aceitável para análise do jitter. Calibração: $0,3 \mathrm{mV}$ e $0,2 \mathrm{~ms}$ por divisão. B) O segundo potencial de ação apresenta evidência de somação na curva de ascensão do potencial, não deve ser utilizado para análise do jitter. O primeiro e terceiro potencial de ação são, aparentemente, de fibra única e aceitáveis para análise do jitter. Calibração; $0,3 \mathrm{mV}$ e $0,5 \mathrm{~ms}$ por divisão

Figura 5 Presença de decremento de $28,8 \%$ entre o primeiro e o quarto potencial em resposta à estimulação repetitiva de $3 \mathrm{~Hz}$ no nervo acessório com registro no músculo Trapezius 
Figura 6 llustração para explicar o jitter neuromuscular e bloqueio. Registros intracelulares, vistos com superposição dos sinais, próximo à placa motora terminal de fibras musculares intercostais, com estimulação indireta a $5 \mathrm{~Hz}$. A flutuação do limiar para que o potencial de placa terminal (PPT) despolarize e deflagre o potencial de ação (PA), propagado na fibra muscular, é supostamente responsável pela variação normal da latência do potencial de ação (A). Em condições em que as amplitudes dos potenciais de placa terminal estão diminuídas (B), essa variação é maior, resultando em jitter aumentado; alguns potenciais de placa terminal não são grandes o suficiente para deflagrar o potencial de ação, resultando em bloqueio intermitente

Figura 7 Métodos para medir o jitter. A) Método do nível da amplitude. O jitter é medido entre níveis de voltagem selecionados na fase de ascensão dos potenciais; setas horizontais indicam o início e fim do intervalo de contagem. B) Método de detecção do pico. O jitter é medido entre os picos calculados dos potenciais (setas verticais). Em ambos os métodos, o operador seleciona o potencial de interesse, fixando-o na tela do equipamento por um nível de gatilho de voltagem

Figura 8 Sinais com intervalos entre potenciais curtos, de $150 \mu s$. Se a técnica de detecção de amplitude for utilizada, o jitter será medido em diferentes partes do potencial, aumentando erroneamente o valor do jitter. A técnica de detecção de pico é menos afetada por esse artefato. Setas horizontais indicam os pontos no sinal onde inicia e termina a contagem do intervalo; setas verticais para a técnica de detecção de pico e setas inclinadas para a técnica de nível de amplitude.

Figura 9 Exemplos de jitter aumentado no músculo Orbicularis Oculi, com a técnica de contração voluntária e registro com agulha concêntrica, em pacientes do grupo miastenia gravis forma generalizada. Traçados ao alto são vistos em modo de varredura de descargas consecutivas; abaixo estão em modo de sobreposição de 10 traçados consecutivos, para melhor análise da morfologia constante do potencial. A) Jitter levemente aumentado; B) Jitter muito aumentado, com bloqueio do potencial de ação, indicados pela seta 
Figura 10 Um dos pontos de inserção da agulha concêntrica no músculo Orbicularis Oculi, em um raio de $1-2 \mathrm{~cm}$ do epicanto lateral, para a análise do jitter com a técnica de contração voluntária. Eletrodo de superfície - terra, também observado na figura

Figura 11 Análise do jitter com a técnica de contração voluntária. (A) Posição da agulha de fibra única entre duas fibras musculares ( 1 e 2) que pertencem a mesma unidade motora. (B) Descargas consecutivas do par de potenciais de ação, com leve contração voluntária do músculo. São indicados o intervalo entre descargas (IDI) e intervalo entre potenciais (IPI); velocidade de varredura da tela do osciloscópio de 0,1s/divisão. (C) O mesmo par de potenciais registrado com velocidade de varredura de $500 \mu$ s/divisão e exibido no modo de varredura, com o primeiro potencial fixado na tela. (D) O mesmo par de potenciais visto no modo de sobreposição, para demonstrar variações no IPI

Figura 12 Análise do jitter com a técnica de estimulação intramuscular. Eletrodos de estímulo e de registro são identificados ao alto. Exemplos de respostas típicas: (A) estimulação muscular direta - (jitter baixo) e (B) estimulação axonal (jitter $>4 \mu \mathrm{s})$. A seta indica 0 artefato de estímulo. Potenciais à direita demonstram o jitter, melhor observado na sobreposição dos traçados

Figura 13 Distribuição da média do MCD dos 20 sujeitos do grupo controle (MCD: mean consecutive difference; dp: desvio padrão; n: quantidade de sujeitos; AD: Teste de Anderson-Darling)

Figura 14 Distribuição do MCD do $18^{\circ}$ valor nos 20 sujeitos do grupo controle (MCD: mean consecutive difference; $d p$ : desvio padrão; n: quantidade de sujeitos; AD: Teste de Anderson-Darling)

Figura 15 Análise comparativa da variável média do $M C D$ em relação aos grupos controle, MGG (generalizado) e MGO (ocular)

Figura 16 Análise comparativa da variável $18^{\circ}$ par em relação aos grupos controle, MGG (generalizado) e MGO (ocular) ...

Figura 17 Análise comparativa da variável média do $M C D$ em relação aos grupos MGG (generalizado) e MGO (ocular) 
Figura 18 Análise comparativa da variável quantidade de pares anormais em relação aos grupos MGG (generalizado) e MGO (ocular)

Figura 19 Análise comparativa da variável quantidade de bloqueios em relação aos MGG (generalizado) e MGO (ocular)

Figura 20 Curva ROC: análise do poder de classificação da variável média do $M C D$ no grupo pacientes (MGG e MGO) versus controle. Valores em $\mu \mathrm{s}$; entre parênteses (especificidade, sensibilidade); ASC: área sob a curva...

Figura 21 Curva ROC: análise do poder de classificação da variável média do $18^{\circ}$ par no grupo pacientes (MGG e MGO) versus controle 


\section{LISTA DE TABELAS}

Tabela 1 Valores do limite superior da normalidade (em vermelho) e análise estatística utilizada

Tabela 2 Dados demográficos, clínicos, laboratoriais e neurofisiológicos dos pacientes com miastenia gravis forma generalizada

Tabela 3 Dados demográficos, clínicos, laboratoriais e neurofisiológicos dos pacientes com miastenia gravis forma ocular

59

Tabela 4 Valores normativos de MCD para agulha de fibra única (estudo multicêntrico), e para a agulha concêntrica em diferentes estudos e no estudo atual. Entre os parênteses estão as metodologias adotadas para definição dos limites superiores da normalidade em cada estudo 



\section{RESUMO}

Machado FCN. Análise do jitter com agulha concêntrica em pacientes com miastenia gravis autoimune adquirida. [tese]. São Paulo: Faculdade de Medicina, Universidade de São Paulo; 2016.

INTRODUÇÃO: A técnica de eletromiografia de fibra única (EMGFU), mediante análise do jitter, é o método neurofisiológico mais sensível para a confirmação do distúrbio da junção neuromuscular na miastenia gravis (MG). Os registros são tradicionalmente obtidos com agulha de fibra única, de alto custo e reutilizável. Por causa da necessidade atual do uso de material descartável, a agulha concêntrica vem sendo utilizada em substituição à agulha de fibra única. A técnica utilizada é semelhante, porém os potencias de ação para a análise do jitter são obtidos com eletrodo de agulha concêntrica (Eletromiografia de fibra única - jitter com agulha concêntrica, EMGFU-JAC). Contudo, os estudos são escassos e as metodologias utilizadas são heterogêneas com a utilização dessa agulha. OBJETIVOS: Este estudo tem por objetivo mensurar os valores de jitter obtidos com agulha concêntrica, no músculo Orbicularis Oculi, em sujeitos saudáveis e em pacientes com MG autoimune adquirida e avaliar a validade do método nas formas generalizada e ocular da doença. MÉTODOS: Foram estudados 20 sujeitos saudáveis, 20 pacientes com miastenia gravis forma generalizada (grupo MGG) e $13 \mathrm{com}$ a forma ocular da doença (grupo MGO). A EMGFU-JAC foi realizada em todos os participantes, idealmente com 20 medidas de jitter em cada estudo. O jitter foi expresso como a média das diferenças consecutivas (MCD). Em todos os pacientes do estudo foram realizados o teste de estimulação repetitiva e dosagem sérica de anticorpo antirreceptor de acetilcolina (ac-AChR) no momento da análise do jitter. Nos pacientes soronegativos para ac-AChR, foi pesquisado o anticorpo antimúsculo específico tirosina-quinase (ac-MuSK). Foram definidos o limite superior da normalidade (LSN) para a média do MCD de cada estudo e para valores individuais de MCD. Os critérios de anormalidade foram: (1) média do MCD acima do LSN; ou (2) mais de $10 \%$ dos valores individuais de MCD acima do LSN. A definição do LSN para valores individuais de MCD baseou-se no conceito de que dois entre 20 valores de MCD acima do LSN são aceitáveis em um músculo saudável, para a técnica de contração voluntária. Portanto, estimou-se o LSN para o $18^{\circ}$ valor mais alto de MCD (18 par). Para análise da acurácia do método, foram construídas duas curvas ROC (Receiver Operating Characteristic) para as variáveis média do MCD e $18^{\circ}$ par, no grupo de pacientes (MGG e MGO) versus controle. RESULTADOS: No grupo controle a média das médias do MCD foi $(19,0 \pm 2,4) \mu s$ e a média do $18^{\circ}$ valor mais alto 
de cada estudo foi $(24,5 \pm 3,6) \mu$ s. Esses valores obtidos apresentaram distribuição Gaussiana e o LSN foi definido como a média desses valores +2 DP. O LSN para a média do MCD foi $24 \mu \mathrm{s}$, e $32 \mu$ s para valores individuais de MCD. No grupo MGG, a análise do jitter foi anormal em todos os 20 pacientes por ambos os critérios de anormalidade, exceto em um paciente que apresentou anormalidade por apenas um dos critérios. No grupo MGO, apenas um dos 13 pacientes não preencheu os critérios de anormalidade. No grupo de pacientes, a positividade da EMGFU-JAC foi maior do que o teste de estimulação repetitiva e dosagens de anticorpos. Nas curvas ROC para as variáveis médias do MCD e $18^{\circ}$ par, o valor de melhor sensibilidade $(93,9 \%)$, sem resultados falsos positivos, foi $24,7 \mu \mathrm{s}$ e $33,1 \mu \mathrm{s}$, respectivamente. CONCLUSÕES: A EMGFU-JAC apresenta alta sensibilidade e especificidade na identificação de distúrbio da transmissão neuromuscular em pacientes com MG. A utilização da agulha concêntrica é válida para a análise do jitter, como alternativa à agulha de fibra única.

Descritores: eletromiografia; miastenia gravis; neurofisiologia; junção neuromuscular; transmissão sináptica; músculos. 


\begin{abstract}
Machado FCN. Concentric needle jitter analysis in patients with autoimmune acquired myasthenia gravis. [Thesis]. São Paulo: "Faculdade de Medicina, Universidade de São Paulo"; 2016.
\end{abstract}

INTRODUCTION: Single fiber electromyography (SFEMG) technique, through jitter analysis, is the most sensitive neurophysiological method for confirmation of neuromuscular junction disorder in myasthenia gravis (MG). Records are traditionally obtained with single fiber needle, which is reusable and has a highcost. Due to the current need of using disposable material, concentric needle has been used to replace single fiber needle. The technique is similar, but the action potential for jitter analysis is obtained with concentric needle electrode (SFEMG - concentric needle jitter, SFEMG-CNJ). However, studies are scarce and methodologies used are heterogeneous with the use of this needle. OBJECTIVES: This study aims to measure jitter values obtained with concentric needle in the Orbicularis Occuli muscle in healthy subjects and in patients with autoimmune acquired $M G$ and to assess the validity of the method in generalized and ocular forms of the disease. METHODS: 20 healthy subjects, 20 patients with generalized myasthenia gravis (GMG group) and 13 with the ocular form of the disease (OMG group) were studied. SFEMG-CNJ was performed on all participants, ideally with 20 jitter values in each study. Jitter was expressed as the mean consecutive difference (MCD). Repetitive nerve stimulation and serum acetylcholine receptor antibody (AChR-ab) were performed in all patients in the study, by the time of jitter analysis. Tyrosine kinase specific antibody muscle antibodies (MuSK-ab) were performed in AChR-ab negative patients. The upper limit of normality (ULN) for the mean $M C D$ and for individual jitter values were defined. The abnormality criteria were: (1) mean MCD above ULN; or (2) more than $10 \%$ of individual jitter values above ULN. The definition of ULN for individual jitter values was based on the concept that two out of 20 jitter values above ULN are acceptable in a healthy muscle for voluntary contraction technique. Therefore, the ULN for the 18th highest jitter value (18 pair) was estimated. To analyze the method's accuracy, two ROC curves (Receiver Operating Characteristic) for the mean MCD and 18th pair in the group of patients (MGG and MGO) versus control were constructed. RESULTS: In the control group the mean of MCD means was $(19.0 \pm 2.4) \mu s$ and the mean of the 18 highest value of each study was (24.5 \pm

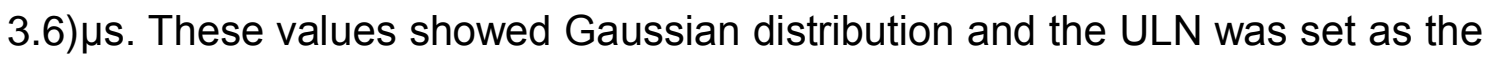
mean of these values +2 SD. The ULN for the mean MCD was $24 \mu \mathrm{s}$, and $32 \mu \mathrm{s}$ for individual values of MCD. In GMG group, jitter analyses were abnormal in all 20 patients based on both abnormality criteria, except in one patient, who had 
abnormalities in only one of the criteria. In OMG group, only one patient from 13 met neither of the abnormality criteria. In patients, the positivity of SFEMG-CNJ was higher than repetitive nerve stimulation test and antibody detection. The ROC curve threshold showing the best sensitivity (93.9\%) with no false positive results was $24.7 \mu \mathrm{s}$ for the mean MCD and $33.1 \mu \mathrm{s}$ for individual pairs, respectively. CONCLUSIONS: SFEMG-CNJ has high sensitivity and specificity in identifying neuromuscular transmission disorder in patients with MG. The use of concentric needle is valid for jitter analysis as an alternative to single fiber needle.

Descriptors: electromyography; myasthenia gravis; neurophysiology; neuromuscular junction; synaptic transmission; muscles. 
1 INTRODUÇÃO 



\section{INTRODUÇÃO}

Nas últimas décadas, 0 desenvolvimento tecnológico e 0 aperfeiçoamento de softwares e técnicas para o registro seletivo da atividade elétrica de uma única fibra muscular contribuiu para melhor entendimento da microfisiologia da unidade motora em indivíduos saudáveis e doentes. $\mathrm{Na}$ década de 60, Ekstedt e Stålberg desenvolveram juntos a eletromiografia de fibra única (EMGFU), método para registro de potenciais de ação (PAs) de uma única fibra muscular em músculos humanos ativados voluntariamente (Ekstedt, 1964; Stålberg, 1966). Ekstedt observou, durante seus estudos, que, quando esse registro era proveniente de duas fibras musculares pertencentes à mesma unidade motora, existia uma variabilidade no intervalo de tempo entre os dois PAs em descargas consecutivas, em torno de $25 \mu \mathrm{s}$. Essa variabilidade, o jitter, foi observada "como um aparente movimento de parte da tela, de uma maneira inquieta e nervosa" (Ekstedt, 1964). A denominação jitter, em inglês (derivado do alemão: zitter) foi, originalmente, adotado da literatura técnica e denota instabilidade de um sinal na tela do osciloscópio. Três fatores contribuem para o fenômeno do jitter: variação no tempo de transmissão do impulso no axônio; variação na transmissão sináptica na placa motora terminal; e, variação no tempo de propagação na fibra muscular (Stålberg et al., 1971) (Figura 1). Ekstedt e Stålberg confirmaram em experimentos seguintes, com agentes bloqueadores neuromusculares (Ekstedt, Stålberg, 1969) e em estudos em pacientes com miastenia gravis (MG) (Ekstedt, Stålberg, 1967), que o fenômeno do jitter tem origem, mormente na junção neuromuscular (JNM) por causa da variabilidade no tempo de transmissão neuromuscular na placa motora terminal. Foi observado, ainda, que além da MG, o jitter também apresentava valores aumentados em outras doenças neurológicas, como neuropatias e doenças do neurônio motor (Stålberg, Ekstedt, 1969; Stålberg et al., 1975). Stålberg iniciou os primeiros cálculos para medir o jitter, o mesmo utilizado atualmente e incorporado em praticamente todos os equipamentos de eletrodiagnóstico (Stålberg et al., 1971; Ekstedt et al., 1974). 
Os valores de jitter são expressos em MCD - mean consecutive difference ou média das diferenças consecutivas. Esse valor representa a média do intervalo de tempo entre dois PAs, pertencentes a uma mesma unidade motora, em descargas consecutivas. Os valores normais do jitter, inicialmente descritos, estavam na ordem de $5 \mu$ s a $50 \mu$ s (Stålberg et al., 1971); a distribuição é predominantemente Gaussiana (Ekstedt et al., 1974).

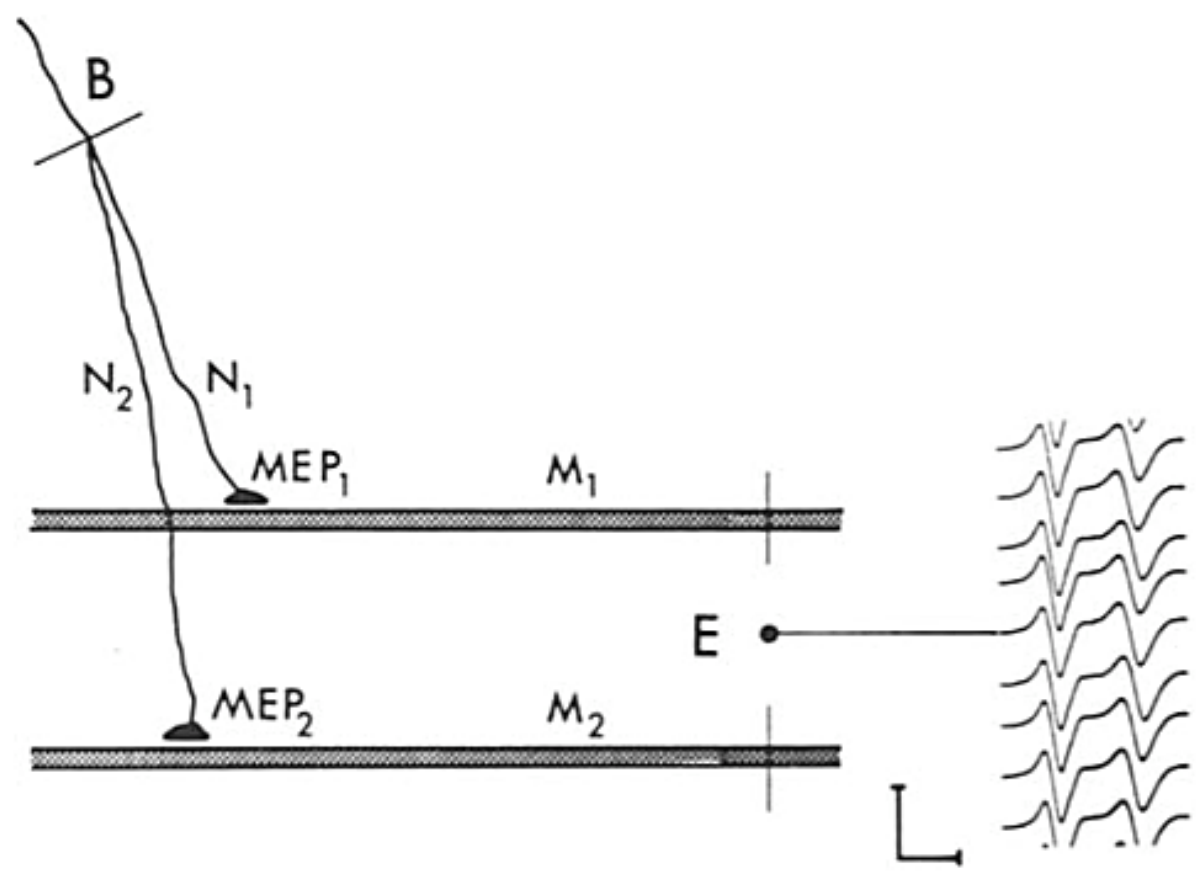

Figura 1. Representação esquemática da unidade motora e do registro dos potenciais de ação de fibras musculares individuais. Duas fibras musculares $\left(M_{1}\right.$ e $\left.M_{2}\right)$ inervadas por um axônio que se divide no ponto $B$ em duas fibras nervosas terminais $\left(N_{1}\right.$ e $\left.N_{2}\right)$. $O$ eletrodo (E) registra um par de potenciais de ação, um de $M_{1}$ e outro de $M_{2}$. O intervalo de tempo entre os dois potenciais de ação das fibras musculares varia em descargas consecutivas (o jitter), por causa das diferenças no tempo de transmissão nas duas vias, entre $B$ e $E$, sobretudo na transmissão sináptica na placa motora terminal $\left(\mathrm{MEP}_{1}\right.$ e $\left.\mathrm{MEP}_{2}\right)$. Calibração: $2 \mathrm{mV}$ e $500 \mu \mathrm{s}$. (Stålberg et al., 1971). 
O eletrodo, inicialmente desenvolvido para o registro de PA de uma única fibra muscular e para medidas da velocidade de propagação na fibra muscular, possuía 14 orifícios de registro em sua extensão e era denominado "multieletrodo" (Ekstedt et al., 1969). Posteriormente, foi desenvolvida a agulha de fibra única (AFU) para ser especificamente utilizada na EMGFU. A AFU consiste de um fio de $25 \mu \mathrm{m}$ de diâmetro dentro de uma cânula, com sua parte terminal exposta por uma saída lateral, alguns milímetros proximal à ponta da cânula. A AFU apresenta uma área de registro muito seletiva, o que permite 0 registro de fibras musculares individuais (Stålberg et al., 2010). Entretanto, a AFU tem custo alto, necessita de manutenções regulares e é reutilizável.

Recentemente, com a necessidade crescente de utilização de material descartável em procedimentos médicos, incluindo os eletrodos de agulha utilizados em eletroneuromiografia (ENMG), iniciou-se uma série de estudos usando eletrodos de agulha convencionais descartáveis, por exemplo, a agulha monopolar (Wiechers, 1985; Buchman, Garratt, 1992; Tutkavul, Baslo, 2010) e a agulha concêntrica (AC) (Ertaş et al., 2000; Benatar et al., 2006; Sarrigiannis et al., 2006; Kouyoumdjian, Stålberg, 2007; 2008a; 2008b; 2011; 2013a). Em comparação com as agulhas monopolar e concêntrica, a AFU possui área de registro muito mais seletiva (King et al., 1997). O fundamento básico da EMGFU consiste na seletividade do registro do eletrodo de agulha, portanto, na substituição da AFU deve-se optar por uma agulha com área de registro menor (Stålberg, Sanders, 2009). A AC, por ter uma área de captação menor do que a agulha monopolar (Sanders, Stålberg, 1996; King et al., 1997; Stålberg, Sanders, 2009), é a mais utilizada como alternativa da AFU. A menor AC disponível comercialmente, conhecida como agulha facial, tem uma área de registro relativa equivalente a $0,019 \mathrm{~mm}^{2}$, enquanto a AFU possui uma área de registro aproximada de $0,0005 \mathrm{~mm}^{2}$ (Sanders, Stålberg, 1996) (Figura 2). 


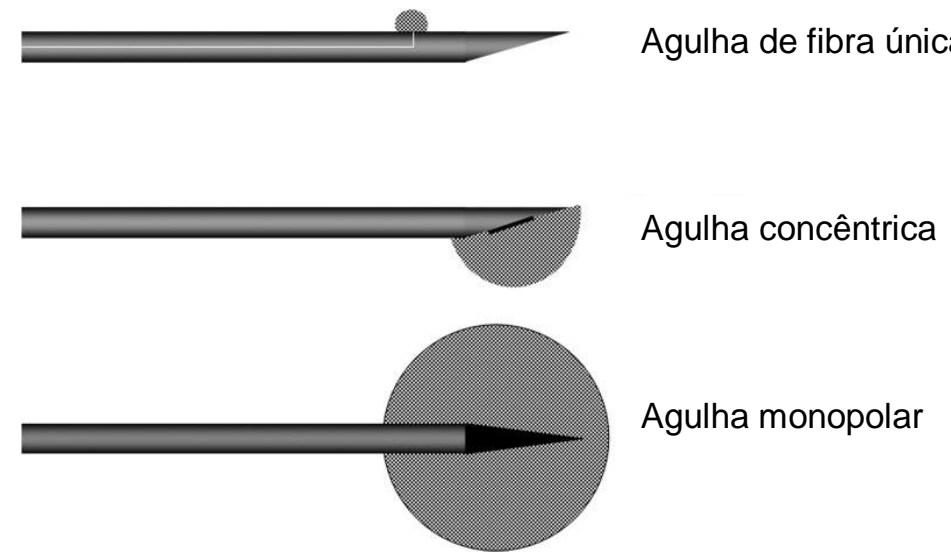

Figura 2. Áreas de registro relativas para o pico do potencial de ação da unidade motora, para as agulhas de fibra única, concêntrica e monopolar. (Adaptado de Stålberg, Sanders, 2009).

Outro fator necessário para a seletividade do registro de um eletrodo de agulha é a filtragem dos sinais captados (Gath, Stålberg, 1976). Todos os equipamentos de ENMG possuem bandas para filtragem de sinais. Na EMGFU o filtro de passa-alta é ajustado em $500 \mathrm{~Hz}$ e restringe a passagem da maioria das frequências abaixo desse valor. Na substituição da AFU pela AC o filtro de passa-alta deve ser reajustado idealmente para $1000 \mathrm{~Hz}$, destacando assim os componentes do pico do potencial, sem grandes distorções de sua amplitude (Stålberg, Sanders, 2009; Stålberg, 2012). O filtro de passa-baixa, ajustado em $10 \mathrm{kHz}$, é o mesmo, independente da escolha do tipo de agulha.

Em razão da menor seletividade da $A C$ em registrar potenciais de ação de fibras musculares isoladas, os potenciais captados não são necessariamente de uma única fibra muscular, como os vistos com registros com a AFU. A filtragem do sinal elimina os componentes de frequência baixa do potencial, provenientes de fibras musculares mais distantes da ponta da agulha, que como consequência diminui, mas não elimina totalmente, a somação de fibras musculares individuais (Sanders, Stålberg, 1996; Stålberg, Sanders, 2009). Embora os PAs registrados com AC possam apresentar morfologia semelhante àquela registrada com o $\mathrm{AFU}$, os $\mathrm{PAs}$ registrados com $A C$ frequentemente correspondem à somação de mais de uma fibra muscular, 
mesmo após a filtragem dos sinais (Sanders, Stålberg, 1996; Stålberg et al., 2010). Portanto, a nomenclatura "potencial de ação aparentemente de fibra única" (PA-AFU) vem sendo utilizada para registros obtidos com eletrodo de AC. Da mesma forma, o termo "análise do jitter com agulha concêntrica" foi sugerido por alguns autores para esses estudos (Kouyoumdjian, Stålberg, 2008b). Para fins práticos, o termo adotado no presente estudo foi eletromiografia de fibra única - jitter com agulha concêntrica (EMGFU-JAC).

Adicionalmente à filtragem de sinais, são necessários cuidados técnicos na aceitação dos PAs obtidos com AC para análise do jitter (Sanders, Stålberg, 1996; Ertaş et al., 2000; Benatar et al., 2006; Sarrigiannis et al., 2006; Kouyoumdjian, Stålberg, 2007; Stålberg, Sanders, 2009). Os critérios técnicos têm por objetivo a aceitação de PAs que, aparentemente, tenham morfologia semelhante aos potenciais obtidos com AFU (Figura 3). Registros que apresentam mudanças na morfologia do PA em descargas consecutivas são considerados potenciais evidentemente somados e não devem ser utilizados para análise do jitter (Figura 4). Os critérios para aceitação de PA-AFU são sugeridos na literatura (Stålberg, Sanders, 2009; Stålberg et al., 2010).
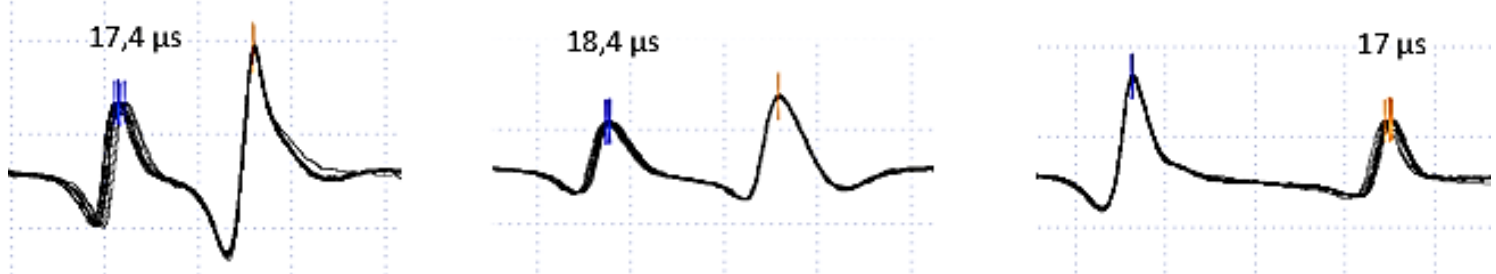

Figura 3. Exemplos de pares de potenciais de ação aparentemente de fibra única (PA-AFU), registrados com ativação voluntária do músculo Orbicularis Oculi, com eletrodo de agulha concêntrica. Traçados vistos no modo de sobreposição de 10 descargas consecutivas, todos com valores normais de jitter. Calibração: $0,3 \mathrm{mV}$ e $0,5 \mathrm{~ms}$ por divisão. 

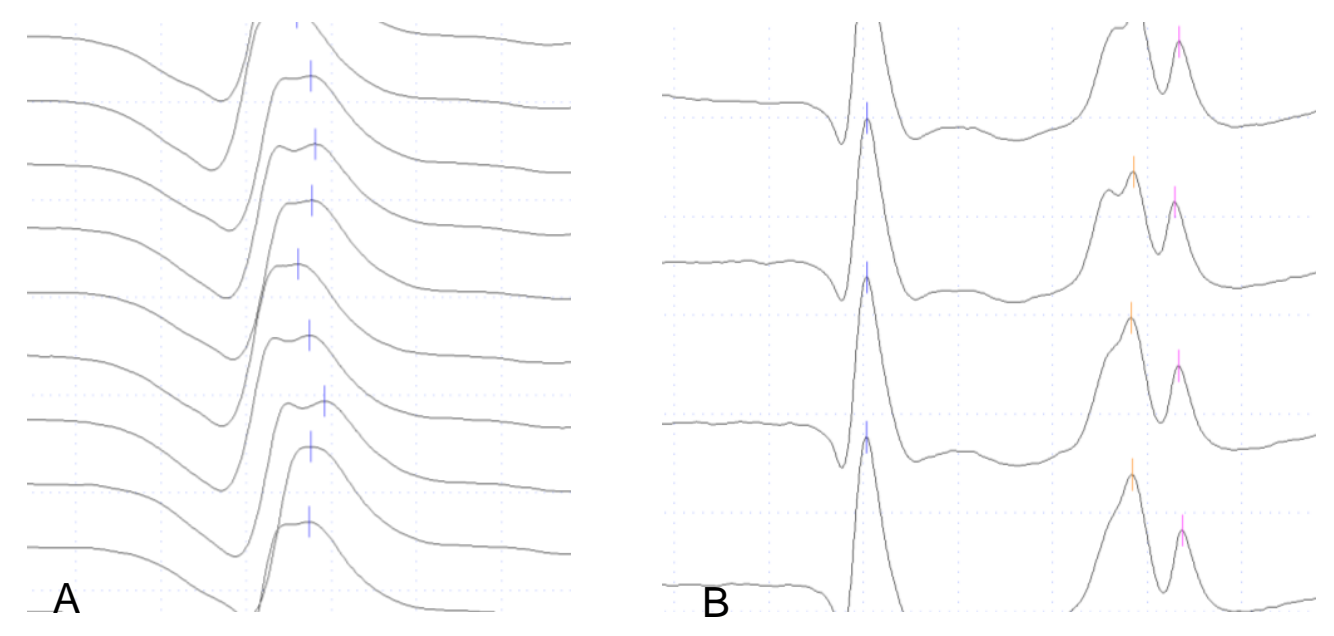

Figura 4. Exemplos de potenciais de ação registrados com eletrodo de agulha concêntrica, com ativação voluntária do músculo Orbicularis Oculi, vistos no modo de varredura de descargas consecutivas. A) potencial de ação com evidência de somação no pico; pico mal definido com marcações variáveis, não aceitável para análise do jitter. Calibração: $0,3 \mathrm{mV}$ e $0,2 \mathrm{~ms}$ por divisão. B) O segundo potencial de ação apresenta evidência de somação na curva de ascensão do potencial, não deve ser utilizado para análise do jitter. O primeiro e terceiro potencial de ação são, aparentemente, de fibra única e aceitáveis para análise do jitter. Calibração; $0,3 \mathrm{mV}$ e $0,5 \mathrm{~ms}$ por divisão.

Além da velocidade de propagação nas fibras musculares individuais (Stålberg, 1966) e do jitter neuromuscular (Stålberg et al., 1971; Ekstedt et al., 1974), a EMGFU também permite o estudo da distribuição das fibras musculares nas unidades motoras individuais, denominado densidade de fibras (Gath, Stålberg, 1976). A média da densidade de fibras em uma unidade motora é calculada mediante a contagem de fibras musculares individuais pertencentes a uma mesma unidade motora, dentro da área de registro da agulha, em diferentes posições do eletrodo no músculo (Gath, Stålberg, 1976). O fator principal relacionado ao aumento da densidade de fibras é a reinervação muscular. Em razão do processo de brotamento colateral dos ramos nervosos terminais remanescentes é possível registrar três a dez fibras musculares pertencentes à mesma unidade motora, em contraste aos registros habituais, isto é, de uma a três fibras musculares; portanto, o aumento da densidade de fibras é, na maioria das vezes, indicativo de brotamento colateral 
(Stålberg et al., 1975). Valores normativos de densidade de fibras, para registros obtidos com AFU, estão disponíveis para diferentes músculos (SINGLE ..., 1992). Entretanto, a análise de densidade de fibras não é possível com a AC, por causa da dificuldade na identificação de PA de fibras musculares individuais.

Infelizmente, a EMGFU não é amplamente difundida no Brasil, porque além da limitação de custo, a técnica requer treinamento específico para que sejam reproduzidos resultados confiáveis e consistentes. Nos centros em que a EMGFU é bem desenvolvida, muitas vezes esse é o método eletrofisiológico de escolha para confirmar ou afastar distúrbios da JNM (Sanders, Stålberg, 1996).

A miastenia gravis é uma doença autoimune adquirida, e é o distúrbio mais frequente da JNM. É provocada pela produção de autoanticorpos patogênicos contra componentes da membrana pós-sináptica da JNM. A doença está associada, em particular, à produção de autoanticorpos antirreceptores nicotínicos de acetilcolina (ac-AChRs) (Lindstrom et al., 1976; Vincent, 2006). Esses anticorpos causam diminuição da quantidade e da função dos receptores de acetilcolina, levando à falência da transmissão neuromuscular e fraqueza muscular (Drachman, 1994). Em uma minoria dos pacientes existe a produção de autoanticorpos antimúsculo específico tirosinaquinase (ac-MuSK) (Hoch et al., 2001), uma proteína de membrana expressa seletivamente no músculo esquelético, e o antirreceptor relacionado à lipoproteína de densidade baixa 4 (LRP4) descrito recentemente (Higuchi et al., 2011; Pevzner et al., 2011). Há vários mecanismos nos quais os autoanticorpos podem interferir na função das proteínas na membrana pós-sináptica, dentre eles: ativação de complemento (Tüzün, Christadoss, 2013); modulação antigênica por ligação à proteína alvo; concorrência com os ligantes nos sítios de ligação; inibição de mudanças conformacionais e ligação a proteínas associadas (Gomez et al., 2010). Esses mecanismos não são igualmente importantes nas diferentes apresentações da MG e também dependem de outros fatores como: especificidade do epítopo; subclasse do anticorpo; ou ainda, da densidade do antígeno (Verschuuren et al., 2013).

A MG tem prevalência de 40 a 180 por milhão de pessoas e incidência anual de 4 a 12 por milhão de pessoas, com distribuição bimodal relacionada 
com a idade (Heldal et al., 2009; Andersen et al., 2010; Carr et al., 2010). O primeiro pico ocorre em adultos jovens, ao redor de 30 anos de idade, período no qual as mulheres são mais acometidas, e o segundo pico após os 50 anos (MG de início tardio), com ligeira predominância no gênero masculino (Heldal et al., 2009; Andersen et al., 2010). A manifestação clínica mais característica da doença é fraqueza flutuante, ou seja, desencadeada ou mais evidente com o exercício. Entretanto, a fraqueza pode ser subestimada clinicamente. Com frequência, a apresentação inicial da doença é ptose e diplopia, decorrente do comprometimento dos músculos oculares extrínsecos e do Levator Palpebrae Superioris. A instalação dos sintomas pode ser aguda ou subaguda, com períodos variáveis de intensidade dos sintomas. A fraqueza pode permanecer localizada em um grupo muscular por muitos anos, principalmente na musculatura ocular, denominando a MG forma ocular, ou pode comprometer outros grupos musculares caracterizando a forma generalizada da doença. $O$ envolvimento dos músculos bulbares e faciais leva à dificuldade na fala, mastigação e deglutição, enquanto a fraqueza nos músculos do pescoço resulta em dificuldade na sustentação da cabeça. Os músculos proximais dos membros superiores e inferiores são mais comprometidos do que os músculos distais. Quando ocorre fraqueza dos músculos respiratórios caracteriza-se a crise miastênica, uma emergência médica. A fraqueza é normalmente detectável ao exame físico, porém nos casos mais leves da MG pode ser evidente somente após testes clínicos de fadiga. Nas formas oculares da MG, a ptose piora com o esforço, comumente é assimétrica, e a oftalmoparesia tende a variar em ocasiões diferentes do exame neurológico, não sendo justificada pelo comprometimento de nervos cranianos de forma isolada (Oosterhuis, 1989; Drachman, 1994; Vincent et al., 2001; Keesey 2004). Aproximadamente $10 \%$ a $20 \%$ dos pacientes com MG apresentam timoma, e tipicamente esses pacientes apresentam fraqueza generalizada e ac-AChR positivo (Keesey, 2004; Marx et al., 2013).

Pacientes com sorologia positiva para ac-MuSK podem apresentar manifestações clínicas distintas. Clinicamente, esses pacientes podem ser indistinguíveis dos pacientes com MG soropositivos para ac-AChR; podem apresentar fraqueza de predomínio oculobulbar, com oftalmoparesia e atrofia 
de língua, ou ainda, crises frequentes de insuficiência respiratória e fraqueza predominante nos músculos da cintura escapular (Sanders et al., 2003; Evoli, 2006; Padua et al., 2006).

O diagnóstico da MG baseia-se em dados clínicos, determinação de anticorpos no soro, estudos neurofisiológicos e teste terapêutico com anticolinesterásicos. O desafio clínico principal é o diagnóstico das formas mais leves da MG, especialmente aquelas com sintomas puramente oculares. Nesses casos, a EMGFU pode ser fundamental para a confirmação ou exclusão da doença. A EMGFU mostrou-se mais útil no diagnóstico da MG em pacientes com valores séricos negativos de ac-AChR, teste de estimulação repetitiva normal e nas formas leves da doença (Stålberg, 1980; Oh et al., 1992; Sanders, Stålberg, 1996; Sanders, 2002; Howard, 2013).

A dosagem de ac-AChR ligador é de especificidade alta para 0 diagnóstico de MG e é amplamente disponível. Entretanto, esses autoanticorpos nem sempre estão presentes nos pacientes com MG, particularmente na fase inicial da doença e naqueles que apresentam a forma generalizada leve ou a forma ocular da doença (Oh et al., 1992; Sanders, Stålberg,1996; Chan et al., 2007). A pesquisa adicional dos outros dois subtipos de ac-AChR, bloqueadores e moduladores, aumenta aproximadamente 10\% o diagnóstico da MG (Kang et al., 2015); anticorpos bloqueadores normalmente estão associados aos ligadores (Howard et al., 1987; Kang et al., 2015). Estima-se que 15\% a 20\% dos pacientes com MG são soronegativos para ac-AChR. (Mossman et al., 1986; Vincent et al., 2001; Padua et al., 2006; Chan et al., 2007) Nesse subgrupo de pacientes, aproximadamente $40 \%$ apresentam dosagem sérica positiva para ac-MuSK, uma proteína de membrana essencial para o desenvolvimento da JNM e integração estável dos receptores de acetilcolina (Sanders et al., 2003; Padua et al., 2006). A utilização atual do termo "MG soronegativa" refere-se aos pacientes com dosagens negativas para ac-AChR e ac-MuSK (Zisimopoulou et al., 2013). Entretanto, a quantidade de pacientes classificados nesse grupo é continuamente reduzida em razão do desenvolvimento de métodos laboratoriais, baseado em célula, para identificação dos autoanticorpos contra antígenos já conhecidos ou, até mesmo, anticorpos contra antígenos 
recentemente descritos na MG, por exemplo o LRP4 (Zisimopoulou et al., 2013; Gilhus, Verschuuren, 2015). O método de radioimunoensaio, rotineiramente utilizado, não identifica ac-AChR de afinidade baixa ou com níveis séricos reduzidos (Zisimopoulou et al., 2013). Anticorpos de afinidade baixa contra receptores de acetilcolina foram identificados por Leite et al (2008) em $66 \%$ dos pacientes primeiramente classificados como soronegativos para ac-AChR. Infelizmente, esses métodos laboratoriais novos ou mais sensíveis para identificação dos autoanticorpos na $M G$ ainda não estão amplamente disponíveis no Brasil.

O estudo neurofisiológico mais simples e rotineiramente utilizado para avaliar a JNM em pacientes com suspeita clínica de MG é a estimulação repetitiva (ER). A técnica faz parte da ENMG convencional e consiste na aplicação de estímulos elétricos supramáximos, sequenciados e de frequência baixa $(3 \mathrm{~Hz})$ sobre o nervo. A presença de decremento anormal $(>10 \%)$, ou seja, uma queda da amplitude do potencial de ação muscular composto (PAMC) entre o primeiro e o quarto potencial evocado é indicativa de um distúrbio pós-sináptico da JNM (Dumitru et al., 2002). A técnica não requer treinamento específico, porém sua sensibilidade para o diagnóstico de MG é relativamente baixa nas formas oculares da MG, variando de $10 \%$ a $17 \%$ (AAEM Quality Assurance Committee American Association of Electrodiagnostic Medicine, 2001a). Oh et al. (1982) observaram uma diferença significativa da sensibilidade da ER nas formas oculares e generalizadas da MG, $17 \%$ e $85 \%$ respectivamente (Oh et al., 1982). Sanders e Howard (1986) realizaram ER em 220 pacientes com MG, e ao mesmo tempo a EMGFU. Para a ER foram avaliados um músculo da mão e outro músculo proximal (Deltoideus, Trapezius ou Biceps Brachii). Em 48\% desses pacientes a ER foi anormal em pelo menos um músculo, enquanto a EMGFU apresentou anormalidade de $88 \%$ a $96 \%$, dependendo se um segundo músculo, geralmente da face, era analisado.

As sensibilidades relativas das dosagens de ac-AChR e estudos eletrofisiológicos foram comparadas por Sanders (2002) em 503 pacientes com MG. Nas formas generalizadas da doença a dosagem de ac-AChR foi positiva em $80 \%$ dos pacientes, a estimulação repetitiva foi anormal em $76 \%$ e a 
EMGFU demonstrou jitter aumentado em até $99 \%$ dos pacientes, quando mais de um músculo foi estudado. Nos pacientes com MG forma ocular, a positividade sérica do ac-AChR e da estimulação repetitiva apresentaram resultados mais modestos (55\% e $48 \%$, respectivamente), enquanto a EMGFU foi alterada em $97 \%$ dos pacientes. Resultados similares, que mostraram sensibilidade da EMGFU maior frente aos outros testes para o diagnóstico da MG, também foram obtidos em outras séries (Stålberg, 1980; Oh et al., 1992; Witoonpanich et al., 2011).

A EMGFU é o método eletrofisiológico mais sensível para o diagnóstico in vivo da MG (Stålberg, 1980; Sanders, 2002; Witoonpanich et al., 2011). Em razão de sensibilidade alta da análise do jitter na identificação de distúrbios da JNM, esse pode ser o teste eletrofisiológico de escolha na avaliação diagnóstica de pacientes com MG (Sanders, Howard, 1986; Sanders, 2002). Entretanto, em presença de anormalidade, é recomendável a realização da ER em pelo menos um músculo distal para afastar distúrbios pré-sinápticos da JNM. O exame é particularmente útil em pacientes com suspeita clínica de MG, com poucos sintomas ou fraqueza restrita aos músculos oculares (Sanders, Howard, 1986). A análise do jitter tem sensibilidade alta para o diagnóstico da MG, porém pode estar alterado também nas doenças do nervo e do músculo (Stålberg, 1990; Wiechers, 1990; Massey, Sanders, 1991; Sanders, Stålberg, 1996). Essas doenças devem ser excluídas mediante exame clínico e ENMG convencional. O diagnóstico de MG pode ser afastado se a análise do jitter for normal em um músculo clinicamente fraco (Sanders, Howard, 1986; Sanders, 2002).

O músculo Orbicularis Oculi (OOc) parece ser particularmente sensível em demonstrar anormalidade na JNM nas fases iniciais da MG, forma generalizada ou puramente ocular (Sanders, Howard, 1986; Trontelj et al. 1988). Contudo, quando os sintomas são restritos aos músculos oculares, os músculos rotineiramente analisados - Frontalis e OOc - (Sanders, Howard, 1986; Oh et al., 1992; Padua et al., 2000; Witoonpanich et al., 2011) podem não estar diretamente relacionados ao sintomas de fraqueza. Na MG, a presença de ptose indica o envolvimento do músculo Levator Palpebrae Superioris, que não é facilmente acessível para a análise do jitter. Portanto, 
nesses casos, é prudente repetir o estudo em outro momento da evolução clínica, antes de uma conclusão diagnóstica definitiva.

Para a análise do jitter, existem duas técnicas, com formas diferentes de ativação muscular: a contração muscular voluntária $(C V)$ e a estimulação axonal (EA) (Sanders, Stålberg, 1996; Stålberg et al., 2010). Ambas as técnicas podem ser aplicadas com a utilização da $A C$, entretanto há mais fatores técnicos envolvidos na EA que podem interferir nos resultados da análise do jitter. Na EA geralmente ocorre a estimulação de mais de um axônio, com consequente ativação de muitas fibras musculares de unidades motoras distintas. Independente do eletrodo utilizado, o efeito de somação é mais limitante para medidas do jitter. Na ativação voluntária do músculo, a somação de PAs de unidades motoras diferentes ocorre eventualmente, pois possuem frequências de disparo diferentes. Adicionalmente, o efeito de somação pode ser facilmente reconhecido pelas diferenças nas morfologias dos potenciais (Stålberg, Sanders, 2009).

Valores normativos de jitter obtidos com AFU, em diferentes músculos, foram estabelecidos em um estudo multicêntrico em 1992 (SINGLE ..., 1992) e, para fins práticos, reeditado em forma de tabela em 1994 (Bromberg, Scott, 1994).

A AC é a mais apropriada para medidas de jitter, em substituição à AFU. Os primeiros valores normativos de jitter obtidos com AC são procedentes de centros independentes, a maioria com poucos sujeitos analisados, para os músculos seguintes: Frontalis (Kouyoumdjian, Stålberg, 2012, 2013a), Extensor Digitorum e OOc (Ertaş et al., 2000; Sarrigiannis et al., 2006; Kouyoumdjian, Stålberg, 2007, 2008b; Farrugia et al., 2009; Kouyoumdjian, Stålberg, 2011), e recentemente para o Masseter (Orhan et al., 2013). Alguns autores destacam a necessidade de cuidados técnicos para obtenção de resultados confiáveis com a utilização da $A C$, e também enfatizam que os valores de referência podem ser válidos em outros laboratórios, se for adotada uma metodologia igual ou similar (Kouyoumdjian, Stålberg, 2008b).

Em 2012, um estudo multicêntrico conduzido no Japão propôs valores de referência para os músculos Extensor Digitorum e Frontalis utilizando as técnicas de contração voluntária e estimulação axonal (Kokubun et al., 2012). 
Esse estudo recebeu críticas teóricas e técnicas, pois os valores obtidos de jitter foram superiores aos relatados em estudos anteriores (Stålberg et al., 2013); a utilização dos valores propostos pelos autores poderia diminuir a sensibilidade diagnóstica da EMGFU-JAC. Em estudo multicêntrico recente, que seguiu critérios metodológicos bem definidos, foram estabelecidos valores de referência para os músculos Extensor Digitorum, Frontalis e OOc, para ambas as técnicas de contração voluntária e estimulação axonal (Stålberg et al., 2016).

Há poucos estudos de EMGFU-JAC em doenças da JNM, particularmente a MG (Ertaş et al., 2000; Sarrigiannis et al., 2006; Farrugia et al., 2009; Kouyoumdjian et al., 2011; Witoonpanich et al., 2011; Kouyoumdjian, Stålberg, 2013b). Existem diferenças metodológicas e de valores normativos entre esses estudos que dificultam as comparações. Provavelmente, nos primeiros trabalhos há erros técnicos na aceitação dos PAs para a análise do jitter, por causa da ausência de padronização inicial da técnica para registro com AC. De uma maneira geral, todos os autores demonstraram que o jitter obtido com AC está aumentado na MG. A avaliação da sensibilidade e especificidade da AC para a análise do jitter, ao utilizar valores de referências para essa agulha, foi avaliada em poucos estudos (Sarrigiannis et al., 2006; Witoonpanich et al., 2011).

No presente estudo foi utilizada a AC para análise do jitter, durante a contração voluntária do músculo OOc, em sujeitos saudáveis e em pacientes com diagnóstico de MG, subdivididos nas formas generalizada e ocular da doença. 

2 OBJETIVOS 



\section{OBJETIVOS}

\subsection{Objetivo Geral}

O objetivo deste estudo é mensurar os valores do jitter por meio da técnica de ativação voluntária, em sujeitos saudáveis e em pacientes com MG, forma generalizada e ocular, utilizando eletrodo de agulha concêntrica descartável.

\subsection{Objetivos específicos}

Determinação de valores de referência do jitter em sujeitos saudáveis e comparação com os referidos na literatura.

Avaliação da validade do método na identificação de distúrbio da JNM na MG, com determinação da acurácia do método. 

3 REVISÃO DA LITERATURA 



\section{REVISÃO DA LITERATURA}

\subsection{Fisiologia da transmissão neuromuscular}

O neurotransmissor responsável pela transmissão neuromuscular é a acetilcolina (ACh). A ACh é sintetizada no nervo motor e armazenada em vesículas em diferentes compartimentos. O maior deles é um compartimento de reserva que não está disponível para liberação imediata de ACh; o menor dos compartimentos é composto por vesículas de liberação imediata, localizadas na parte terminal do nervo. A quantidade de ACh em cada vesícula constitui a unidade básica do transmissor, denominado quanta. Na ativação do nervo motor, uma onda de despolarização atinge a parte terminal do nervo, onde canais de cálcio voltagem dependentes na membrana pré-sináptica são ativados, permitindo influxo de cálcio. $O$ aumento da concentração de cálcio intracelular promove a fusão das vesículas de ACh nas zonas ativas da membrana pré-sináptica e a liberação, por exocitose, de milhares de moléculas de ACh na fenda sináptica. A fenda sináptica é um espaço pequeno, de aproximadamente $100 \mathrm{~nm}$ de largura, que separa a membrana pré-sináptica da membrana pós-sináptica. O neurotransmissor, então, atravessa a fenda sináptica para interagir com receptores nicotínicos de acetilcolina (AChRs) localizados na superfície das dobras juncionais da membrana pós-sináptica. A interação da ACh nesses receptores propicia a abertura de canais de sódio, localizados na profundidade das dobras juncionais da membrana pós-sináptica, permitindo a movimentação de sódio para dentro do músculo. Esse influxo de sódio produz uma despolarização local na região juncional, ou seja, produz um potencial pós-sináptico excitatório, designado como potencial de placa terminal (PPT). Após a interação do neurotransmissor com o receptor na membrana pós-sináptica, a ACh é hidrolisada em menos de $1 \mathrm{~ms}$, pela enzima acetilcolinesterase, em colina e acetato. A colina é então absorvida por endocitose na região terminal do nervo e é novamente sintetizada em moléculas de ACh (Kandel, Schwartz, 2013). 
No estado de repouso, a liberação do quanta de ACh na fenda sináptica é intermitente e aleatória, e depende da concentração extracelular de cálcio e da temperatura. A consequente despolarização localizada apenas na região juncional, denominada PPT em miniatura, ocorre em resposta à liberação de ACh e sua integração com os AChRs, por meio do processo descrito acima. No entanto, em resposta a um estímulo no nervo motor, ocorre a liberação de aproximadamente 100 quanta de $\mathrm{ACh}$ na fenda sináptica que se ligam a 100.000 AChRs, produzindo uma despolarização localizada muito maior, o PPT (Keesey, 1989). Quando esses potenciais são grandes o suficiente e atingem um nível crítico de despolarização da membrana muscular, conhecido como limiar de disparo, um PA é gerado e a despolarização espalha-se para as regiões próximas da placa terminal, propagando-se bidirecionalmente na fibra muscular, com consequente contração muscular.

A relação entre a amplitude do PPT e o limiar para desencadear o PA é denominado fator de segurança da JNM. Em uma JNM normal, o fator de segurança é grande o suficiente para garantir que cada impulso nervoso resulte em contração muscular (Trontelj et al., 2002). Portanto, ocorre a liberação de muitas moléculas de ACh na JNM, com ativação de muitos AChRs, mais do que o necessário para garantir que os PPTs atinjam o limiar de disparo da membrana muscular. Se o fator de segurança da JNM estiver reduzido, como na MG, o comprometimento transmissão sináptica torna-se clinica e eletrofisiologicamente evidente.

\subsection{Estimulação repetitiva}

O PAMC registrado com eletrodo de superfície na ENMG, após estímulo elétrico supramáximo do nervo, corresponde à somação temporal e espacial de todas as fibras musculares inervadas por aquele nervo. A amplitude do PAMC equivale à quantidade de fibras musculares ativadas. A quantidade de quanta liberada pela região terminal do nervo varia a cada estímulo elétrico e depende da quantidade de vesículas de ACh disponíveis imediatamente para liberação. Estímulos elétricos repetidos em frequência baixa, reduzem a liberação do 
quanta nos primeiros impulsos, e após o quinto estímulo elétrico a quantidade média de ACh é relativamente constante (Dumitru et al., 2002). Em músculos normais, graças ao fator de segurança da JNM, o PAMC produzido por estímulos elétricos repetidos em frequência baixa não apresenta alteração de amplitude em descargas consecutivas.

Na MG, entretanto, ocorre diminuição do fator de segurança da JNM, em decorrência de vários mecanismos fisiopatogênicos. A diminuição no tamanho dos PPTs, por causa da ativação menor de AChR, pode ser suficiente para a falência da transmissão neuromuscular em algumas JNMs (bloqueio do impulso). A consequência, na prática, é a diminuição da amplitude do PAMC em resposta aos estímulos elétricos de frequência baixa. Portanto, a reposta inicial clássica no teste de ER na MG é um decremento entre o primeiro e o quarto, ou quinto, potencial seguido por recuperação parcial da amplitude do PAMC, que produz a resposta característica em "U".

$\mathrm{Na}$ ER em frequências maiores que $10 \mathrm{~Hz}$ ou após breve contração muscular máxima, na qual a unidade motora é ativada ao redor de $20 \mathrm{~Hz}$ a $30 \mathrm{~Hz}$, ocorre o fenômeno de facilitação pós-ativação. Fisiologicamente, esse fenômeno é explicado pelo acúmulo de cálcio na placa terminal, aumentando a liberação de neurotransmissores, com consequente reversão parcial ou total do decremento observado inicialmente no teste de $E R$, em baixa frequência, na MG. Mecanismos de facilitação aumentam a eficiência da transmissão neuromuscular (Dumitru et al., 2002). Alguns minutos após o fenômeno de facilitação pós-ativação, a concentração de cálcio residual acumulada na placa terminal diminui, assim como a liberação do quanta de ACh. Esse período conhecido como exaustão pós-ativação, dura em torno de dois a cinco minutos e é caracterizado pela diminuição da amplitude do PAMC em impulsos elétricos repetidos em frequência baixa.

A ER foi inicialmente descrita por Harvey e Masland ${ }^{1}$ (1941, apud American Association of Electrodiagnostic Medicine (AAEM) Quality Assurance

\footnotetext{
${ }^{1}$ Harvey AM, Masland RL. A method for the study of neuro-muscular transmission in human subjects. Bull Johns Hopkins Hosp. 1941;68:81-93.
} 
Committee, 2001a) com a aplicação de estímulos elétricos supramáximos, de $20 \mathrm{~Hz}$ e $30 \mathrm{~Hz}$, em pacientes com diversas anormalidades neurológicas. Os autores, ao realizarem o teste de ER em pacientes com MG, observaram que a ER em frequências mais baixas $(13 \mathrm{~Hz})$ do que as inicialmente utilizadas, apresentava maior grau de decremento quando comparadas às frequências mais altas.

A técnica de ER é simples e amplamente utilizada para a avaliação de distúrbios da JNM, porém há necessidade de cuidados técnicos para obtenção de respostas confiáveis, por exemplo, imobilização adequada do músculo e aquecimento do membro a ser examinado. Recomenda-se também, quando possível, suspender drogas anticolinesterásicas de 12 horas a 24 horas antes do estudo, para evitar a normalização da ER em razão do uso da medicação (AAEM Quality Assurance Committee American Association of Electrodiagnostic Medicine, 2001a). Considera anormal a presença de diminuição da amplitude do PAMC $\geq 10 \%$ entre o primeiro e o quarto, ou quinto, estímulo (Figura 5). A frequência de estímulo recomendada é entre $2 \mathrm{~Hz}$ e $5 \mathrm{~Hz}$ (AAEM Quality Assurance Committee American Association of Electrodiagnostic Medicine, 2001b).

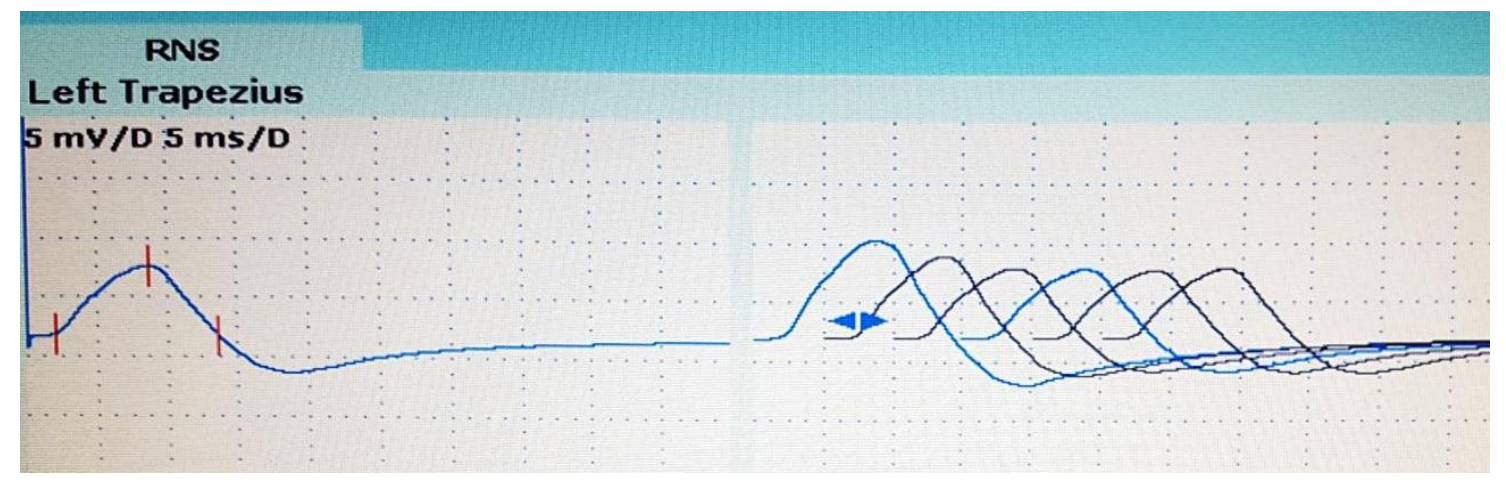

Figura 5. Presença de decremento de $28,8 \%$ entre o primeiro e o quarto potencial de ação muscular composto em resposta à estimulação repetitiva de $3 \mathrm{~Hz}$ no nervo acessório com registro no músculo Trapezius. 


\subsection{Jitter neuromuscular}

As amplitudes dos PPTs apresentam variações aleatórias entre descargas consecutivas, e como consequência, oscilações no fator de segurança da JNM. O jitter neuromuscular reflete as pequenas flutuações no tempo que levam os PPTs para atingir o limiar de disparo do PA, com consequente variação no tempo de transmissão neuromuscular em JNMs normais (Figura 6).

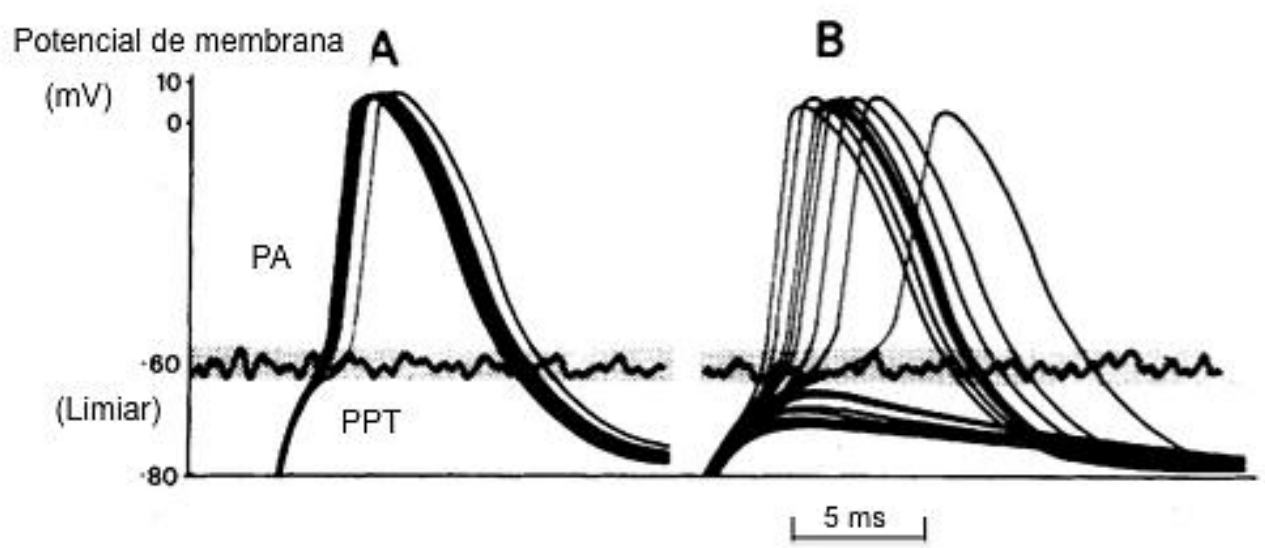

Figura 6. Ilustração para explicar o jitter neuromuscular e bloqueio. Registros intracelulares, vistos com sobreposição dos sinais, próximo à placa motora terminal de fibras musculares intercostais, com estimulação indireta a $5 \mathrm{~Hz}$. A flutuação do limiar para que o potencial de placa terminal (PPT) despolarize e deflagre o potencial de ação (PA), propagado na fibra muscular, é supostamente responsável pela variação normal da latência do potencial de ação $(A)$. Em condições em que as amplitudes dos potenciais de placa terminal estão diminuídas (B), essa variação é maior, resultando em jitter aumentado; alguns potenciais de placa terminal não são grandes o suficiente para deflagrar o potencial de ação, resultando em bloqueio intermitente (Adaptado de Kessey, 1989).

Praticamente todo o jitter obtido em músculos normais, com frequências de ativação regulares, provém da JNM (Stålberg et al., 2010). Em 1975, Schiller et al. demonstraram que o jitter refletia o fator de segurança da placa motora terminal. Nesse estudo, uma dose de curare, agente bloqueador 
neuromuscular potente, foi utilizada para diminuir parcialmente o fator de segurança da JNM. Pequenas doses adicionais de curare aumentaram ainda mais o jitter, com efeito mais significativo em JNMs que inicialmente apresentaram valores mais altos de jitter (Schiller et al., 1975). Trontelj et al. (2002) observaram que em JNMs normais os valores do jitter sofreram relativamente poucas alterações com frequências de estímulos diferentes, sugerindo um fator de segurança alto da JNM. Em JNMs normais com valores de jitter relativamente altos, os autores observaram maior facilitação quando a frequência do estímulo foi aumentada de $5 \mathrm{~Hz}$ ou $10 \mathrm{~Hz}$ para $20 \mathrm{~Hz}$. Resultados similares, porém mais marcantes, foram vistos em JNM de pacientes com MG, demonstrando o efeito do fenômeno de facilitação para aumentar o fator de segurança de JNM (Trontelj et al., 2002).

Uma pequena proporção do jitter em músculos normais, entretanto, pode advir de outras fontes não relacionadas à transmissão sináptica, principalmente da fibra muscular. O tempo de transmissão no trajeto do axônio e ao longo da fibra muscular possui um jitter combinado menor do que $4 \mu$ s ("jitter miogênico") (Trontelj et al., 1992). Na fibra muscular, a velocidade de propagação varia levemente em impulsos consecutivos, e depende do intervalo de descarga do impulso precedente (IDI - interdischarge interval ou intervalo entre descarga) (Stålberg, 1966). Um intervalo curto após uma descarga precedente (frequência de descarga alta) aumenta a velocidade de propagação da fibra muscular na descarga seguinte. Esse fenômeno é conhecido como função de recuperação da velocidade (VRF - velocity recovery function, ou função de recuperação da velocidade) e pode ser analisado em gráficos que demonstram uma correlação positiva entre o IDI e o intervalo entre potencial (IPI interpotential interval, ou intervalo entre potencial) seguinte, em descargas consecutivas. A VRF pode ser facilmente observada na ativação muscular por estimulação axonal do nervo, no qual, no início do estímulo ou na mudança da frequência do estímulo, ocorre uma diminuição da latência do potencial registrado nas primeiras descargas subsequentes (Trontelj et al., 1986). Se a medida do jitter for realizada em frequências irregulares de descargas, a VRF contribuirá significativamente para 0 aumento do valor do jitter. Adicionalmente, quando o IPI é maior do que $4 \mathrm{~ms}$, o efeito da VRF também é 
significativo (Trontelj et al., 1986). A contribuição da VRF no valor do jitter pode ser parcialmente compensada por algoritmos matemáticos, com a utilização do MSD (mean sorted data, ou média dos dados classificados) ao invés do MCD. No cálculo do MSD, as medidas dos IPI são classificadas em ordem crescente de acordo com o IDI precedente, calculando-se então a média dessas medidas. $\mathrm{Na}$ prática, os equipamentos modernos disponibilizam um índice que representa a relação MCD/MSD. Se esse valor for maior do que 1,25 o jitter medido foi influenciado pelo IDI e, portanto, deve ser utilizado o MSD para o cálculo. Na prática diária esses registros são incomuns e normalmente não são aceitos para medidas do jitter.

A melhor maneira matemática de expressar o valor do jitter é o cálculo da diferença do IPI em descargas consecutivas (idealmente 100 e no mínimo 50) e usar a média das diferenças consecutivas (MCD) em valores absolutos de todos os IPI medidos (Ekstedt et al., 1974):

$$
\text { MCD }=\left[\left(\mathrm{IPI}_{1}-\mathrm{IPI}_{2}\right)+\left(\mathrm{IPI}_{2}-\mathrm{IPI}_{3}\right)+\cdots+\left(\mathrm{IPI}_{\mathrm{n}-1}-\mathrm{IPI}_{n}\right)\right] /(n-1)
$$

Onde: $\mathrm{IPI}_{i}$ é o intervalo entre potenciais da i-ésima descarga e $n$ é a quantidade de pares medidos.

Nos equipamentos de ENMG modernos existe um relógio interno que mede o jitter. Há duas formas de medir o intervalo de tempo entre os potenciais (jitter): método de detecção do pico ou por nível da amplitude. No primeiro, os picos dos potenciais são detectados automaticamente e o ponto exato da ocorrência do pico do potencial é definido matematicamente para aumentar a acurácia da medida. Em músculos ativados voluntariamente, o jitter é medido entre o pico do potencial fixado na tela e a variação dos picos do outro potencial, em descargas consecutivas. No método por detecção do nível da amplitude a medida é realizada entre um ponto da fase de ascensão do potencial, próximo à linha de base, e em um ponto correspondente no potencial que precede ou sucede o potencial fixado na tela do osciloscópio (Figura 7). 

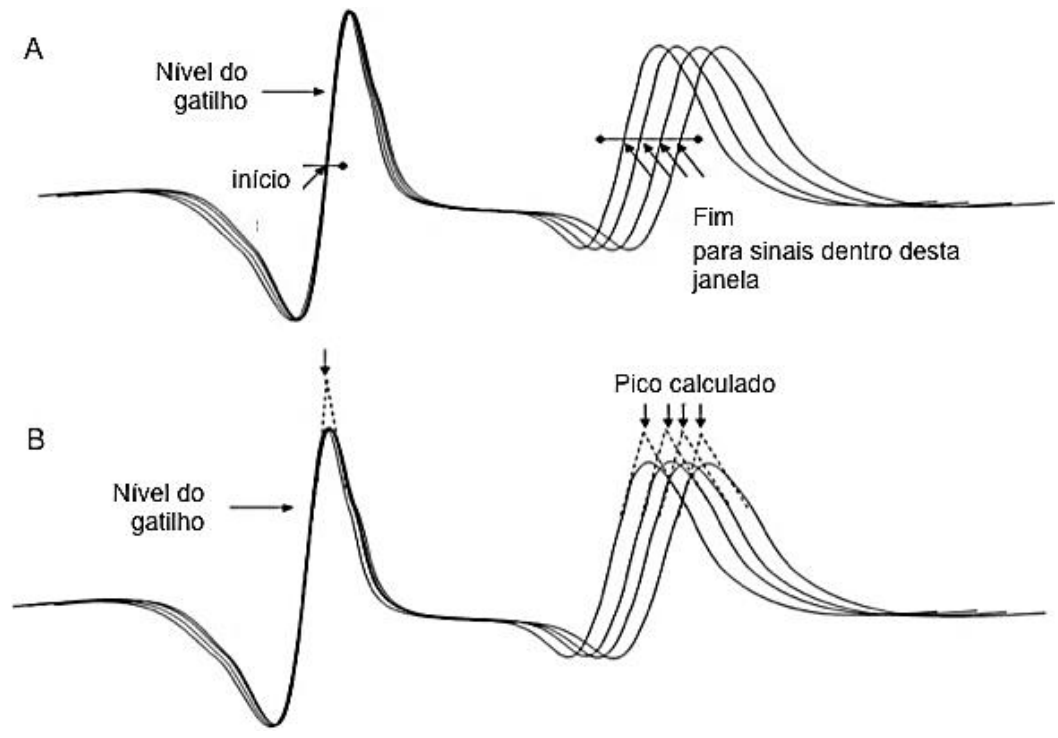

Figura 7. Métodos para medir o jitter. A) Método do nível da amplitude. O jitter é medido entre níveis de voltagem selecionados na fase de ascensão dos potenciais; setas horizontais indicam o início e fim do intervalo de contagem. B) Método de detecção do pico. O jitter é medido entre os picos calculados dos potenciais (setas verticais). Em ambos os métodos, o operador seleciona o potencial de interesse, fixando-o na tela do equipamento por um nível de gatilho de voltagem. (Adaptado de Stålberg, Sanders, 2009)

O método de detecção do pico parece ser mais prático, pois não há necessidade de ajustes manuais. Além disso, esse método possibilita medidas corretas quando o IPI é curto, até $150 \mu \mathrm{s}$. Nesses casos, o método de detecção por nível de amplitude aumenta erroneamente o valor do jitter, porque as medidas ocorrem em pontos diferentes do sinal (Stålberg, Sanders, 2009) (Figura 8). 


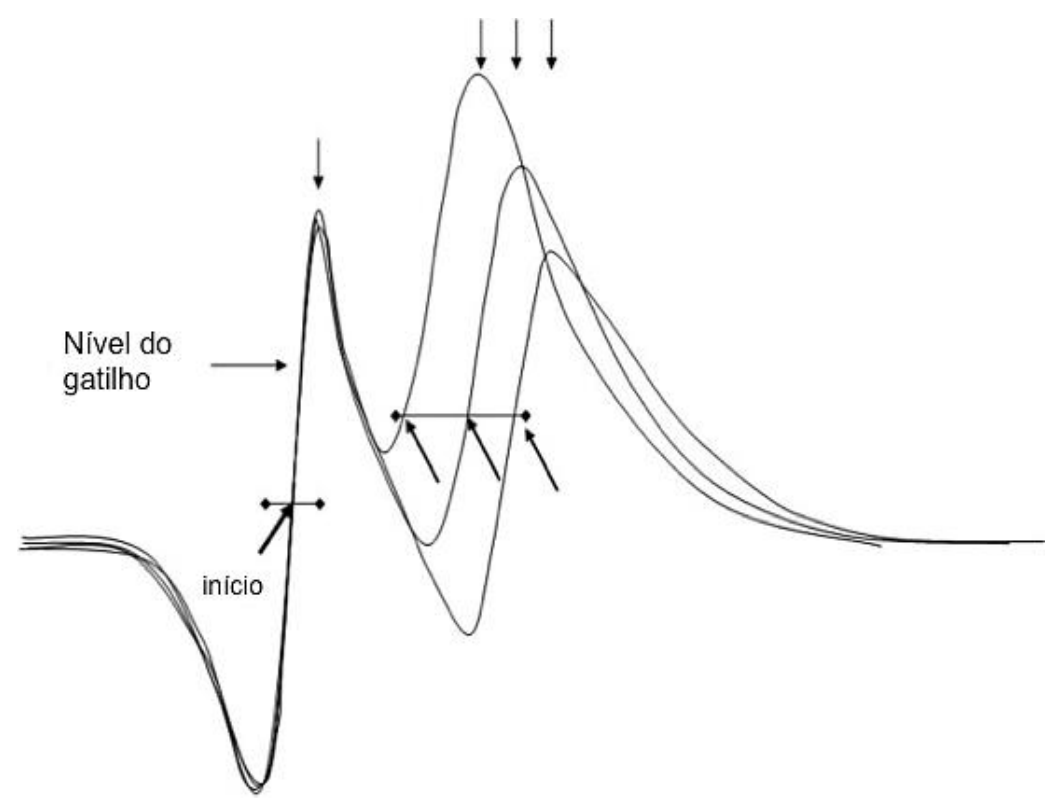

Figura 8. Sinais com intervalos entre potenciais curtos, de $150 \mu \mathrm{s}$. Se a técnica de detecção de amplitude for utilizada, o jitter será medido em diferentes partes do potencial, aumentando erroneamente o valor do jitter. A técnica de detecção de pico é menos afetada por esse artefato. Setas horizontais indicam os pontos no sinal onde inicia e termina a contagem do intervalo; setas verticais para a técnica de detecção de pico e setas inclinadas para a técnica de nível de amplitude. (Adaptado de Stålberg, Sanders, 2009)

Valores normais de jitter variam para diferentes músculos, técnicas e faixas etárias, havendo também diferenças entre indivíduos, refletindo a variabilidade dos fatores de segurança das JNMs; os valores variam até mesmo entre JNMs pertencentes a uma mesma unidade motora.

O jitter está mais comumente aumentado em distúrbios da JNM como: MG (Sanders, 2002); Síndrome de Lambert-Eaton (Oh et al., 1989; Chaudhry et al., 1991; Sadeh et al., 1997; Oh, Ohira, 2013); e, botulismo (Sanders et al., 1986; Padua et al., 1999) (Figura 9). Porém, o jitter também pode estar aumentado em distúrbios da condução dos nervos e da fibra muscular, particularmente nos casos de reinervação e distrofias musculares (Stålberg, 1990; Wiechers, 1990; Massey, Sanders, 1991; Gantayat et al., 1992; Bertorini et al., 1994; Bril et al., 1996; Grimby et al., 1998; Lagueny et al., 1998). Os valores do jitter estarão aumentados em qualquer distúrbio da JNM que curse com diminuição do fator de segurança. Dependendo do grau de 
comprometimento da JNM, os PPTs não são grandes o suficiente para atingir o limiar de disparo, ocorrendo, então, bloqueio do impulso (Keesey, 1989). Enquanto pequenas flutuações na transmissão neuromuscular já são detectáveis na análise jitter, a ER apresenta anormalidades apenas na presença de bloqueio em uma determinada quantidade de JNMs.

$0,3 \mathrm{mV} / \mathrm{D} \quad 0,5 \mathrm{~ms} / \mathrm{D}$
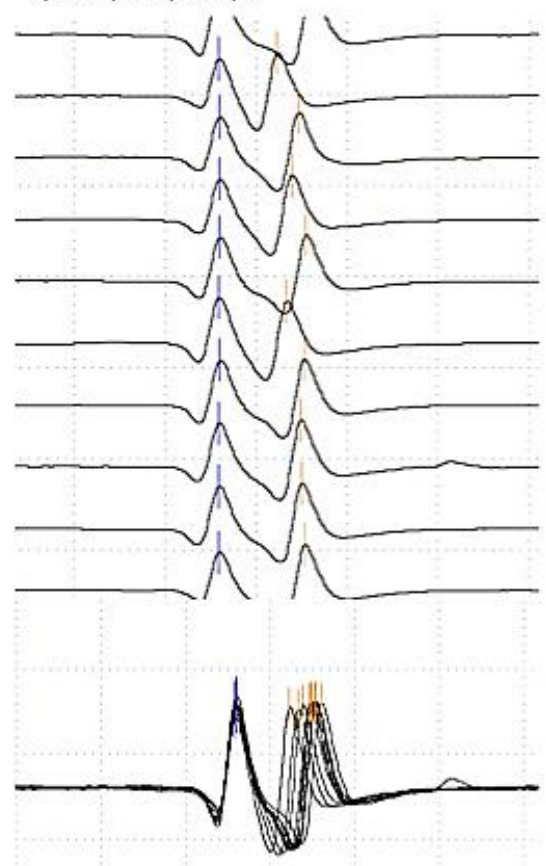

A

$49 \mu \mathrm{s}$

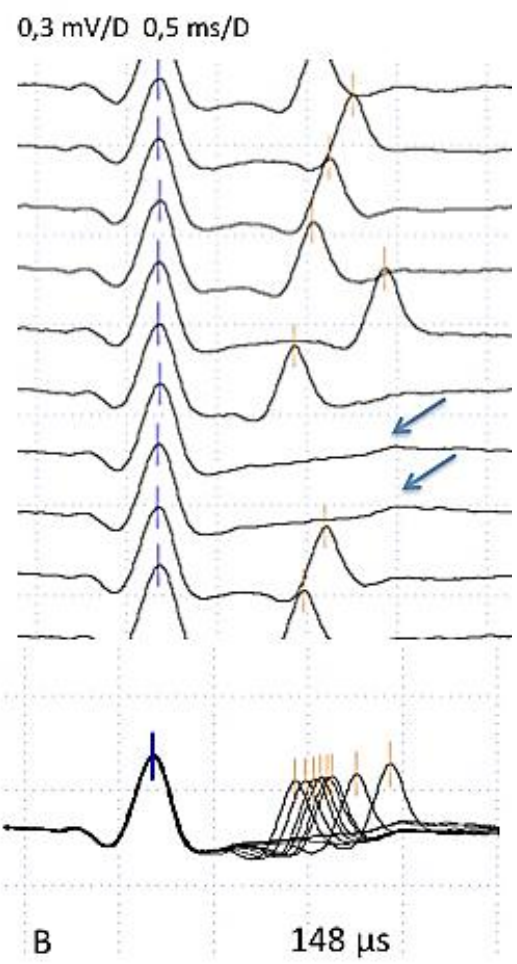

Figura 9. Exemplos de jitter aumentado no músculo Orbicularis Oculi, com a técnica de contração voluntária e registro com agulha concêntrica, em pacientes do grupo miastenia gravis forma generalizada. Traçados ao alto são vistos em modo de varredura de descargas consecutivas; abaixo estão em modo de sobreposição de 10 traçados consecutivos, para melhor análise da morfologia constante do potencial. A) Jitter levemente aumentado; B) Jitter muito aumentado, com bloqueio do potencial de ação, indicados pela seta.

Em algumas condições de doença, como na MG, o bloqueio da transmissão pode usualmente ser visto com valores de jitter acima do intervalo

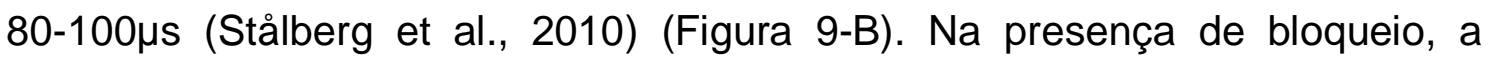
medida do jitter pode ser erroneamente alta. $O$ bloqueio produz efeitos 
indesejáveis na frequência de disparo da fibra muscular que introduz o jitter decorrente do efeito da VRF (Stålberg et al., 2010).

\subsection{Técnicas de análise do jitter e critérios de anormalidade}

As técnicas de contração voluntária e a estimulação axonal (Stålberg, 1966; Trontelj et al., 1988; Stålberg et al., 2010) são as mesmas independente do eletrodo utilizado, AFU ou AC (Stålberg, Sanders, 2009). A escolha da técnica depende da colaboração do paciente e da preferência do examinador. As complicações são as mesmas da ENMG convencional, como sangramento ou, mais raramente, infecções no local da introdução da agulha. Pode ocorrer um pequeno hematoma no local, porém os músculos examinados são superficiais e passíveis de compressão externa, não havendo consequências graves para o paciente (Sanders, Stålberg, 1996). De uma forma geral, pacientes relatam menor desconforto com a EMGFU do que com a ER em músculos proximais (Sanders, Stålberg, 1996); a AC é mais bem tolerada em comparação com a AFU (Farrugia et al., 2009).

$\mathrm{Na} C V$, há necessidade de cooperação do paciente, que precisa manter uma contração voluntária leve e constante do músculo examinado. O eletrodo de agulha é inserido no músculo para registrar pares de PAs pertencentes à mesma unidade motora (Figura 10). São realizados pequenos movimentos do

eletrodo para a identificação desses potenciais. Quando um par de PAs é identificado, um deles é escolhido como referência de tempo e é fixado na tela do equipamento; a variação combinada dos dois registros é demonstrada na outra resposta. Portanto, nessa técnica, duas JNMs contribuem para o valor do jitter. Para cada par, 50 a 100 descargas consecutivas são registradas para o cálculo do MCD. Idealmente, 20 pares são obtidos em cada estudo e a média do MCD é calculada (Stålberg et al., 2010). Na prática, o jitter é considerado como uma variação no IPI em descargas consecutivas (Figura 11). A média do intervalo entre potencial (MIPI - mean interpotential interval ou média do intervalo entre potencial) reflete a diferença nos tempos de condução nos ramos nervosos (axônios), JNMs e fibras musculares nas duas vias, além de 
diferenças anatômicas do comprimento dos nervos até as fibras musculares. Na maioria dos registros obtidos em músculos normais, o IPI é em geral menor do que $1 \mathrm{~ms}$.

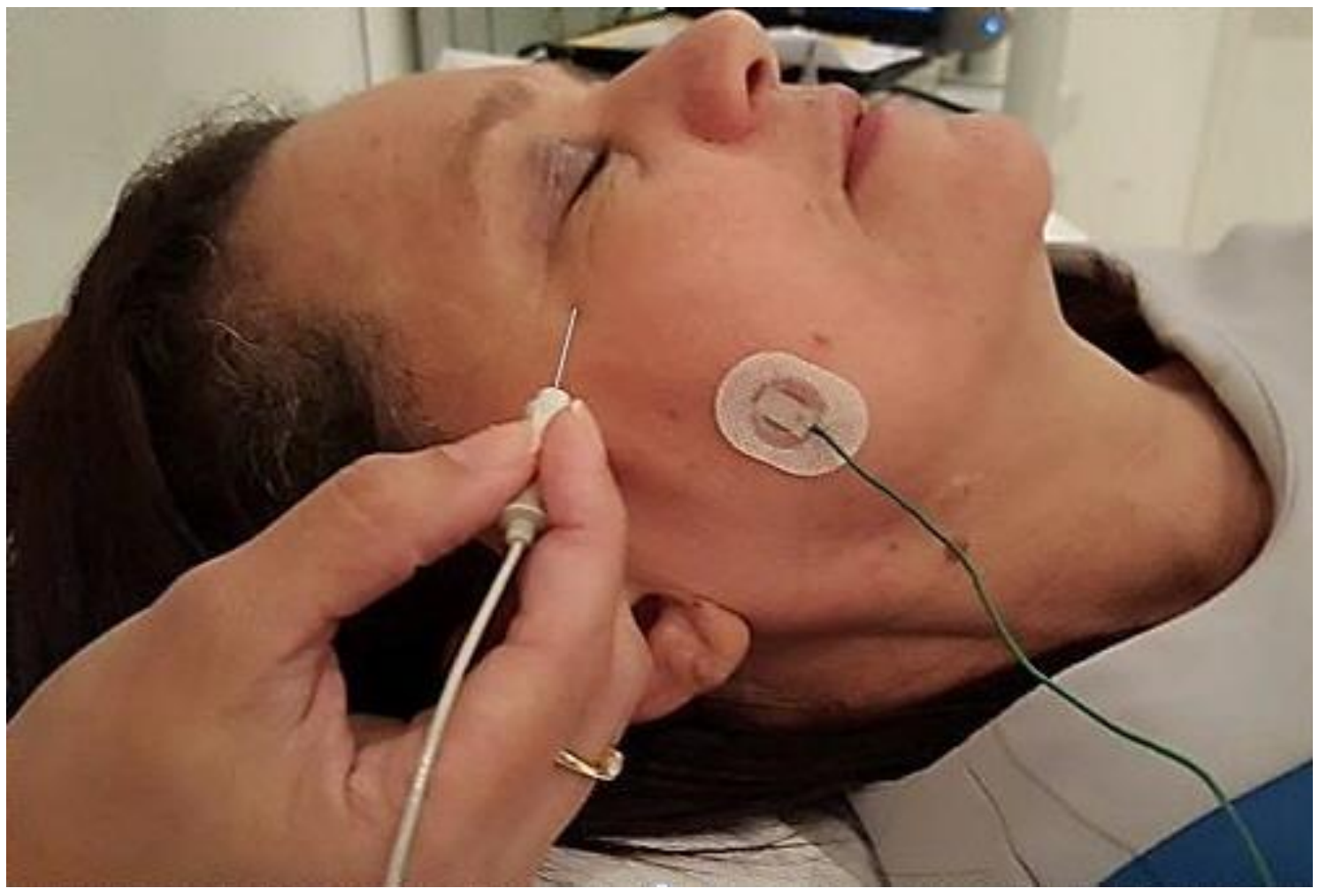

Figura 10. Um dos pontos de inserção da agulha concêntrica no músculo Orbicularis Oculi, em um raio de $1-2 \mathrm{~cm}$ do epicanto lateral, para a análise do jitter com a técnica de contração voluntária. Eletrodo de superfície - terra, também observado na figura. 

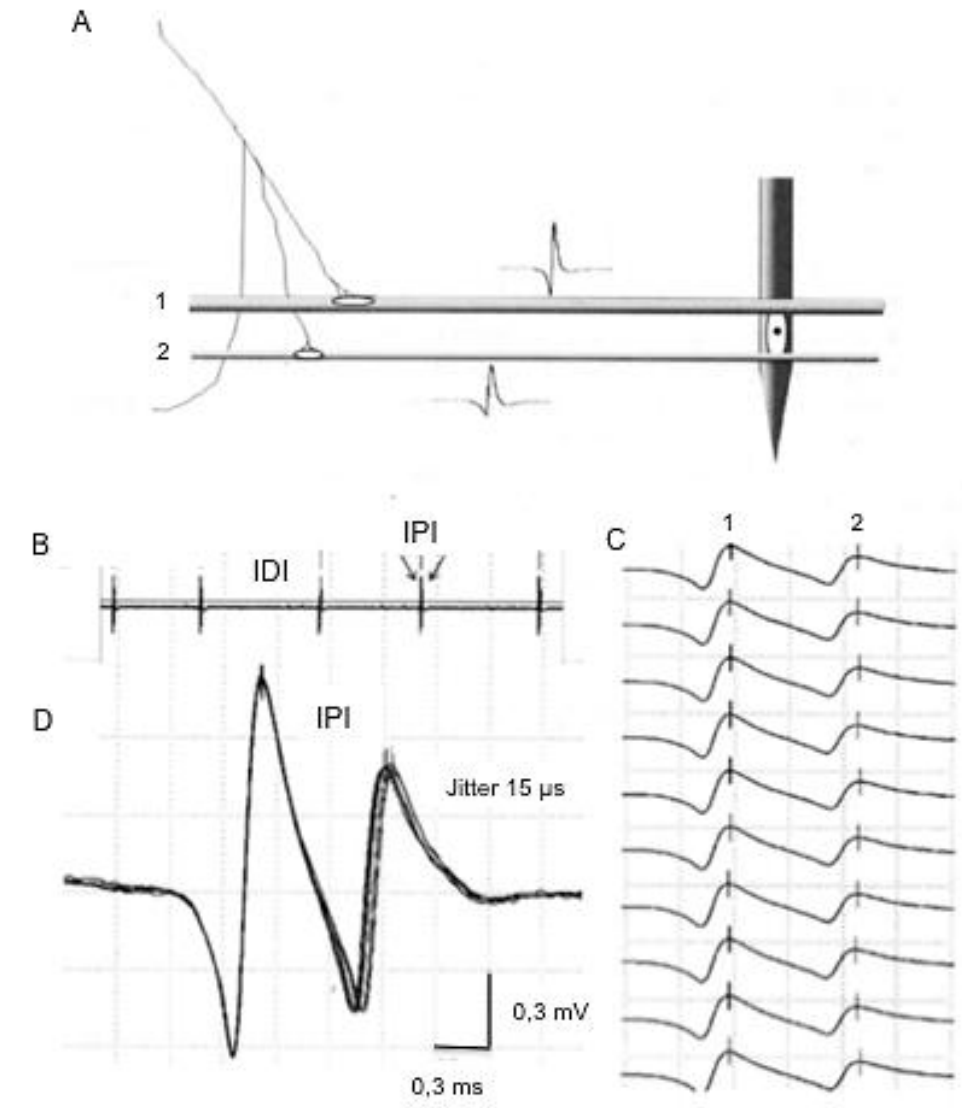

Figura 11. Análise do jitter com a técnica de contração voluntária. (A) Posição da agulha de fibra única entre duas fibras musculares (1 e 2) que pertencem a mesma unidade motora. (B) Descargas consecutivas do par de potenciais de ação, com leve contração voluntária do músculo. São indicados o intervalo entre descargas (IDI) e intervalo entre potenciais (IPI); velocidade de varredura da tela do osciloscópio de $0,1 \mathrm{~s} /$ divisão. (C) $O$ mesmo par de potenciais registrado com velocidade de

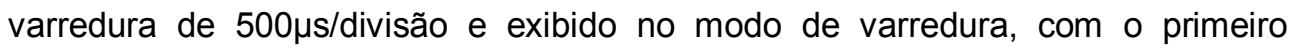
potencial fixado na tela. (D) O mesmo par de potenciais visto no modo de sobreposição, para demonstrar variações no IPI. (Adaptado de Stålberg et al., 2010)

A EA é indicada, especialmente, para pacientes pouco cooperativos, inconscientes, que apresentam tremor ou fracos demais para contrair voluntariamente o músculo a ser estudado (Sanders, Stålberg, 1996). Segmentos distais do nervo são estimulados, com intensidade baixa e frequência constante, por um eletrodo de agulha monopolar (Trontelj, Stålberg, 1992) ou eletrodo de superfície (Ertaş et al., 1998; Kouyoumdjian, Stålberg, 2012). A estimulação pode ser axonal no nervo periférico, como estímulo do ramo do nervo facial para estudo do músculo $00 c$, ou estimulação microaxonal 
intramuscular, próximo ao ponto motor do nervo, como utilizada no estudo do músculo Extensor Digitorum. Uma segunda agulha é inserida no músculo para registro dos PAs (Figura 12). Na estimulação do nervo, acima de seu limiar, as latências das respostas registradas de uma única fibra muscular variam em descargas consecutivas (jitter). Nessa técnica, o jitter é medido entre o estímulo elétrico e o PA gerado na fibra muscular, portanto, representa o jitter de apenas uma JNM. São registradas 50 a 100 descargas consecutivas. Idealmente, 30 PAs de fibras musculares diferentes são obtidos para o cálculo da média do MCD (Trontelj et al., 1986). Estímulos subliminares podem produzir jitter falsamente aumentado, nesses casos, pequenos aumentos na intensidade do estímulo são suficientes para corrigir esse erro (Trontelj, Stålberg, 1992). Por outro lado, valores de jitter menores que $5 \mu \mathrm{s}$, provavelmente refletem estimulação muscular direta, ao invés de estimulação axonal, e não devem ser utilizados para análise do jitter (Figura 12) (Trontelj et al., 1986). Além dos cuidados descritos, a técnica de EA está mais sujeita a erros de análise, uma vez que vários axônios são estimulados simultaneamente, tornando o efeito de somação dos PAs ainda mais significativo, particularmente, nos registros com AC (Stålberg, Sanders, 2009). 


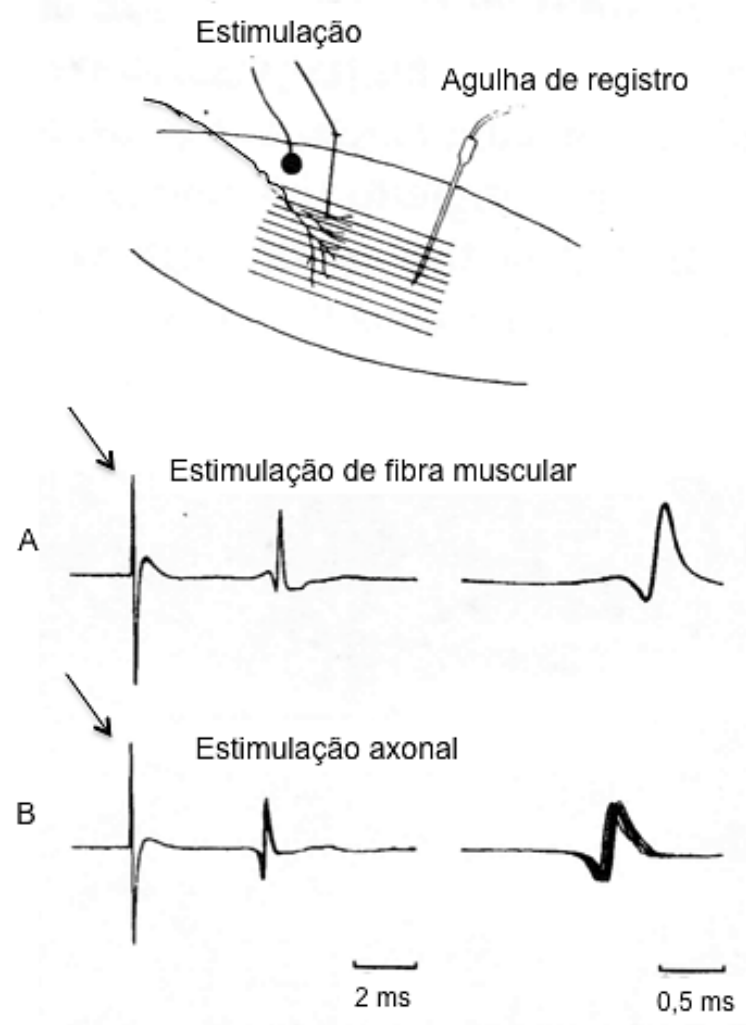

Figura 12. Análise do jitter com a técnica de estimulação microaxonal intramuscular. Eletrodos de estímulo e de registro são identificados ao alto. Exemplos de respostas típicas: (A) estimulação muscular direta - (jitter baixo) e (B) estimulação axonal (jitter $>4 \mu \mathrm{s})$. A seta indica 0 artefato de estímulo. Potenciais à direita demonstram 0 jitter, melhor observado na sobreposição dos traçados. (Adaptado de Stålberg et al., 2010).

Uma análise comparativa entre as duas técnicas, CV e EA, com a utilização da $A C$, mostrou uma redução dos valores de jitter em torno de $20 \%$ na última técnica em comparação com a primeira (Kouyoumdjian, Stålberg 2008ª). Essa diferença é menor do que em comparações similares com a AFU (Trontelj et al., 1986) e, provavelmente, reflete as dificuldades técnicas de registros com a $\mathrm{AC}$, por causa do registro de PAs somados e valores subestimados de jitter (Kouyoumdjian, Stålberg, 2008b).

A definição de anormalidade em um estudo determinado, independente da técnica utilizada, pois deve preencher pelo menos um dos critérios seguintes: 1) mais de $10 \%$ dos PAs apresentam valores individuais de MCD aumentados; 2) a média do MCD de todos os registros está aumentada (Sanders, Howard, 1986; SINGLE ..., 1992). 
Além da utilização da EMGFU para fins diagnósticos, estudos seriados de jitter para acompanhamento individual do tratamento clínico da MG mostraram-se promissores (Howard, Sanders, 1981; Massey, Sanders, 1993; Meriggioli, Rowin, 2003). Alterações na medida do jitter, em um determinado músculo, apresentam boa correlação na maioria dos pacientes, com modificações quanto à gravidade da doença (Howard, Sanders, 1981; Konishi et al., 1981). Em medidas seriadas de jitter em 41 pacientes com MG, tratados por Howard e Sanders (1981), com inibidores da acetilcolinesterase, corticoesteróides ou plasmaferese, houve aumento em 10\% da média do MCD em dois terços dos pacientes que pioraram clinicamente; em $80 \%$ dos pacientes que apresentaram melhora clínica o jitter diminuiu em 10\%. Estudos seriados também podem ser úteis em algumas situações, por exemplo, em pacientes submetidos à terapia imunossupressora, nos quais os valores do jitter tendem a diminuir conforme a doença melhora, e se ocorrerem desvios desse padrão isso pode sugerir que a terapia imunossupressora não está sendo eficaz. Ou ainda, se valores do jitter estiverem relativamente constantes em várias medidas seriadas, qualquer aumento subsequente normalmente acompanha a deterioração clínica (Sanders, 2002). Embora as modificações no tratamento individual da MG sejam primordialmente fundamentadas em dados clínicos, estudos seriados do jitter somam informações para o processo de decisão terapêutica. 
4 MÉTODOS 



\section{MÉTODOS}

\subsection{População do estudo}

A Comissão de Ética para Análise de Projetos de Pesquisa do Hospital das Clínicas (HC)/Faculdade de Medicina da Universidade de São Paulo (FMUSP) e o Comitê de Ética e Pesquisa do laboratório Fleury Medicina e Saúde aprovaram o protocolo de pesquisa (Apêndices 1 e 2).

Todos os participantes do estudo assinaram o Termo de Consentimento Livre e Esclarecido (Apêndice 3) e a pesquisa foi executada de acordo com as normas da Declaração de Helsinque.

Para todos os sujeitos e pacientes do estudo foram preenchidos protocolos, com dados e informações relevantes para cada grupo (Apêndices 4 e 5). No grupo de pacientes, utilizou-se a classificação da MGFA (Myasthenia Gravis Foundation of America) (Jaretzki et al., 2000), no momento do estudo (atual - MGFAa) e na pior fase da doença (MGFAp). De acordo com a MGFA, sintomas puramente oculares (diplopia, queda palpebral) são classificados como I e sintomas generalizados (fraqueza em musculatura axial, apendicular) variam de II a IV em ordem crescente de gravidade da doença. O protocolo de participação preenchido considerou dados referidos pelos pacientes, registrados nos prontuários médicos, além da avaliação objetiva, pelo pesquisador, no momento do recrutamento (Apêndice 5).

\subsubsection{Grupo Controle}

O grupo controle era composto por 20 voluntários, escolhidos no período de março a julho de 2011, treze mulheres e sete homens com idades entre 20 anos e 59 anos.

\subsubsection{Critérios de inclusão}

- Pessoa saudável 
- Não familiar de paciente

\subsubsection{Critérios de exclusão}

- Uso de medicação com ação conhecida na junção neuromuscular (bloqueadores do canal de cálcio, betabloqueadores, toxina botulínica, exposição a agrotóxicos);

- Doença neurológica ou suspeita de distúrbio da transmissão neuromuscular.

4.1.2 Grupo miastenia gravis forma generalizada

O grupo miastenia gravis forma generalizada (MGG) foi constituído por 21 pacientes com diagnóstico de MG forma generalizada, acompanhados no ambulatório de Neurologia, Grupo de Miastenia, do Hospital das Clínicas da FMUSP. Dezesseis mulheres e cinco homens, com idades entre 24 anos e 65 anos participaram do estudo. Os pacientes foram recrutados consecutivamente entre outubro de 2011 e setembro de 2013. Um paciente foi excluído por apresentar fraqueza acentuada da musculatura da face, impossibilitando o estudo.

4.1.2.1 Critérios diagnósticos de inclusão

- Diagnóstico clínico de MG forma generalizada, caracterizado por:

a) fraqueza generalizada, ptose e diplopia;

b) fatigabilidade e flutuação dos sintomas de fraqueza generalizada;

c) melhora clínica ao tratamento com piridostigmina (Mestinon ${ }^{\circledR}$ ).

- Pelo menos um dos métodos diagnósticos:

a) dosagem sérica positiva para ac-AChR;

b) teste de ER com decremento de pelo menos $10 \%$ da amplitude entre o primeiro e o quarto potencial, a uma frequência de $2 \mathrm{~Hz}$ ou $3 \mathrm{~Hz}$. 
4.1.2.2 Critérios de exclusão

- Início dos sintomas ao nascimento ou nos primeiros cinco anos de vida;

- Impossibilidade clínica de suspensão da piridostigmina 24 horas antes do exame;

- História clínica ou alterações na ENMG compatíveis com neuropatia periférica.

\subsubsection{Grupo miastenia gravis forma ocular}

O grupo miastenia gravis forma ocular (MGO) constituiu-se de 13 pacientes com diagnóstico ou forte suspeita clínica de MG forma ocular, acompanhados no ambulatório de Neurologia, Grupo de Miastenia, do HC/FMUSP. Sete mulheres e seis homens, com idades entre 18 anos e 54 anos participaram do estudo. Os pacientes foram recrutados consecutivamente entre outubro de 2011 e julho de 2014.

\subsubsection{Critérios diagnósticos de inclusão}

- Diagnóstico clínico de MG forma ocular, caracterizado por:

a) fraqueza restrita à musculatura ocular extrínseca e músculo Levator Palpebrae Superioris, particularmente assimétrica e não restrita aos músculos inervados por um único nervo craniano;

b) fatigabilidade e flutuação dos sintomas oculares (ptose palpebral e/ou diplopia);

c) melhora clínica ao tratamento com piridostigmina (Mestinon ${ }^{\circledR}$ ) e/ou teste do edrofônio (Tensilon ${ }^{\circledR}$ ).

- Métodos diagnósticos que podem ser somados aos critérios para diagnóstico clínico, porém não sendo obrigatórios:

a) dosagem sérica positiva para ac-AChR;

b) teste de ER com decremento de pelo menos $10 \%$ da amplitude entre o primeiro e o quarto potencial, a uma frequência de $2 \mathrm{~Hz}$ ou $3 \mathrm{~Hz}$. 


\subsubsection{Critérios de exclusão}

- Início dos sintomas ao nascimento ou nos primeiros cinco anos de vida;

- Antecedente de doença do sistema nervoso central ou periférico relacionado com a motricidade ocular e/ou exame de imagem craniana com anormalidades que comprometem a motricidade ocular;

- Uso de medicação com ação conhecida na junção neuromuscular;

- História clínica ou alterações na ENMG compatíveis com neuropatia periférica.

\subsection{Procedimentos}

Foi utilizada a técnica de EMGFU-JAC em todos os participantes do estudo, descrita a seguir. Nos grupos de pacientes MGG e MGO, a piridostigmina $\left(\right.$ Mestinon ${ }^{\circledR}$ ) foi suspensa 24 horas antes da avaliação eletrofisiológica, e o teste de ER a uma frequência de $3 \mathrm{~Hz}$ também foi aplicado. A ENMG convencional foi realizada apenas nos pacientes que ainda não tinham avaliação prévia, para afastar outras doenças do sistema nervoso periférico. A dosagem de ac-AChR ligador foi efetuada em todos os pacientes dos grupos MGG e MGO. Naqueles pacientes com dosagem negativa para acAChR ligador, a dosagem ac-MuSK também foi realizada. O estudo eletrofisiológico e a coleta de sangue para as dosagens de anticorpos foram executados em uma única visita ao laboratório Fleury Medicina e Saúde, Unidade Higienópolis, São Paulo.

A técnica de EMGFU-JAC foi aplicada pela autora, após estágio com 0 Prof. Emérito Erik V. Stålberg, MD, PhD (Institute of Neuroscience Uppsala University, Uppsala, Suécia) e experiência prática. Todos os registros obtidos foram posteriormente revisados e editados, quando necessário, em conjunto com o Prof. Dr. João Aris Kouyoumdijan, Professor Adjunto do Departamento de Ciências Neurológicas da Faculdade de Medicina de São José do Rio Preto, São José do Rio Preto, São Paulo (FAMERP) e coordenador do Laboratório de Investigação Neuromuscular da mesma instituição. 
4.2.1 Análise do jitter com agulha concêntrica

A metodologia utilizada para EMGFU-JAC é similar à estabelecida na literatura para a EMGFU (Stålberg et al., 2010). Além da substituição da AFU pela AC para o registro dos PA-AFUs, o filtro passa-alta foi reajustado, de $500 \mathrm{~Hz}$ para $1 \mathrm{kHz}$, a fim de diminuir a captação de fibras musculares mais distantes da área central de registro da agulha.

Utilizou-se o equipamento portátil de ENMG Keypoint Net (Medtronic, Skovlunde, Denmark), com um software específico de EMGFU, que realiza medidas do jitter por meio de um algoritmo de detecção do intervalo de pico dos PA-AFUs. Para a captação desses potenciais foi utilizada uma AC descartável com diâmetro de 0,30mm, com área de registro de 0,019 $\mathrm{mm}^{2}$ (Alpine BioMed Skovlunde, Denmark), a menor área de registro disponível comercialmente. Os filtros passa-alta e passa-baixa do software de EMGFU foram ajustados em $1 \mathrm{kHz}$ e $10 \mathrm{kHz}$, respectivamente. Para registro do sinal utilizou-se: sensibilidade de $0,2 \mathrm{mV}$ por divisão e varredura de $0,5 \mathrm{~ms}$ por divisão.

O estudo foi realizado com o sujeito/paciente confortavelmente deitado em uma maca e temperatura mensurada na pele acima de $32^{\circ} \mathrm{C}$. Foi realizada a inserção da AC no músculo OOc, a uma distância aproximada de $1 \mathrm{~cm}$ a $2 \mathrm{~cm}$ do epicanto lateral do olho, em um raio de até $2 \mathrm{~cm}$. Foram necessárias, no mínimo, três ou mais inserções da agulha na pele. Nos pacientes, a escolha do lado direito ou esquerdo da face foi de acordo com o lado clinicamente mais acometido. A captação dos PA-AFUs ocorreu durante a contração voluntária leve e mantida do músculo OOc. Movimentos sutis para reposicionamento da agulha foram realizados nas tentativas de identificação dos potenciais.

Foram aceitos para análise do jitter o PA-AFU que obedecia os critérios seguintes: sinal nitidamente destacado do ruído de base; pico de amplitude bem definido; tempo rápido de ascensão (potenciais com tempo de ascensão $>300 \mu$ s são provavelmente somados); morfologia constante em descargas consecutivas (pequenas variações de amplitude foram aceitas), sem sinais evidentes de somação de PAs como entalhes, mormente se esses ocorriam na fase de ascensão ou no pico do potencial. Pares de PA-AFUs foram obtidos 


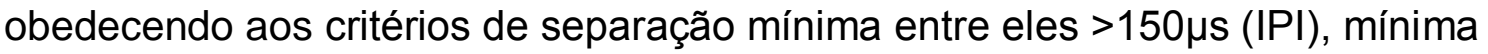
ou nenhuma sobreposição de um potencial no outro. Foram aceitos apenas PA-AFUs com frequências regulares de disparo, para evitar o efeito da VRF na medida do jitter.

A média do jitter e o desvio padrão foram analisados de acordo com método proposto por Stålberg et al. (2010), isto é, média do MCD de 20 pares de PA-AFUs. De acordo com o conceito de que dois dos 20 valores de MCD obtidos podem estar acima do limite superior calculado em um músculo saudável, foi utilizado o $18^{\circ}$ valor mais alto de cada estudo ( $18^{\circ}$ par) para definir o limite superior da normalidade para valores individuais de MCD.

Os critérios de anormalidade definidos para cada estudo foram os mesmos recomendados na literatura (Stålberg et al., 2010):

- Média do MCD acima do limite superior da normalidade (LSN) definido no grupo controle; e/ou,

- Mais de $10 \%$ dos pares com valores individuais de MCD acima do LSN definido no grupo controle.

Em cada estudo foram obtidos 20 pares de potenciais, ou seja, 20 medidas de jitter expressas em MCD, exceto em um estudo do grupo MGG no qual foram obtidos 17 pares. Para cada par de potencial foram registradas idealmente 100 descargas consecutivas ou, o mínimo aceitável de 50. A média do MCD e a média do MIPI foram automaticamente calculadas pelo software do equipamento.

Foram rejeitados imediatamente os traçados com sinais evidentes de somação: inflecções na fase de ascensão do potencial; picos mal definidos; e, fase de ascensão $>300 \mu \mathrm{s}$. Também não foram aceitos potenciais com frequências irregulares de disparo. Após o fim do exame, os traçados foram revisados e editados excluindo-se aqueles com erros evidentes na marcação do pico do potencial e registros com interferência de outros potenciais que tiveram seus picos automaticamente detectados pelo equipamento. Foi dada atenção, também, para a confirmação do bloqueio indicado pelo software. $O$ tempo de cada exame foi de aproximadamente $60 \mathrm{~min}$, dependendo da colaboração do participante, e em média outros $60 \mathrm{~min}$ foram utilizados para a revisão dos traçados após o estudo. Os registros foram posteriormente 
reavaliados em conjunto com o Prof. Dr. João Aris Kouyoumdijan na FAMERP, em um mesmo software e marca de equipamento utilizado nos registros, para fins de controle de qualidade.

\subsubsection{Estimulação repetitiva e eletroneuromiografia}

A técnica utilizada para ER é a mesma descrita na literatura (Keesey, 1989; Dumitru et al., 2002). Foram aplicados em todos os pacientes seis estímulos elétricos supramáximos a uma frequência de $3 \mathrm{~Hz}$ sobre o nervo responsável pela inervação dos músculos Abductor Digiti Minimi, Trapezius e OOc (ulnar, acessório e facial, respectivamente). Essa sequência de estímulos foi repetida para verificar a reprodutibilidade do resultado. A escolha do lado direito ou esquerdo foi de acordo com o lado mais sintomático; na ausência de assimetria, foi escolhido o lado esquerdo.

Em cinco pacientes que não possuíam exame de ENMG prévia, realizou-se estudo de condução sensitivo-motora e a eletromiografia para afastar outras doenças do sistema nervoso periférico que podem cursar com anormalidade do jitter.

\subsubsection{Dosagens de ac-AChR e ac-MuSK}

O sangue para as duas dosagens foi coletado no mesmo dia do estudo eletrofisiológico no laboratório Fleury. Em um primeiro momento apenas a dosagem do ac-AChR ligador foi processada, por radioimunoensaio. A dosagem de ac-MuSK foi condicionada ao resultado negativo para ac-AChR. Para o processamento das dosagens de ac-MuSK por radioimunoensaio, o laboratório Fleury enviou as amostras de sangue para a Mayo Clinic, Rochester, Minnesota, Estados Unidos, que, por sua vez, as reenviou para a Athena Diagnostics, Marlbourough, Massachusetts, Estados Unidos. 


\subsection{Análise estatística}

\subsubsection{Definição dos valores normativos}

Para a análise estatística e definição dos valores normativos do estudo no grupo controle utilizou-se o software Minitab 15 (Minitab Inc.). Os parâmetros do MCD foram analisados de acordo com a distribuição dos valores, Gaussiana ou não-Gaussiana, utilizando-se o teste de normalidade Anderson-Darling.

\subsubsection{Análise descritiva em relação aos grupos}

Para análise estatística descritiva das variáveis média do MCD e $18^{\circ}$ par em relação aos grupos controle, MGG e MGO, utilizou-se o teste Análise de variância (ANOVA) sob a hipótese de heterocedasticidade (aproximação do teste de Welch); para comparar dois a dois as médias de cada grupo na ANOVA utilizou-se o teste de Welch com correção para múltiplas comparações pelo método de Tukey.

Para a análise descritiva das variáveis média do MCD, quantidade de pares anormais e quantidade de bloqueios em cada estudo em relação aos grupos MGG e MGO utilizou-se o teste de Welch (teste t para populações com variâncias diferentes).

\subsubsection{Análise de sensibilidade e especificidade - curvas ROC}

Para analisar a capacidade de uma determinada variável em classificar o sujeito em controle ou paciente foi utilizada a curva ROC (Receiver Operating Characteristic). Foram construídas duas curvas ROC, uma para analisar a variável média do MCD e outra para o $18^{\circ}$ par, no grupo pacientes (MGG e MGO) versus controle. Valores de MCD maiores que $150 \mu \mathrm{s}$, foram fixados em $150 \mu \mathrm{s}$, pois as medidas de jitter são inexatas para valores muito altos, por causa da presença de bloqueio, que induz o efeito da VRF. 
Para cada valor possível de corte do parâmetro testado, representado por um único ponto na curva, pode ser calculada sua sensibilidade e especificidade. Uma das vantagens da curva ROC é avaliar o impacto diagnóstico em diferentes pontos da curva. É importante ressaltar que a curva ROC não faz referência a um valor específico para determinar a positividade do teste.

Foi identificado 0 valor de corte com melhor relação sensibilidade/especificidade da variável analisada, ou seja, o ponto com melhor sensibilidade, sem resultados falsos positivos. Assim como, o valor de corte para $100 \%$ de sensibilidade e a melhor especificidade. O poder de classificação do teste foi representado pelo cálculo da área sob a curva (ASC). 



\section{RESULTADOS}





\section{RESULTADOS}

\subsection{Grupo controle}

No grupo controle, a média de idade era de (35,6 \pm 10,6)anos (20-59 anos). Foram analisados 400 pares de PA-AFU, com valores individuais de MCD com média $(19,0 \pm 6,5) \mu s(7,2 \mu s$ a $66,5 \mu s)$. Não foram observados pares de potenciais com bloqueio.

Os valores obtidos para a média do MCD e o $18^{\circ}$ par de cada estudo apresentaram distribuição Gaussiana, de acordo com o teste de Anderson Darling ( $p=0,58$ e $p=0,952$ respectivamente) (Figuras 13 e 14). Portanto, o LSN para a média do MCD foi definido como a média do MCD mais 2dp (percentil 95\%); e o LSN para valores individuais de MCD como a média do $18^{\circ}$ par mais 2dp (percentil 95\%).

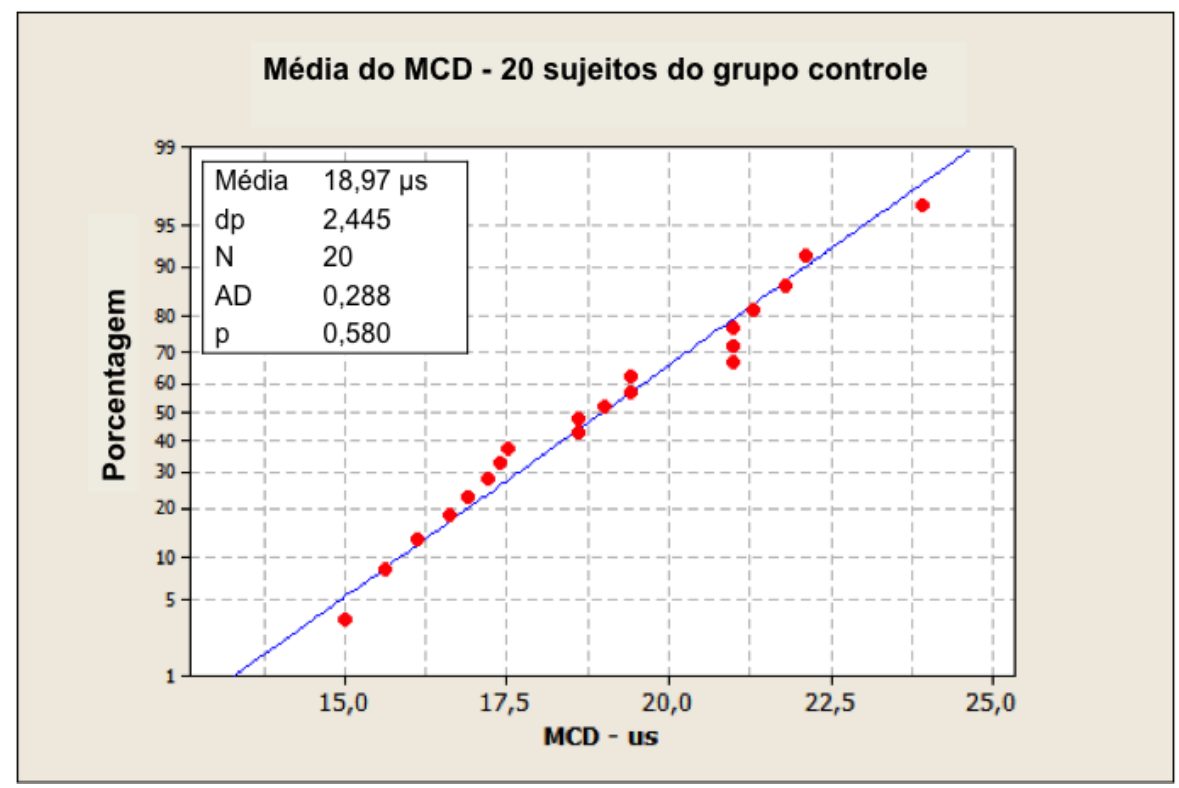

Figura 13. Distribuição da média do $M C D$ dos 20 sujeitos do grupo controle (MCD: mean consecutive difference; dp: desvio padrão; $\mathrm{n}$ : quantidade de sujeitos; AD: Teste de Anderson-Darling) 


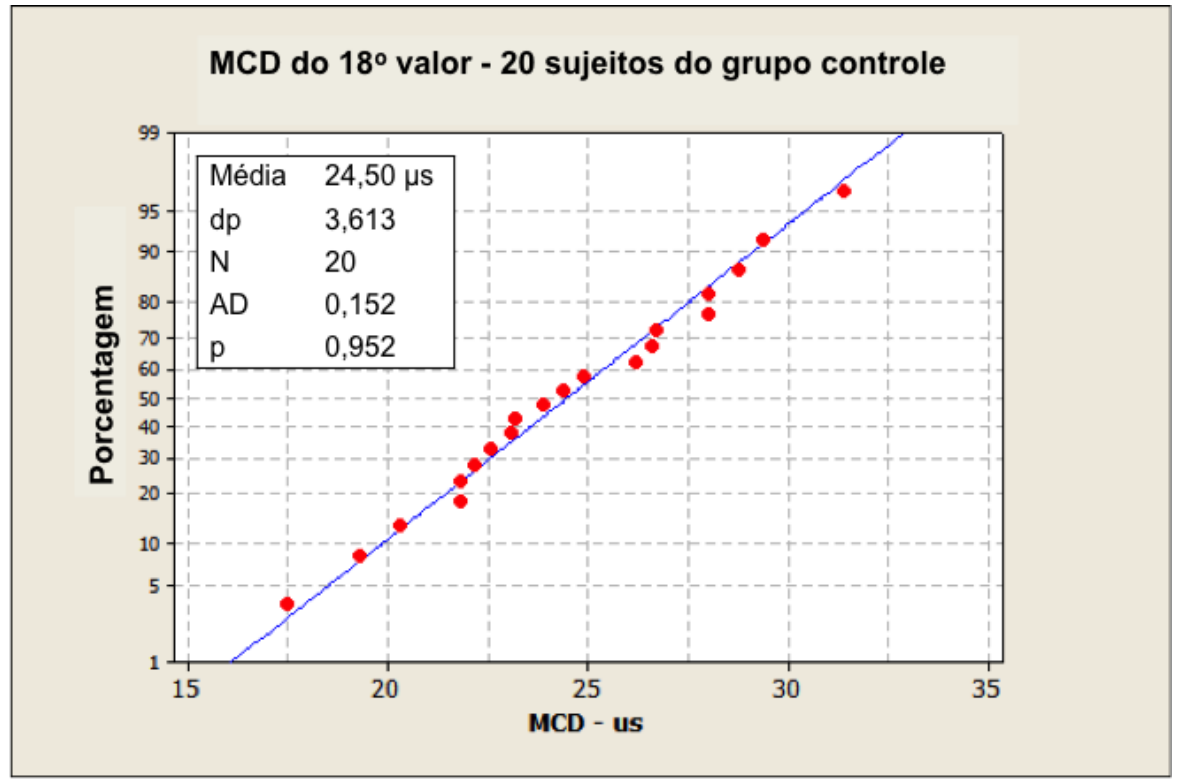

Figura 14. Distribuição do MCD do $18^{\circ}$ par nos 20 sujeitos do grupo controle (MCD: mean consecutive difference; dp: desvio padrão; $n$ : quantidade de sujeitos; AD: Teste de Anderson-Darling)

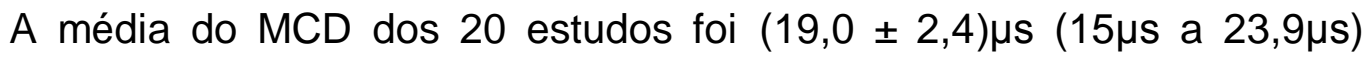
(Figura 13) e a média do $18^{\circ}$ par foi $(24,5 \pm 3,6) \mu s(17,5 \mu$ s a $31,4 \mu s)$ (Figura 14). O LSN para a média do MCD foi $23,9 \mu$ s. O LSN para valores individuais de MCD foi de $31,7 \mu \mathrm{s}$. Assim, para fins práticos, o valor definido como LSN para a média do MCD foi $24 \mu$ s e $32 \mu$ s para valores individuais de MCD. A média do MIPI foi $(780 \pm 150) \mu s(520 \mu s$ a $1030 \mu s)$. A Tabela 1 mostra os valores do LSN e o critério utilizado.

Tabela 1. Valores do limite superior da normalidade (em vermelho) e análise estatística utilizada

\begin{tabular}{|c|c|c|c|c|c|c|}
\hline & $\begin{array}{c}\text { Média } \\
(\mu s)\end{array}$ & $\underset{(\mu s)}{d p}$ & AD & $\begin{array}{l}+2 \mathrm{dp} \\
(\mu s)\end{array}$ & $95,7 \%$ & $\begin{array}{c}\text { Limite } \\
(\mu s)\end{array}$ \\
\hline Média do MCD & 19,0 & 2,4 & 0,58 & 23,9 & - & 24,0 \\
\hline $\begin{array}{l}\text { MCD do } 18^{\circ} \text { par } \\
(n=20)\end{array}$ & 24,5 & 3,6 & 0,952 & 31,7 & & 32,0 \\
\hline
\end{tabular}

dp: desvio padrão; AD: Teste de Anderson-Darling; MCD: mean consecutive difference; $\mathrm{n}$ : quantidade de sujeitos 


\subsection{Grupo pacientes (MGG e MGO)}

\subsubsection{Grupo miastenia gravis forma generalizada}

Nos 20 pacientes do grupo miastenia gravis forma generalizada (MGG) (Tabela 2) a média de idade era de (42,5 $\pm 11,1)$ anos (24-65 anos), o tempo de duração dos sintomas foi em média $(109 \pm 90,7)$ meses $(9-408$ meses) e 0 tempo de diagnóstico da doença foi em média (84,9 \pm 93,3)meses (1-384meses). A classificação da gravidade da doença, de acordo com a MGFA, na pior fase da doença (MGFAp) variou de III b até V. A classificação MGFA atual, no momento do estudo (MGFAa) variou de assintomático a III b. Três pacientes foram classificados como III b, 14 pacientes como II (a ou b), dois pacientes apresentavam apenas sintomas oculares e um estava assintomático no momento do estudo. A timectomia foi realizada em cinco pacientes (25\%); em três o diagnóstico anatomopatológico foi timoma (15\% do total de pacientes) e nos outros dois era normal. Todos os pacientes estavam sendo tratados com piridostigmina em associação à prednisona, em doses variadas, exceto um que não usava prednisona. Quatro pacientes $(20 \%)$ também usavam azatioprina e apenas um ambenônio.

A dosagem de ac-AChR foi positiva em 12 (60\%) pacientes. Entre os oito pacientes negativos para ac-AChR, a dosagem de ac-MuSK foi positiva em dois (25\%). O teste de ER evidenciou anormalidades em pelo menos um dos músculos analisados em cinco pacientes (25\%).

Na EMGFU-JAC no músculo OOc foram analisados 397 pares de PAAFU, com média dos valores individuais de MCD de $(60,3 \pm 49,3) \mu s(7,6 \mu \mathrm{s}$ a $301 \mu \mathrm{s})$, média do MIPI de $(1000 \pm 200) \mu \mathrm{s}(700 \mu \mathrm{s}$ a $1300 \mu \mathrm{s})$. Foram 248 pares de PA-AFU (62,5\%) com valores individuais de MCD acima do LSN e bloqueio de condução em 52 deles (13\% do total). O estudo mostrou ser anormal em todos os pacientes por ambos os critérios de anormalidade (média do MCD acima de $24 \mu$ s e mais de $10 \%$ dos valores individuais de MCD acima de $32 \mu \mathrm{s}$ ), exceto em um paciente que apresentou anormalidade apenas pelo critério da média do MCD (25,6us); esse paciente apresentava sintomas leves, apenas oculares, no momento do estudo e dois pares de potenciais apresentaram 
valores individuais de MCD alterados, com identificação de bloqueio em um dos pares.

No único paciente assintomático do grupo no momento do estudo, a análise do jitter mostrou ser anormal com ambos os critérios, com média do MCD de $35,5 \mu$ s e três valores individuais de MCD acima de $32 \mu \mathrm{s}(48 \mu \mathrm{s}, 49,7 \mu \mathrm{s}$ e $37 \mu \mathrm{s})$. A dosagem de ac-AChR e o teste de ER não apresentaram anormalidades.

Em apenas um paciente foram obtidos 17 pares de potenciais, com média do MCD de $111 \mu \mathrm{s}$, todos os pares com valores individuais de MCD alterados e aproximadamente $40 \%$ deles com bloqueio de condução. A MGFA no momento do estudo foi III a, a dosagem de ac-AChR foi positiva e o teste de ER também foi anormal.

Dois pacientes do grupo foram positivos para ac-MuSK. Ambos eram do gênero feminino, com fraqueza predominantemente bulbar, MGFA II b no momento do estudo, testes de ER normal e análise do jitter alterada por ambos os critérios de anormalidade, porém com valores de jitter muito diferentes. Um

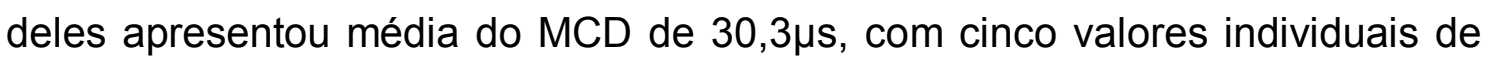
MCD alterados, e o outro com média do MCD de 83,6us e 19 pares alterados. 


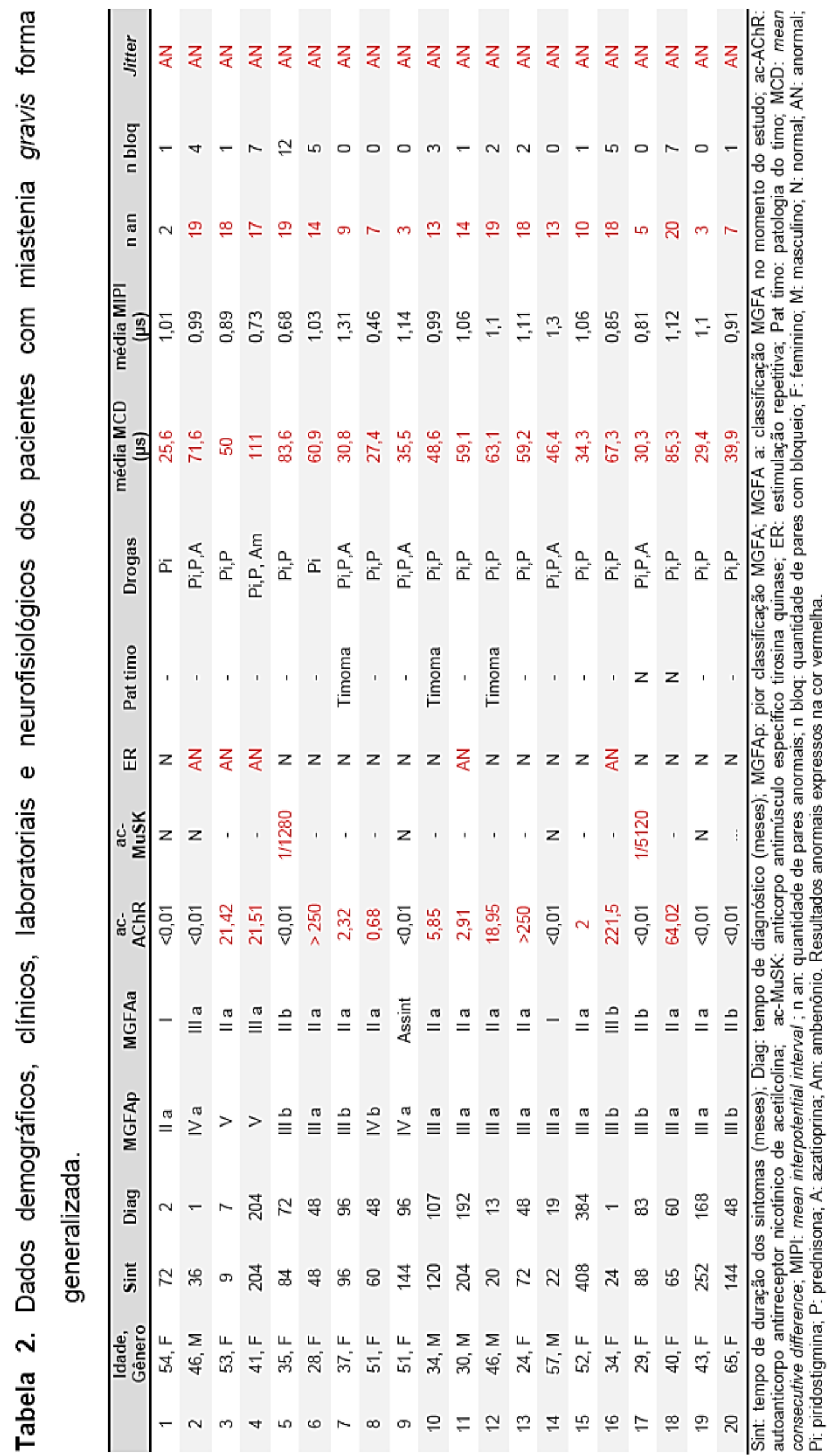




\subsubsection{Grupo miastenia gravis forma ocular}

Nos 13 pacientes do grupo miastenia forma ocular (MGO) (Tabela 3) a média de idade foi $(37,3 \pm 11,1)$ anos (18-54 anos), a duração dos sintomas foi em média (48 $\pm 63,3)$ meses $(2-240$ meses $)$ e o tempo para diagnóstico foi em média $(22,5 \pm 24,9)$ meses (1-82 meses). O estudo de imagem do tórax foi normal em todos os pacientes e nenhum foi submetido à timectomia. Todos os pacientes usavam piridostigmina, sete deles em associação com prednisona. Apenas um paciente estava em terapia com droga imunossupressora micofenolato de mofetila - para tratamento de lúpus eritematoso sistêmico.

A dosagem de ac-AChR foi positiva em $46 \%$ dos pacientes e nenhum caso soropositivo para ac-MuSK nos demais pacientes. O teste de ER foi normal em todos pacientes.

$\mathrm{Na}$ EMGFU-JAC no OOc foram analisados 260 pares de potenciais, com média dos valores individuais de MCD de $(38,3 \pm 30,6) \mu s(8,4-233 \mu s)$, média do MIPI de $(1100 \pm 300) \mu s(700-1400 \mu s)$. Foram 108 valores individuais de MCD alterados $(41,5 \%)$ e sete pares de potenciais $(2,7 \%)$ com presença de bloqueio. Segundo os critérios de anormalidade, média do MCD maior que $24 \mu \mathrm{s}$ e/ou mais de $10 \%$ dos valores individuais de MCD maior que $32 \mu \mathrm{s}$, o estudo mostrou ser anormal em 12 pacientes (92,3\%) por ambos critérios de anormalidade, exceto um. Esse paciente demonstrou anormalidade na EMGFU-JAC apenas pelo critério da quantidade de valores individuais de MCD alterados. Apenas um paciente $(7,7 \%)$ não preencheu nenhum critério de anormalidade. 


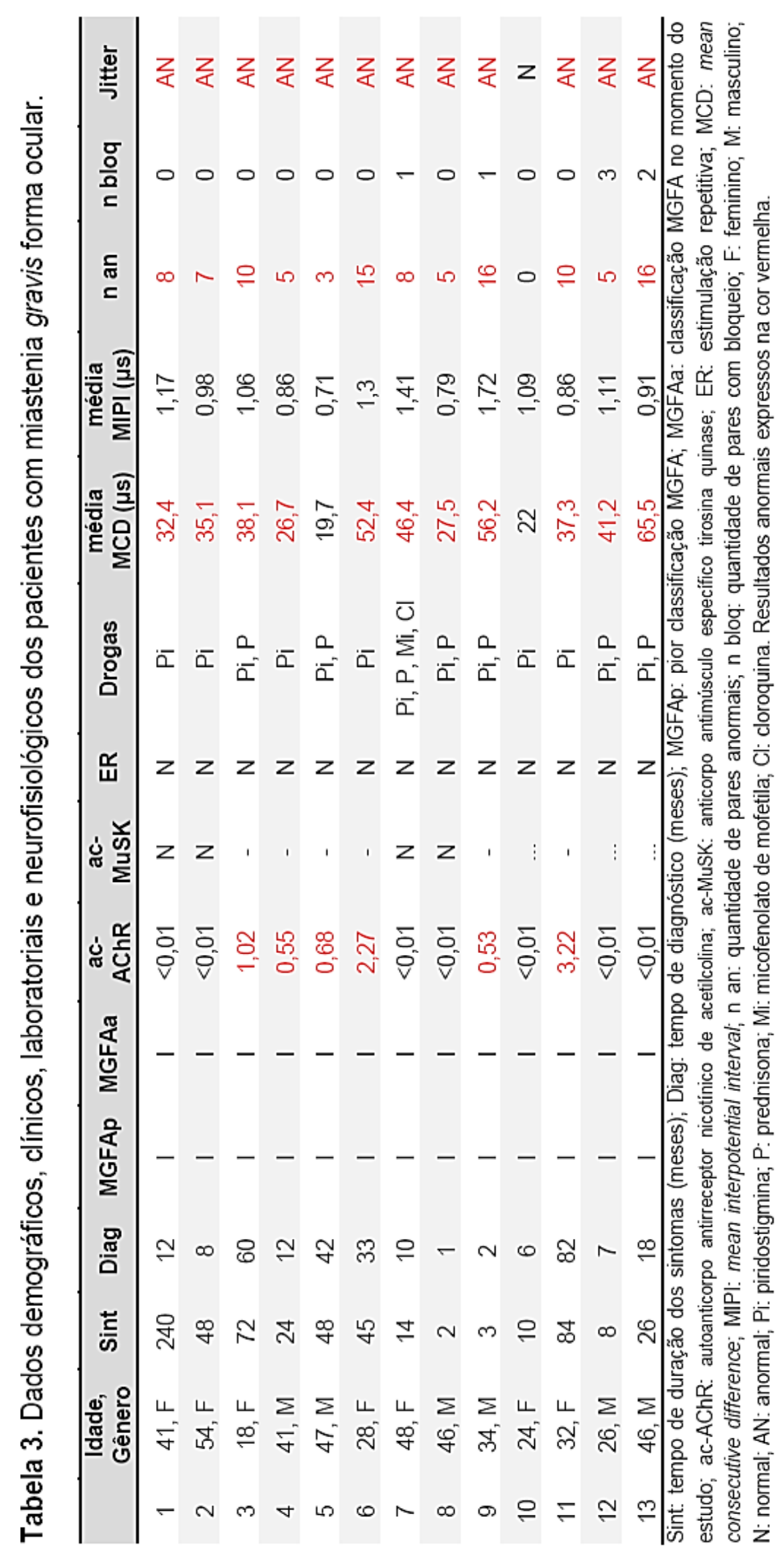




\subsection{Análise descritiva em relação aos grupos}

A análise comparativa com relação aos grupos controle, MGG e MGO, utilizando as variáveis dependentes média do MCD e $18^{\circ}$ par por meio da Análise de variância (ANOVA), mostrou que os grupos possuem médias diferentes para as variáveis analisadas ( $p<0,05$, Figuras 15 e 16). A análise Pos-Hoc (Tukey) mostrou que esses grupos também são diferentes entre si $(p<0,05)$.

As figuras de diagrama de caixa ou boxplot, exibidas a seguir (Figuras 15 a 19), identificam a localização de $50 \%$ dos valores, a mediana e os valores extremos. A caixa contém $50 \%$ dos dados, entre os percentis $25 \%$ e $75 \%$. A linha em negrito, dentro da caixa, indica a mediana. As barras em "T" estendem-se da borda da caixa até 1,5 vezes a altura da caixa. Valores fora desses limites são considerados extremos. Tanto a altura da caixa, quanto o tamanho da barra em "T" fornecem informações sobre a dispersão dos dados.

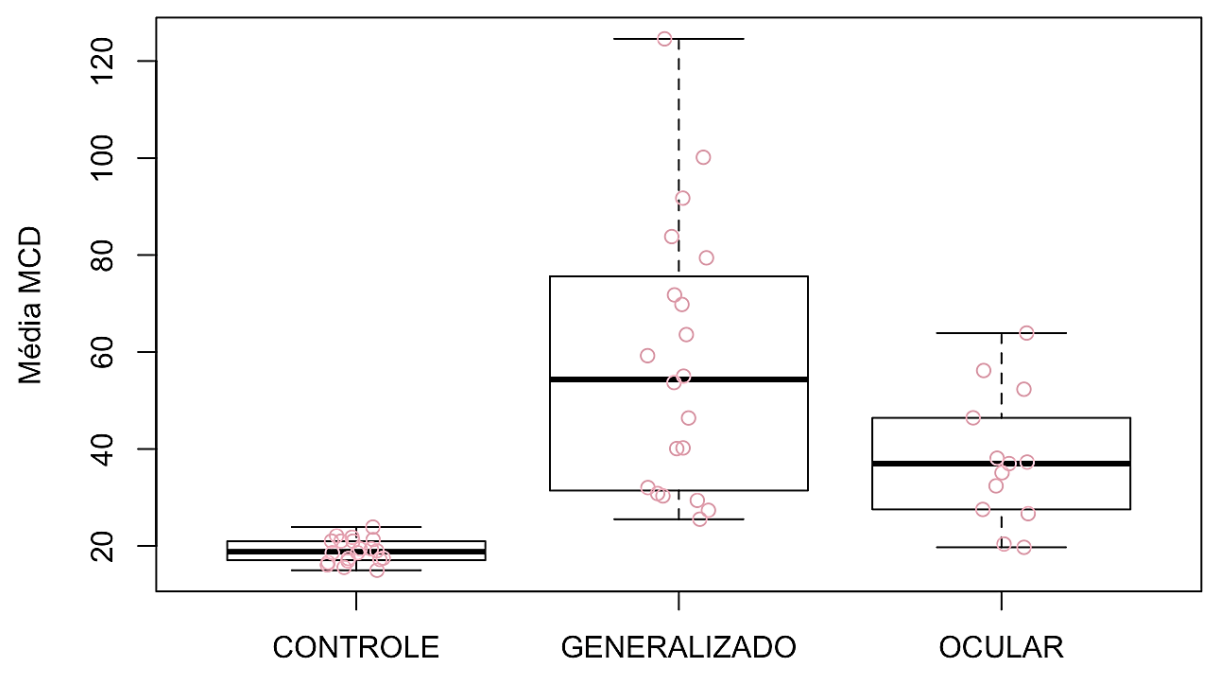

Figura 15. Análise comparativa da variável média do $M C D$ em relação aos grupos controle, MGG (generalizado) e MGO (ocular) 


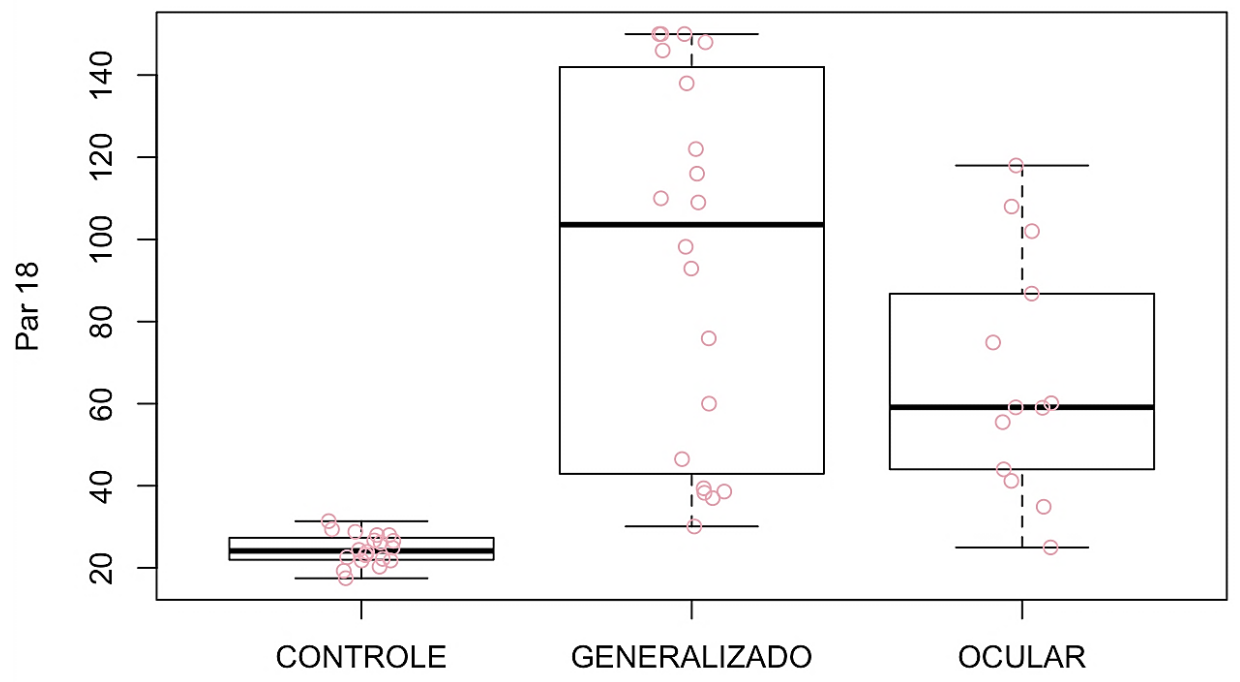

Figura 16. Análise comparativa da variável $18^{\circ}$ par em relação aos grupos controle, MGG (generalizado) e MGO (ocular)

A análise com relação aos grupos MGG e MGO utilizando a variável dependente média do MCD por meio do teste $t$ de duas amostras (Welch) mostrou que os grupos são diferentes ( $\mathrm{p}<0,05$, Figura 17). $\mathrm{Na}$ análise individual das variáveis dependentes quantidade de anormais (quantidade de pares com valores individuais de MCD maiores que $32 \mu \mathrm{s}$ ) e quantidade de bloqueios (quantidade de pares com bloqueio) com relação aos grupos MGG e MGO também mostrou que os grupos possuem valores diferentes para a média das variáveis analisadas $(p<0,05$ em todas as análises; Figuras 18 e 19). 


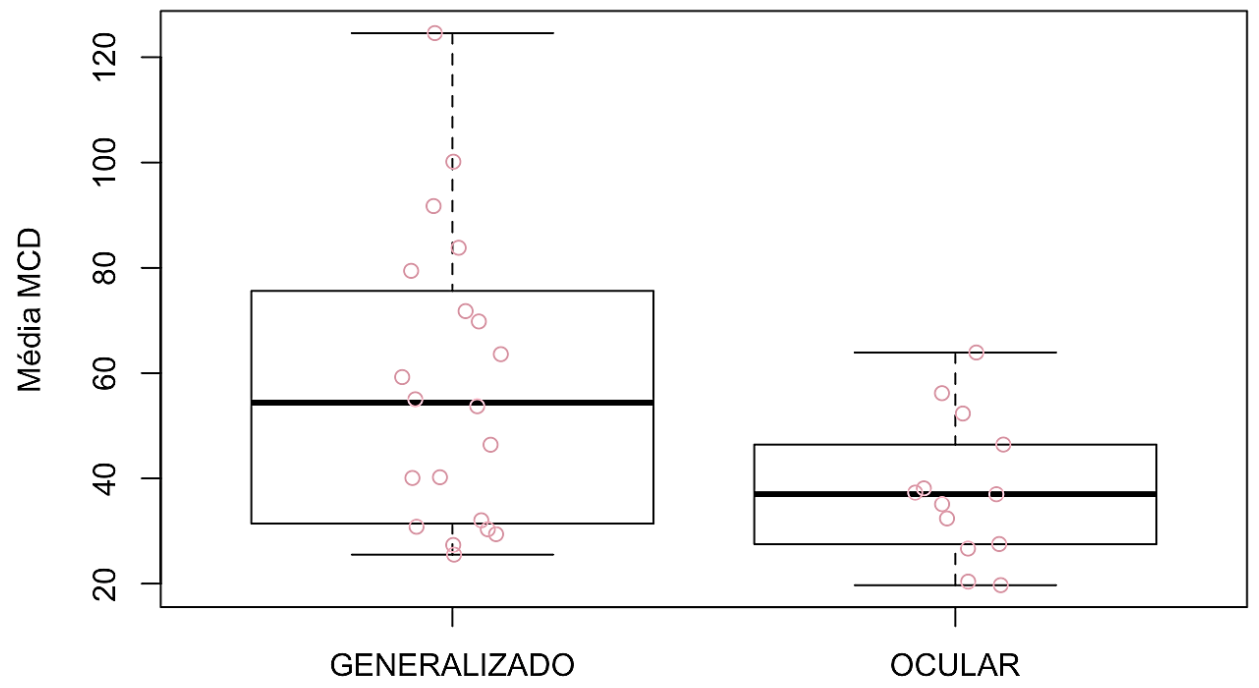

Figura 17. Análise comparativa da variável média do $M C D$ em relação aos grupos $M G G$ (generalizado) e MGO (ocular)

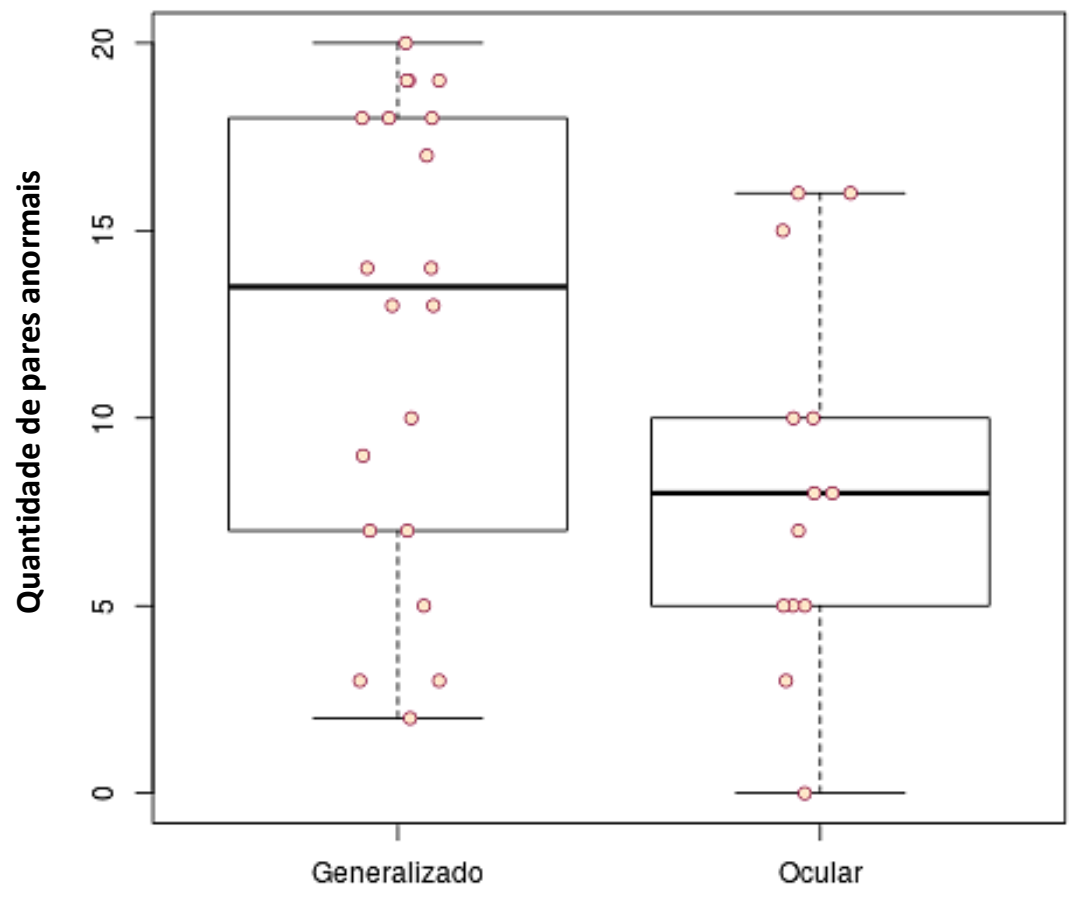

Figura 18. Análise comparativa da variável quantidade de pares anormais em relação aos grupos MGG (generalizado) e MGO (ocular) 


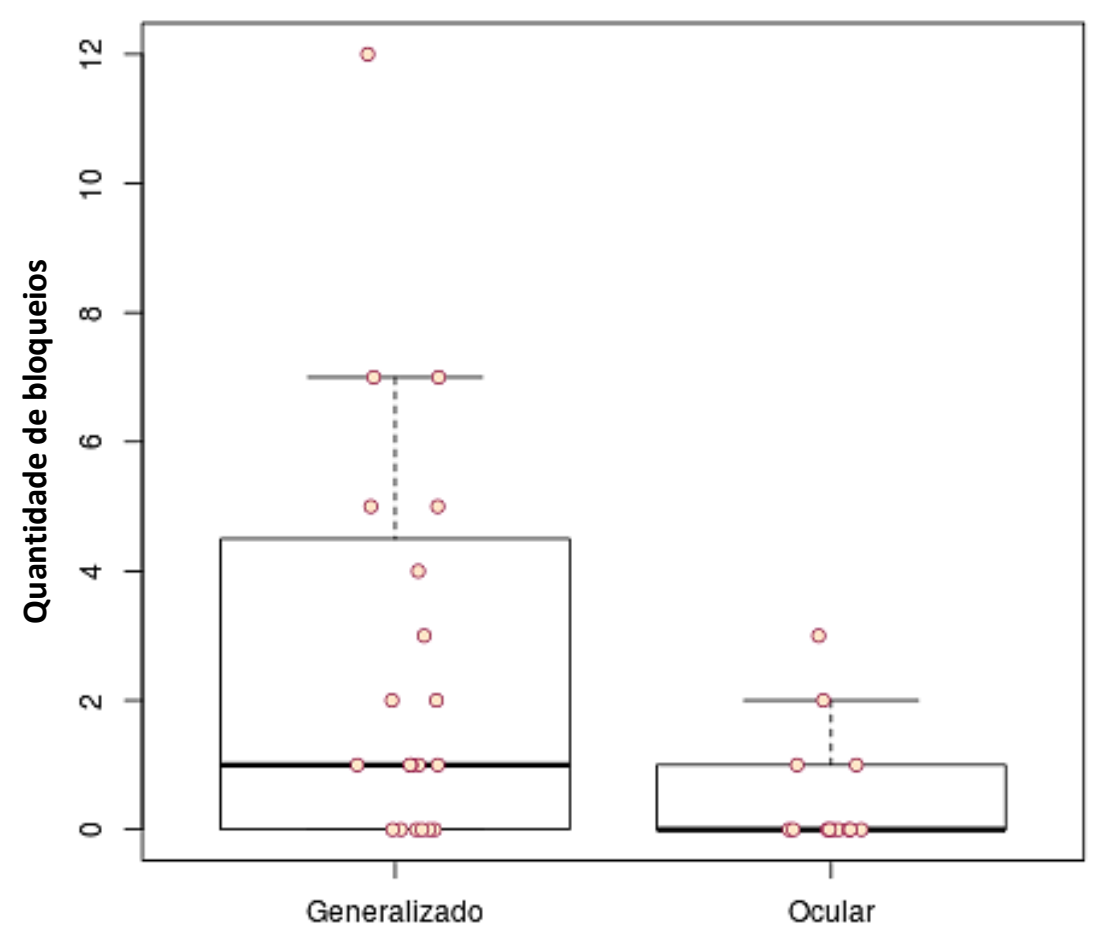

Figura 19. Análise comparativa da variável quantidade de bloqueios em relação aos MGG (generalizado) e MGO (ocular)

\subsection{Análise de sensibilidade e especificidade - curvas ROC}

Com relação à análise do poder de classificação da variável média do MCD por meio da curva ROC, no grupo de pacientes (MGG e MGO) versus controles, o ponto de corte com melhor sensibilidade, sem resultados falsos positivos, foi $24,7 \mu$ s (93,9\% sensibilidade e $100 \%$ especificidade). O valor de corte com $100 \%$ de sensibilidade, entretanto com diminuição da especificidade para $65 \%$ foi $19,6 \mu$ s; a área sob a curva igual a $96,7 \%$ indicou que a variável média do MCD possui um ótimo poder de classificação. (Figura 20) 


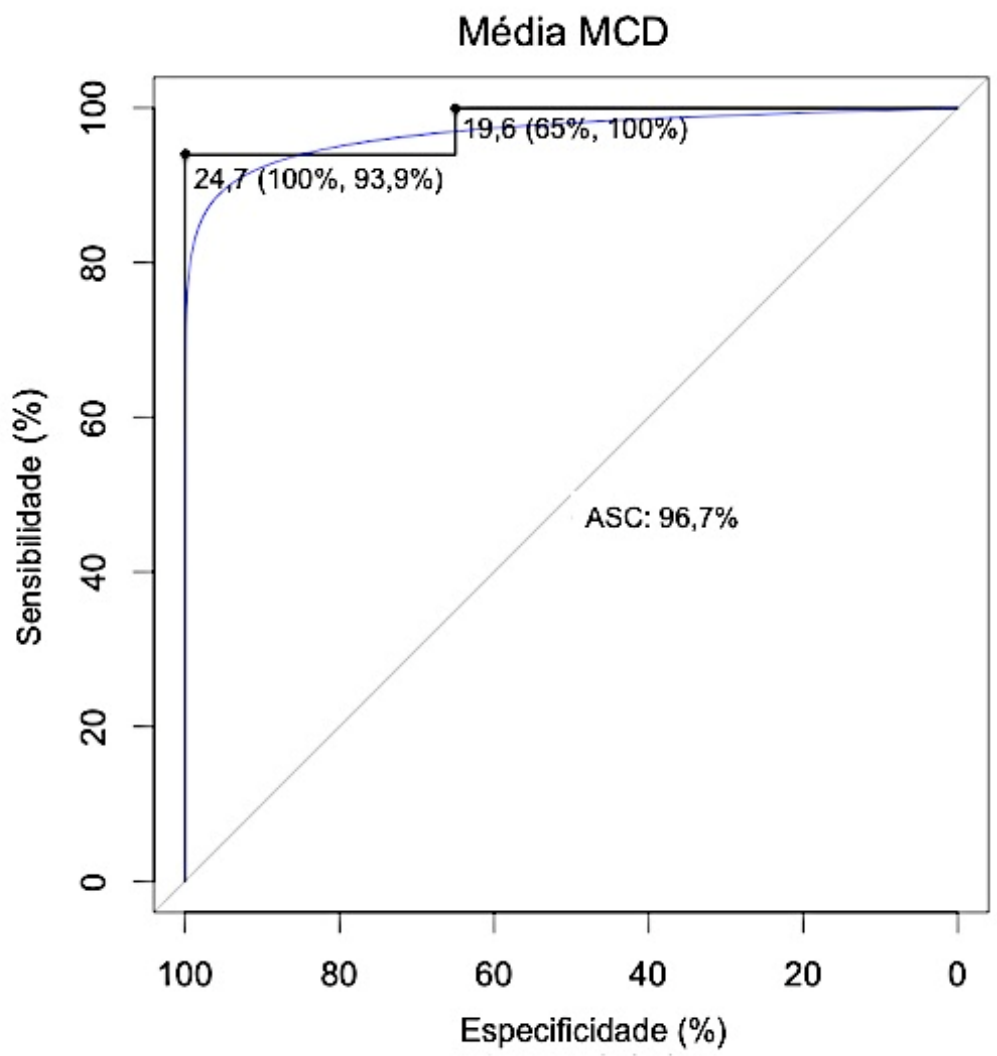

Figura 20. Curva ROC: análise do poder de classificação da variável média do $M C D$ no grupo pacientes (MGG e MGO) versus controle. (Valores em $\mu \mathrm{s}$; entre parêntesis (especificidade, sensibilidade); ASC: área sob a curva)

A curva ROC da variável $18^{\circ}$ par, no grupo paciente versus controle, o ponto de corte com melhor sensibilidade, sem resultados falsos positivos, foi de $33,1 \mu \mathrm{s}$ (93,9\% sensibilidade e $100 \%$ especificidade). O valor de corte com $100 \%$ de sensibilidade, entretanto com diminuição da especificidade para $60 \%$ foi de $24,9 \mu \mathrm{s}$. Um valor de corte intermediário em $29,8 \mu \mathrm{s}$, apontado pela curva ROC, apresentou sensibilidade de $97 \%$ e especificidade de $95 \%$; a área sob a curva de $97,9 \%$ indica que a variável $18^{\circ}$ par possui um ótimo poder de classificação. (Figura 21) 


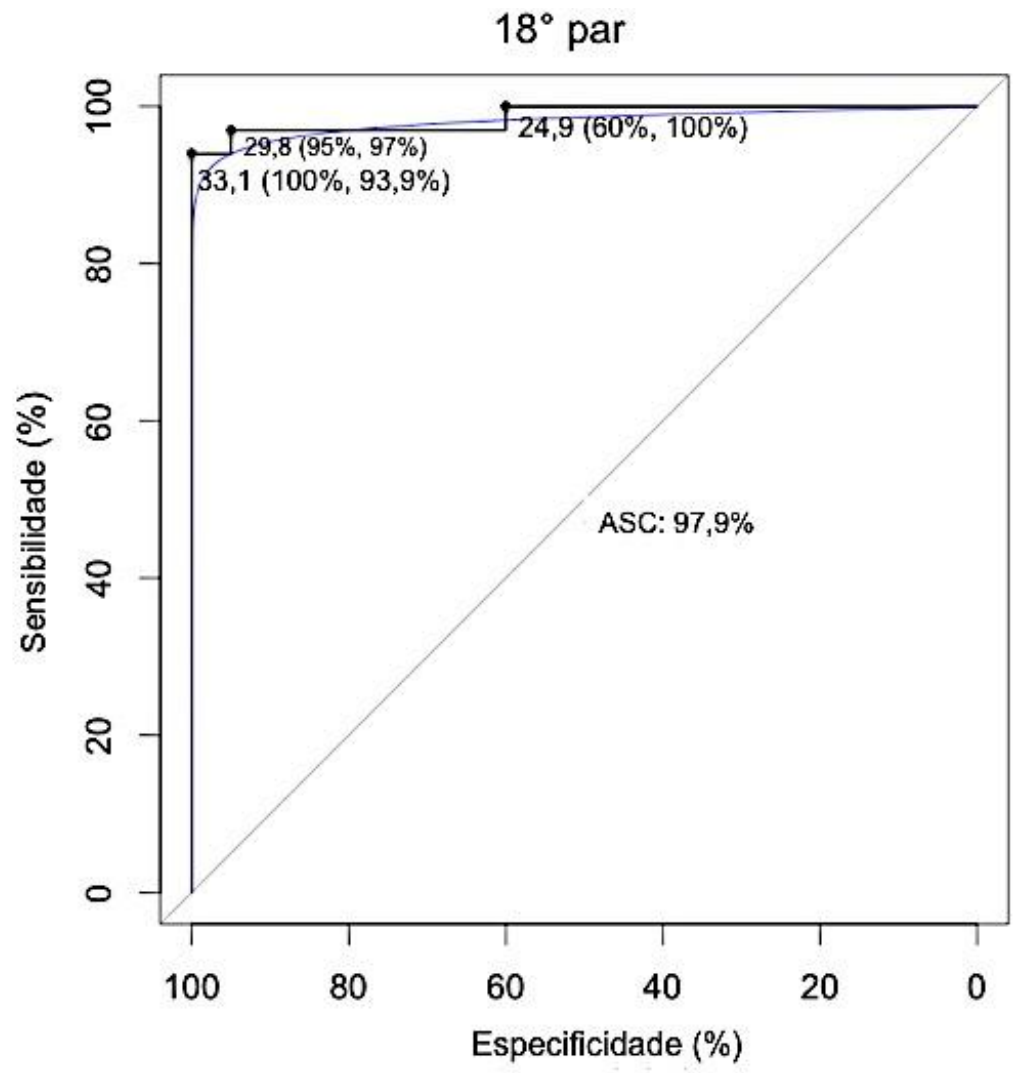

Figura 21. Curva ROC: análise do poder de classificação da variável média do $18^{\circ}$ par no grupo pacientes (MGG e MGO) versus controle. (Valores em $\mu \mathrm{s}$; entre parênteses (especificidade, sensibilidade); ASC: área sob a curva) 

6 DISCUSSÃO 



\section{DISCUSSÃO}

O diagnóstico da MG baseia-se, inicialmente, em dados clínicos. Sinais e sintomas de fraqueza muscular com flutuação e fatigabilidade, em distribuição característica, com nítida piora após atividades motoras e melhora após repouso são sugestivos de MG. O diagnóstico pode ser confirmado por meio de testes eletrofisiológicos (ER e EMGFU), dosagens séricas positivas para ac-AChR ou ac-MuSK e boa resposta clínica para inibidores da acetilcolinesterase. A dosagem de ac-AChR tem especificidade alta para o diagnóstico de $M G$ e, quando positiva, confirma o diagnóstico (Padua et al., 2000; Vincent, 2006). Porém, a dosagem do ac-AChR pode ser negativa em até 50\% dos pacientes com MG forma ocular (Sanders, Howard, 1986; Vincent et al., 2001). O teste de ER também tem sensibilidade baixa nas formas mais leves da MG (AAEM Quality Assurance Committee American Association of Electrodiagnostic Medicine, 2001b). Nesses casos, o desafio diagnóstico é muito maior e a EMGFU tem papel fundamental para a identificação do distúrbio da transmissão neuromuscular.

Nos poucos estudos de EMGFU-JAC em pacientes com MG (Ertaş et al., 2000; Sarrigiannis et al., 2006; Farrugia et al., 2009; Kouyoumdjian et al., 2011; Witoonpanich et al., 2011; Kouyoumdjian, Stålberg, 2013b), existem diferenças metodológicas, por exemplo, filtragem dos sinais e eletrodo de agulha utilizado. A menor AC descartável, com superfície de registro de $0,019 \mathrm{~mm}^{2}$, mostrou-se a mais apropriada para análise do jitter em substituição à AFU (Stålberg, Sanders, 2009). Por ser a área de registro da AC maior quando comparada à AFU, ocorre a somação de potenciais de ação de muitas fibras musculares e, portanto, os valores de referência são diferentes daqueles obtidos com a AFU. Recomenda-se o ajuste do filtro de frequência baixa para $1 \mathrm{kHz}$ na utilização da $A C$ para análise do jitter (Stålberg, 2012). Filtragens acima de $1 \mathrm{kHz}$ reduzem a amplitude dos sinais e produzem componentes espiculados que podem ser confundidos com PAAFU. Em filtros acima de $2 \mathrm{kHz}$, as incisuras e entalhes na fase rápida de 
ascensão do sinal, indicativas de somação do potencial de ação, não são mais detectáveis (Kouyoumdjian, Stålberg, 2008a; Stålberg, Sanders, 2009), o que prejudica a identificação de sinais não aceitáveis para a análise do jitter.

O diagnóstico da MG, no presente estudo, baseou-se em dados clínicos, resposta a inibidores da acetilcolinesterase e métodos complementares (dosagem de anticorpos e teste de ER). As características clínicas essenciais para o diagnóstico foram início assimétrico da ptose, flutuação dos sintomas de fraqueza (ocular ou generalizada), fatigabilidade aos esforços e melhora clínica ao tratamento com piridostigmina. Foram considerados os dados referidos pelos pacientes, documentados no prontuário e testados objetivamente pelo médico, por meio do exame físico. No grupo MGG, a doença foi confirmada por um dos métodos complementares seguintes: teste de ER e/ou dosagem de anticorpos. Nas formas oculares da $M G$, em que os métodos complementares não confirmaram a doença, o diagnóstico baseou-se em dados clínicos, incluindo a resposta apropriada aos inibidores da acetilcolinesterase, administrados como teste ou tratamento. O padrão de referência escolhido para diagnóstico de MGO nos pacientes deste estudo não incluiu necessariamente a dosagem sérica positiva para ac-AChR ou anormalidade na ER, evitando, assim, a exclusão de pacientes em que esses testes são frequentemente negativos (Oh et al., 1992; AAEM Quality Assurance Committee American Association of Electrodiagnostic Medicine, 2001a). É exatamente nesse grupo de pacientes que a análise do jitter tem maior impacto diagnóstico. Estudos que testam a acurácia de um método, em uma população em que o teste seria utilizado na prática clínica, ou seja, naqueles casos em que a suspeita diagnóstica é alta, porém ainda não foi comprovada, são os de maior relevância clínica (Benatar et al., 2006).

Foram recrutados menos pacientes do que o previsto para o grupo MG forma ocular, em razão da necessidade de resposta clínica adequada ao uso de inibidores da acetilcolinesterase. Não existe nenhuma recomendação fundamentada em evidências a respeito da eficácia dos inibidores da 
acetilcolinesterase, corticoesteróides ou imunossupressores que melhoram os sintomas da forma ocular da MG (Benatar, Kaminski, 2007, 2012). No entanto, o tratamento proposto para MG inclui essas drogas, que apresentam efeito puramente sintomático ou ação supressora sob o sistema imunológico (Benatar et al., 2012). A eficácia limitada da piridostigmina na melhora dos sintomas oculares da MG (Benatar et al., 2012) e as limitações na execução ambulatorial do teste do edrofônio no Hospital das Clínicas FMUSP, por causa da probabilidade de efeitos cardiovasculares graves, embora raros, (Pascuzzi, 2003) limitaram a inclusão de pacientes com MG forma ocular. $O$ teste do cubo de gelo no globo ocular não foi utilizado como critério de inclusão nesse grupo de pacientes. Apesar desse teste apresentar valor preditivo negativo alto no diagnóstico de $M G$ em pacientes com ptose (Fakiri et al., 2013), o diagnóstico definitivo só pode ser confirmado por meio da dosagem de anticorpos ou testes eletrofisiológicos (Jaretzki et al., 2000).

O grupo de pacientes do estudo era heterogêneo, particularmente 0 grupo MGG, quanto à classificação MGFA, presença de timoma, timectomia e uso de terapia imunossupressora. Todos os pacientes estavam em tratamento e a maioria apresentava sintomas leves (inclusive um paciente assintomático) no momento do recrutamento; é provável que esses fatores tenham influenciado os resultados dos testes diagnósticos. No grupo MGO, o tempo de duração dos sintomas oculares em cinco pacientes (38\%) foi inferior a dois anos no momento da inclusão no estudo. Após mais de dois anos de seguimento clínico, nenhum desses pacientes apresentou sinais de fraqueza em outros territórios musculares.

A positividade da EMGFU-JAC no estudo atual, tanto na forma generalizada (100\%) quanto na forma ocular (92,3\%), foi superior à ER e à dosagem de anticorpos para confirmação diagnóstica da $M G$, em concordância com resultados de estudos prévios (Oh et al., 1992; Sanders, Stålberg, 1996; Witoonpanich et al., 2011). Os estudos que atestam a acurácia da ER no diagnóstico da MG são heterogêneos quanto ao desenho do estudo, quantidade de nervos-músculos estudados e qualidade metodológica, dificultando conclusões baseadas em evidências (Benatar, 
2006). De uma maneira geral, a sensibilidade reportada do teste de ER na MGG é $75-85 \%$, e apenas 30-60\% na MGO (Zambelis et al., 2011). Em comparação aos estudos anteriores (Benatar, 2006), a positividade do teste de ER para diagnóstico de MG no presente estudo foi inferior (MGG $25 \%$ e nenhuma na MGO). Entretanto, em algumas séries compostas por pacientes com MG com diferentes graus de comprometimento clínico, a ER também apresentou positividade baixa; 36\% (Gilchrist et al., 1994) e 40\% (Sonoo et al., 2001).

A ER apresenta sensibilidade diagnóstica mais elevada em pacientes clinicamente mais comprometidos (Oh et al., 1992), e quando realizada em músculos proximais, particularmente o músculo Deltoideus (Yannikas et al., 1994). O músculo Deltoideus não foi incluído no presente protocolo por ser suscetível a erros técnicos, como: estimulação do nervo axilar abaixo do limiar; e, artefatos de movimento. Além disto, a estimulação é mais dolorosa quando comparada à estimulação do nervo acessório (músculo Trapezius) (Schumm, Stöhr, 1984; Oh et al., 1992; Yannikas et al., 1994). Contudo, o músculo OOc, incluído no presente protocolo, foi reportado como o mais sensível para esse teste diagnóstico (Zambelis et al., 2011). A análise de uma quantidade limitada de nervos-músculos pode ter contribuído para a positividade baixa do teste de ER no presente estudo, assim como também mostram Witoonpanich et al. (2011). Adicionalmente, a maioria dos pacientes incluídos já apresentavam melhora clínica ao tratamento instituído, com MGFA I e II no momento do recrutamento (30/33). Apenas três pacientes (9\% do total) possuíam graus moderados de fraqueza (MGFA III), todos com decremento à ER. A inclusão do exercício como manobra de ativação, para aumentar a sensibilização do teste de ER no diagnóstico da MG, é recomendada na literatura (AAEM Quality Assurance Committee American Association of Electrodiagnostic Medicine, 2001a), porém não foi aplicada e pode ter contribuído, pelo menos em parte, para a menor positividade do teste na amostra estudada.

A sensibilidade da positividade aos anticorpos pode estar reduzida, por vários mecanismos, em decorrência do tratamento imunossupressor 
(Vincent, 2006; Heldal et al., 2014). A titulação do ac-AChR varia e não tem correlação adequada com a gravidade da doença entre os pacientes, entretanto, tem correlação apropriada com escores clínicos após plasmaferese, timectomia ou imunossupressão (Vincent, 2006). No estudo atual, a positividade do ac-AChR (MGG 60\% e MGO 46,2\%,) foi menor do que o encontrado por Sanders et al. (2010) - 80\% na MGG e 55\% na MGO - em que foram avaliados pacientes antes do início do tratamento imunossupressor.

Aproximadamente $85 \%$ dos pacientes com MG apresentam positividade sérica para ac-AChR (Vincent et al., 2001). Na primeira descrição desse anticorpo na MG (Hoch et al., 2001), em média, metade dos pacientes soronegativos para ac-AChR revelaram-se positivos para acMuSK. No presente estudo, dois pacientes do gênero feminino, do grupo MGG, foram positivos para ac-MuSK, correspondendo a $25 \%$ dos pacientes negativos para ac-AChR. A MG com ac-MuSK positivo é considerada uma entidade clínica distinta da MG ac-AChR positivo (Stickler et al., 2005; Guptill et al., 2011; Nikolic et al., 2014). Pacientes com essa forma da doença são caracteristicamente mulheres adultas jovens, com fraqueza focal oculobulbar grave, na face e/ou músculos do pescoço (Evoli et al., 2003; Sanders et al., 2003), crises frequentes de insuficiência respiratória, além de reposta clínica limitada ao uso de piridostigmina e imunossupressão (Scuderi et al., 2002; Evoli et al., 2003; Guptill et al., 2011). Entretanto, nem sempre esses pacientes têm fraqueza grave e resposta pobre ao tratamento, mas podem ter apresentação clínica indistinguível daquela de pacientes positivos para ac-AChR (Sanders et al., 2003), conforme os pacientes vistos no presente estudo. Ambos os pacientes apresentavam fraqueza leve, de predomínio oculobulbar, e resposta apropriada ao tratamento com piridostigmina e prednisona. A EMGFU-JAC no músculo OOc demonstrou valores aumentados nesses pacientes, em contraste ao teste de ER normal. Com relação ao perfil eletrofisiológico, pacientes com sorologia positiva para acMuSK frequentemente apresentam resultados normais à ER, enquanto a EMGFU tem sensibilidade alta, especialmente nos músculos da face 
(Stickler et al., 2005; Nikolic et al., 2014). O músculo Extensor Digitorum apresenta valores aumentados de jitter nas formas mais graves da doença e em fase mais tardia da evolução clínica (Nikolic et al., 2014), ressaltando-se a importância do estudo em um músculo da face, na avaliação inicial nesses pacientes.

$\mathrm{Na} M G$, as anormalidades observadas na ER e na EMGFU correlacionam-se com a gravidade da fraqueza na MG (Srivastava et al., 2007). Enquanto a EMGFU é capaz de identificar aumento do jitter em músculos sem evidência clínica de fraqueza, a ER só apresenta decremento em músculos fracos, quando há uma quantidade significativa de fibras musculares com bloqueio (Keesey,1989). O bloqueio observado na EMGFU é supostamente decorrente do mesmo fenômeno fisiológico que causa decremento no teste de ER (Schwartz, Stålberg, 1975; Gilchrist et al., 1994). Entretanto, nem sempre existe um decremento significativo (>10\%) na presença de bloqueio identificado na EMGFU (Gilchrist et al., 1994). Músculos com até $67 \%$ de pares com bloqueio na EMGFU não demonstraram decremento na ER (Sonoo et al., 2001). Em concordância com a literatura, no presente estudo, todos os pacientes que apresentaram ER com decremento significativo ( $>10 \%$ ), também apresentaram, na EMGFU-JAC, pares de PA-AFU com bloqueio ( $5 \%$ a $60 \%$ dos pares), e valores aumentados de jitter na maioria dos pares registrados $(70 \%$ a 100\%). Em contraste, o bloqueio foi observado em até $60 \%$ dos pares, mesmo na ausência de decremento na ER.

Valores de jitter e presença de bloqueio variam entre diferentes JNMs de um mesmo músculo e até na mesma unidade motora (Stålberg et al., 1974; Keesey, 1989). Embora a proporção de JNMs com valores aumentados de jitter e/ou bloqueio correlacione-se com a gravidade da fraqueza do músculo analisado, existe grande variabilidade entre pacientes com características clínicas semelhantes (Sanders et al., 1979; Sanders, Stålberg, 1996). Sanders, em 2002, no relato dos seus 15 anos de experiência com EMGFU e MG, confirmou a correlação adequada entre o grau de anormalidade no jitter e a classificação da MG. Entretanto, o autor 
afirma que não é possível predizer a gravidade da doença a partir dos valores individuais do jitter, por causa da dispersão ampla desses valores em uma mesma classificação da MG. O presente estudo demonstrou médias diferentes para valores do MCD entre os grupos (controle, MGG e MGO), e mais alta na MGG. Adicionalmente, a média de pares individuais com valores aumentados de jitter e a média de bloqueios foram maiores no grupo MGG. Os dados sugerem correlação dos valores do MCD e quantidade de bloqueios com o grau de comprometimento clínico, também observado por outros autores, com a utilização da AFU (Konishi et al., 1981).

Até 2015, valores normativos de jitter para o músculo OOc, com registros obtidos com $\mathrm{AC}$ e técnica de $\mathrm{CV}$, eram provenientes de alguns estudos de centros independentes (Sarrigiannis et al., 2006; Kouyoumdjian, Stålberg, 2008a; Farrugia et al., 2009). Em 2016, um estudo multicêntrico definiu valores normativos de jitter para os músculos OOc, Frontalis e Extensor Digitorum para as técnicas de contração voluntária e estimulação axonal (Stålberg et al., 2016). Nesse estudo multicêntrico foram sugeridos critérios bem definidos para aceitação de PA-AFU, minimizando o efeito de somação de PAs de fibras musculares diferentes, inerentes aos registros obtidos com AC.

A definição dos valores de jitter obtidos no presente estudo, assim como a escolha da $\mathrm{AC}$ e filtragem dos sinais, seguiu os critérios do estudo de Kouyoumdjian e Stålberg (2008b). Metodologia semelhante também foi utilizada no estudo multicêntrico (Stålberg et al., 2016). O registro digital dos pares de PA obtidos no grupo controle do presente estudo foram revisados e incluídos no estudo multicêntrico de Stålberg et al. (2016). Os valores normativos de MCD obtidos para o músculo OOc, com a utilização da $A C$ e técnica de contração voluntária, são comparados aos resultados de outros autores e também aos valores de referência para a AFU, para a faixa etária de 40 anos (Tabela 4). 
Tabela 4. Valores normativos de MCD para agulha de fibra única (estudo multicêntrico), e para a agulha concêntrica em diferentes estudos e no estudo atual, no músculo Orbicularis Oculi. Entre os parênteses estão as metodologias adotadas para definição dos limites superiores da normalidade em cada estudo.

\begin{tabular}{|c|c|c|c|c|c|c|}
\hline Estudo & $\mathrm{np}$ & $\begin{array}{l}\text { Média } \\
\text { MCD }\end{array}$ & $\begin{array}{c}\text { LSN } \\
\text { média MCD } \\
(\mu \mathrm{s})\end{array}$ & $\begin{array}{c}\text { Média MCD } \\
\text { todos os pares } \\
(\mu \mathrm{s})\end{array}$ & $\begin{array}{l}\text { Média do } \\
18^{\circ} \text { valor } \\
(\mu \mathrm{s})\end{array}$ & $\begin{array}{c}\text { LSN } \\
\text { valores } \\
\text { individuais } \\
\text { de MCD ( } \mu s)\end{array}$ \\
\hline $\begin{array}{c}\text { AANEM Special } \\
\text { Group } \\
\text { on Single Fiber } \\
\text { EMG } \\
(1992,1994)\end{array}$ & Multic & - & 40,4 (2 dp) & - & - & $\begin{array}{c}54,8 \\
\left(2 \text { dp do } 18^{\circ}\right. \\
\text { valor) }\end{array}$ \\
\hline $\begin{array}{l}\text { Sarrigiannis } \\
(2006)\end{array}$ & 484 & $29,1 \pm 3,9$ & $37(\mathrm{ROC})$ & $28,8 \pm 10,5$ & - & $55,2(\mathrm{ROC})$ \\
\hline $\begin{array}{l}\text { Kouyoumdjian e } \\
\text { Stålberg } \\
\text { (2008b) }\end{array}$ & 1000 & $24,7 \pm 3,1$ & 30,9 (2 dp) & $\begin{array}{c}24,7 \pm 7,1 \\
(97,5 \%=38,9)\end{array}$ & $\begin{array}{c}32,7 \pm 4,1 \\
(2 \mathrm{dp}=40,9)\end{array}$ & $\begin{array}{c}40,9 \\
\text { (2 dp do } 18^{\circ} \\
\text { valor) }\end{array}$ \\
\hline $\begin{array}{c}\text { Farrugia } \\
(2009)\end{array}$ & 238 & $26,5 \pm 4,6$ & 35,7 (2 dp) & $26,1 \pm 9,5$ & - & $\begin{array}{c}49,7 \\
(2,5 \mathrm{dp} \text { de } \\
\text { todos os } \\
\text { pares })\end{array}$ \\
\hline Presente estudo & 400 & $19,0 \pm 2,4$ & $\begin{array}{l}23,9 \text { (2 dp) } \\
24,7 \text { (ROC) }\end{array}$ & $\begin{array}{c}19,0 \pm 6,5 \\
(97,5 \%=31,8)\end{array}$ & $\begin{array}{c}24,5 \pm 3,6 \\
(2 \mathrm{dp}=31,7) \\
33,1(\mathrm{ROC})\end{array}$ & $\begin{array}{c}32 \\
\left(2 \mathrm{dp} \text { do } 18^{\circ}\right. \\
\text { valor) }\end{array}$ \\
\hline $\begin{array}{l}\text { Stålberg et al. - } \\
\text { AC Multic. } \\
\text { (2016) }\end{array}$ & 1796 & $22,9 \pm 3,9$ & 31 (2dp) & - & $\begin{array}{c}29,0 \pm 7,6(2 \\
d p)\end{array}$ & $\begin{array}{c}45 \\
\left(2 \mathrm{dp} \text { do } 18^{\circ}\right. \\
\text { valor })\end{array}$ \\
\hline
\end{tabular}

Os valores de referência obtidos no presente estudo foram mais baixos do que os valores de outros estudos, provavelmente por diferenças metodológicas e por controle mais rigoroso para aceitação de PA-AFU. Os estudos divergem quanto ao tamanho da amostra, filtragem dos sinais de frequência baixa em $1 \mathrm{kHz}$ (Kouyoumdjian, Stålberg, 2008b) ou $2 \mathrm{kHz}$ (Farrugia et al., 2006; Sarrigiannis et al., 2006), área de registro da AC utilizada de $0,03 \mathrm{~mm}^{2}$ (Farrugia et al., 2006; Sarrigiannis et al., 2006) ou $0,0019 \mathrm{~mm}^{2}$ (Kouyoumdjian, Stålberg, 2008b). Além disso, diferentes métodos para análise estatística (Tabela 4) e descrição limitada dos critérios 
utilizados nos primeiros estudos para aceitação de PA-AFU dificultam comparações objetivas.

No estudo multicêntrico para definição dos valores de jitter obtidos com AC, a distribuição desses valores foi diferente entre os sujeitos, entre os examinadores e em um mesmo examinador (Stålberg et al., 2016). Houve uma variação acentuada na quantidade e nas idades dos sujeitos investigados em laboratórios diferentes, além de diferenças no equipamento utilizado. De uma maneira geral, a média do MCD foi similar entre operadores que contribuíram com mais de quatro estudos, incluindo o pesquisador do presente estudo. Entre esses operadores, a média da média do MCD para estudos individuais variou de $18,8 \mu$ s a $25,4 \mu$ s para o músculo OOc e técnica de contração voluntária (Stålberg et al., 2016).

O estudo atual seguiu critérios metodológicos muito semelhantes aos estudos de Kouyoumdjian e Stålberg (2008b) e o multicêntrico (Stålberg et al., 2016). Ainda assim, os valores de jitter foram mais baixos no presente estudo. Valores de jitter tendem a aumentar com o avançar da idade. (SINGLE ..., 1992). No presente estudo, a quantidade de amostras (400 pares de PA-AFU) e a média de idade do grupo controle (35,6 anos) foi menor quando comparada ao estudo multicêntrico (1796 pares de PA-AFU; 39,1 anos para mulheres e 43,4 anos para homens), podendo, em parte, ter contribuído para valores mais baixos de jitter. Outro fator que pode ter colaborado para diferenças nas medidas do jitter entre esses estudos é a edição dos sinais registrados, executado no presente estudo para controle melhor da qualidade do sinal.

A EMGFU frequentemente é o último recurso diagnóstico para pacientes com suspeita de MG, com resultados negativos para o teste de ER e dosagens de anticorpos. Portanto, é desejável que o teste tenha sensibilidade adequada e sem resultados falsos positivos. No presente estudo, foram construídas curvas ROC juntando pacientes MGG e MGO no mesmo grupo e estabelecendo o melhor valor de corte, com sensibilidade maior, sem resultados falsos positivos, para a média do MCD e valores individuais de MCD - $18^{\circ}$ par (para $24,7 \mu \mathrm{s}$ e $33,1 \mu \mathrm{s}$, respectivamente). A 
sensibilidade de ambos os parâmetros testados foi $93,9 \%$, tão altas quanto as reportadas por Sarrigiannis et al. (2006). A sensibilidade da EMGFU-JAC no presente estudo é similar à reportada previamente para EMGFU $(88 \%$ a 99\%) (Meriggioli, Sanders, 2005). Adicionalmente a ASC derivada da curva ROC, mostrou que ambos os critérios para definição de anormalidade do teste apresentaram acurácia diagnóstica semelhante $(96,7 \%$ para a média do MCD e 97,9\% para valores individuais de MCD).

Em uma revisão sistemática da acurácia dos métodos diagnósticos para MG, Benatar et al. (2006) encontraram 98\% de sensibilidade e especificidade da EMGFU para diagnóstico de MGG, enquanto a sensibilidade e especificidade para diagnóstico de MGO variou de $86-97 \%$ (variação da sensibilidade) a $73-92 \%$ (variação da especificidade), respectivamente, dependendo da metodologia adotada em cada estudo. Ao contrário da EMGFU, há poucos estudos sobre a acurácia diagnóstica da EMGFU-JAC em pacientes com MG (Benatar et al., 2006; Sarrigiannis et al., 2006; Witoonpanich et al., 2011). Um estudo retrospectivo em pacientes com MG confirmada encontrou uma sensibilidade de $96,4 \%$, sem resultados falsos positivos, para análise do jitter com AC, mesmo utilizando valores de

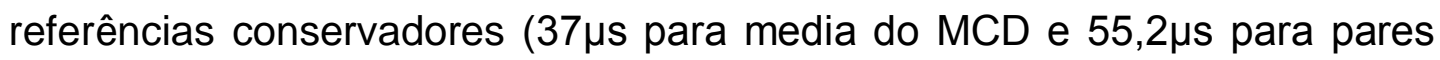
individuais) (Sarrigiannis et al., 2006). À semelhança com o presente estudo, Witoonpanich et al. (2011) também reportaram sensibilidade alta da EMGFU-JAC para MGO (93\%) e MGG (99\%). Por outro lado, em estudo retrospectivo foram mostradas sensibilidades menores da EMGFU-JAC para diagnóstico de MGG (75\%) e MGO (62\%) (Benatar et al., 2006). Entretanto, o uso de valores de referência para AFU, ao invés de valores para $A C$, pode ter contribuído para a sensibilidade reduzida da EMGFU-JAC nesse último estudo (Benatar et al., 2006).

A EMGFU é uma técnica demorada, particularmente com registros obtidos com AC (EMGFU-JAC) (Stålberg et al., 2016). Na técnica de contração voluntária, é necessário completar a aquisição dos 20 pares de PA antes de afastar distúrbio da JNM no músculo examinado. Na tentativa de diminuir a quantidade de pares necessários, Narayanaswami et al. (2012) 
aplicaram os princípios do teste de futilidade, derivado de ensaios clínicos (futility test). Os autores propõem que o estudo pode ser interrompido no $12^{\circ}$ par, ao invés do $20^{\circ}$ ( $40 \%$ de redução do exame), quando todos os pares de PAFU apresentam valores de jitter normais, com frequência de erro $<5 \%$. $\mathrm{Na}$ presença de um valor de jitter anormal, o estudo deve continuar até a obtenção do $17^{\circ}$ par, antes que a EMGFU seja considerada normal (15\% de redução do exame). Entretanto, esse estudo somente considerou um dos critérios de anormalidade da EMGFU: $>10 \%$ dos pares com valores de jitter aumentados. Poderia ser útil o desenvolvimento de um método, fundamentado nos dois critérios de anormalidade para antecipar o fim do estudo e poupar tempo de execução do exame.

Rotineiramente, recomenda-se a análise do jitter em um segundo músculo, normalmente um músculo da face, quando o primeiro demonstra resultados normais (Sanders, Stålberg, 1996). Uma das vantagens da curva ROC é a possibilidade de avaliar o impacto diagnóstico com a variação do valor de corte ao longo da curva. No presente estudo, o valor da média do MCD de $19,6 \mu$ s apresentou $100 \%$ de sensibilidade e queda progressiva na especificidade com a diminuição desse valor. Nenhum paciente da amostra estudada apresentou valor de jitter tão baixo, nem sequer o paciente assintomático. Esse valor de corte com $100 \%$ de sensibilidade no músculo OOc poderia ser utilizado, ao invés da análise do jitter em um segundo músculo, no intuito de evitar o prolongamento do exame.

Essa proposta é reforçada pela constatação de que o músculo $\mathrm{OOc}$ pode ser mais apropriado que o músculo Frontalis para a confirmação diagnóstica de pacientes com MGO (Valls-Canals et al., 2003). Valls Canals et al. (2003) demonstraram que a EMGFU (técnica de estimulação axonal), em 20 pacientes com MGO, foi mais sensível no músculo OOc do que no músculo Frontalis. Em todos os casos a média do MCD e a quantidade de PA com valores de jitter aumentados foi maior no músculo OOc. Em dois pacientes os valores de jitter foram normais no músculo Frontalis e anormais no músculo OOc. Os autores levantaram a hipótese de que a sensibilidade maior do músculo OOc seria, provavelmente, causada por fator de 
segurança da JNM menor ou um espectro diferente de ac-AChR nesse músculo. Trotelj et al. (1988), em um pequena série de pacientes com MGG leve e em remissão clínica, perceberam que o músculo $O O c$ apresentava resultados aumentados de jitter com maior frequência do que o músculo Frontalis; entretanto, os dados numéricos não foram publicados.

Atualmente, a regulamentação hospitalar restringe o uso de materiais reesterilizados; a EMGFU praticamente só é realizada com registros obtidos com AC (EMGFU-JAC) em diferentes laboratórios de neurofisiologia, internacionais e nacionais. Enquanto não houver interesse da indústria em desenvolver uma AFU descartável e de custo baixo, a AC permite maior acesso ao método. Provavelmente a EMGFU-JAC vem sendo utilizada há mais tempo do que reportado pelos primeiros trabalhos publicados (10-15 anos). Contudo, apenas recentemente (2016) os valores de referência para EMGFU-JAC foram derivados de um estudo multicêntrico coordenado por Erik Stålberg, o pioneiro da EMGFU. Claramente, os cuidados técnicos para a aceitação dos potenciais de ação para análise do jitter obtidos com AC são maiores dos que com a AFU, podendo ser uma das principais fontes de divergências entre os estudos. Pesquisas futuras com a utilização da EMFGU-JAC deveriam seguir os cuidados técnicos, agora oficialmente estabelecidos pelo estudo multicêntrico, para que os resultados sejam mais facilmente equiparáveis. 
7 CONCLUSÕES 



\section{CONCLUSÕES}

1- Mediante análise do jitter com eletrodo agulha concêntrica em sujeitos saudáveis, por meio da técnica de ativação voluntária no músculo Orbicularis Oculi, foram obtidos os valores de $24 \mu$ s e $32 \mu$ s para média do MCD e $18^{\circ}$ par, respectivamente.

2- Valores de jitter obtidos com agulha concêntrica, em sujeitos saudáveis, foram menores dos que aqueles obtidos em estudos que utilizaram agulha de fibra única.

3- A utilização da agulha concêntrica para análise do jitter apresenta sensibilidade e especificidade altas na identificação de distúrbio da JNM em pacientes com MG; a agulha concêntrica é uma alternativa à agulha de fibra única para medidas de jitter. 



\section{REFERÊNCIAS}





\section{REFERÊNCIAS ${ }^{2}$}

AAEM Quality Assurance Committee American Association of Electrodiagnostic Medicine. Literature review of the usefulness of repetitive nerve stimulation and single fiber EMG in the electrodiagnostic evaluation of patients with suspected myasthenia gravis or Lambert-Eaton myasthenic syndrome. Muscle Nerve. 2001a;24(9):1239-47.

AAEM Quality Assurance Committee American Association of Electrodiagnostic Medicine. Practice parameter for repetitive nerve stimulation and single fiber EMG evaluation of adults with suspected myasthenia gravis or LambertEaton myasthenic syndrome: summary statement. Muscle Nerve. 2001b;24(9):1236-8.

Andersen JB, Engeland A, Owe JF, Gilhus NE. Myasthenia gravis requiring pyridostigmine treatment in a national population cohort. Eur $\mathrm{J}$ Neurol. 2010;17(12):1445-50.

Benatar M. A systematic review of diagnostic studies in myasthenia gravis. Neuromuscular Disorders. 2006 Jul;16(7):459-67.

Benatar M, Hammad M, Doss-Riney $H$. Concentric-needle single-fiber electromyography for the diagnosis of myasthenia gravis. Muscle Nerve. 2006;34(2):163-8.

Benatar M, Kaminski H. Medical and surgical treatment for ocular myasthenia. Benatar M, editor. Chichester, UK: John Wiley \& Sons, Ltd; Cocharne Database Syst Rev. 2012;12:CD005081.

Benatar M, Kaminski HJ. Evidence report: The medical treatment of ocular myasthenia (an evidence-based review) - Report of the quality standards subcommittee of the American Academy of Neurology. Neurology. 2007;68(24):2144-9.

${ }^{2}$ Esta tese está de acordo com as seguintes normas, em vigor no momento desta publicação: Referências: adaptado de International Committee of Medical Journals Editors (Vancouver). Universidade de São Paulo. Faculdade de Medicina. Divisão de Biblioteca e Documentação. Guia de apresentação de dissertações, teses e monografias. Elaborado por Anneliese Carneiro da Cunha, Maria Julia de A. L. Freddi, Maria F. Crestana, Marinalva de Souza Aragão, Suely Campos Cardoso, Valéria Vilhena. 3a ed. São Paulo: Divisão de Biblioteca e Documentação; 2011.

Abreviaturas dos títulos dos periódicos de acordo com List of Journals Indexed in Index Medicus. 
Benatar M, Sanders DB, Wolfe GI, McDermott MP, Tawil R. Design of the efficacy of prednisone in the treatment of ocular myasthenia (EPITOME) trial. Ann NY Acad Sci. 2012;1275(1):17-22.

Bertorini TE, Stålberg E, Yuson CP, Engel WK. Single-fiber electromyography in neuromuscular disorders: correlation of muscle histochemistry, single-fiber electromyography, and clinical findings. Muscle Nerve. 1994;17(3):345-53.

Bril V, Werb MR, Greene DA, Sima AA. Single-fiber electromyography in diabetic peripheral polyneuropathy. Muscle Nerve. 1996;19(1):2-9.

Bromberg MB, Scott DM. Single fiber EMG reference values: reformatted in tabular form. AD HOC Committee of the AAEM Single Fiber Special Interest Group. Muscle Nerve. 1994;17(7):820-1.

Buchman AS, Garratt M. Determining neuromuscular jitter using a monopolar electrode. Muscle Nerve. 1992;15(5):615-9.

Carr AS, Cardwell CR, McCarron PO, McConville J. A systematic review of population based epidemiological studies in myasthenia gravis. BMC Neurol. 2010;10(1):46-9.

Cattaneo L, Cucurachi L, Pavesi G. Concentric needle recording of neuromuscular jitter in the temporalis muscle. Neurophysiol Clin. 20071;37(1):50-1.

Chan $\mathrm{KH}$, Lachance DH, Harper CM, Lennon VA. Frequency of seronegativity in adult-acquired generalized myasthenia gravis. Muscle Nerve. 2007;36(5):651-8.

Chaudhry V, Watson DF, Bird SJ, Cornblath DR. Stimulated single-fiber electromyography in Lambert-Eaton myasthenic syndrome. Muscle Nerve. 1991;14(12):1227-30.

Drachman DB. Myasthenia gravis. N Engl J Med. 1994;330(25):1797-810.

Dumitru D, Amato AA, Zwarts MJ. Neuromuscular junction disorders. Electrodiagnostic medicine. Second Edition. Philadelphia: Hanley and Belfus Inc; 2002. pp. 1127-227.

Ekstedt J. Human single fiber action potentials. Extracellular recording during voluntary and chemical activation. With some comments on end-plate physiology and on the fiber arrangement of the motor unit. Acta Physiol Scand Suppl. 1964;SUPPL226:1+. 
Ekstedt J, Häggqvist P, Stålberg E. The construction of needle multi-electrodes for single fiber electromyography. Electroencephalogr Clin Neurophysiol. 1969;27(5):540-3.

Ekstedt J, Nilsson G, Stålberg E. Calculation of the electromyographic jitter. J Neurol Neurosurg Psychiatr. 1974;37(5):526-39.

Ekstedt J, Stalberg E. Myasthenia gravis. Diagnostic aspects by a new electrophysiological method. Opuscular Medica. 1967;(12):73-6.

Ekstedt J, Stålberg E. The effect of non-paralytic doses of D-tubocurarine on individual motor end-plates in man, studied with a new electrophysiological method. Electroencephalogr Clin Neurophysiol. 1969;27(6):557-62.

Ertaş M, Baslo MB, Yildiz N, Yazici J, Oge AE. Concentric needle electrode for neuromuscular jitter analysis. Muscle Nerve. 2000;23:715-9.

Ertaş M, Erdinç O, Aydin N, Uludağ B, Ertekin C. Surface stimulation singlefiber electromyography. Muscle Nerve. 1998;(21):118-20.

Evoli A. Clinical aspects of neuromuscular transmission disorders. Acta Neurol Scand Suppl. 2006;183:8-11.

Evoli A, Tonali PA, Padua L, Monaco ML, Scuderi F, Batocchi AP, et al. Clinical correlates with anti-MuSK antibodies in generalized seronegative myasthenia gravis. Brain. 2003;126(Pt 10):2304-11.

Fakiri MO, Tavy DLJ, Hama-Amin AD, Wirtz PW. Accuracy of the ice test in the diagnosis of myasthenia gravis in patients with ptosis. Muscle Nerve. 2013;48(6):902-4.

Farrugia ME, Kennett RP, Newsom-Davis J, Hilton-Jones D, Vincent A. Singlefiber electromyography in limb and facial muscles in muscle-specific kinase antibody and acetylcholine receptor antibody myasthenia gravis. Muscle Nerve. 2006;33(4):568-70.

Farrugia ME, Weir Al, Cleary M, Cooper S, Metcalfe R, Mallik A. Concentric and single fiber needle electrodes yield comparable jitter results in myasthenia gravis. Muscle Nerve. 2009;39(5):579-85.

Gantayat M, Swash M, Schwartz MS. Fiber density in acute and chronic inflammatory demyelinating polyneuropathy. Muscle Nerve. 1992;15(2):16871.

Gath I, Stålberg E. Techniques for improving the selectivity of electromyographic recordings. IEEE Trans Biomed Eng. 1976;23(6):467-72. 
Gilchrist JM, Massey JM, Sanders DB. Single fiber EMG and repetitive stimulation of the same muscle in myasthenia gravis. Muscle Nerve. 1994;17(2):171-5.

Gilhus NE, Verschuuren JJ. Myasthenia gravis: subgroup classification and therapeutic strategies. Lancet Neurol. 2015;14(10):1023-36.

Gomez AM, Van Den Broeck J, Vrolix K, Janssen SP, Lemmens MAM, Van Der Esch E, et al. Antibody effector mechanisms in myasthenia gravis pathogenesis at the neuromuscular junction. Autoimmunity. 2010;43(56):353-70.

Grimby G, Stålberg E, Sandberg A, Sunnerhagen KS. An 8-year longitudinal study of muscle strength, muscle fiber size, and dynamic electromyogram in individuals with late polio. Muscle Nerve. 1998;21(11):1428-37.

Guptill JT, Sanders DB, Evoli A. Anti-musk antibody myasthenia gravis: Clinical findings and response to treatment in two large cohorts. Muscle Nerve. 2011;44(1):36-40.

Heldal AT, Eide GE, Romi F, Owe JF, Gilhus NE. Repeated acetylcholine receptor antibody-concentrations and association to clinical myasthenia gravis development. Saruhan-Direskeneli G, editor. PLoS ONE. 2014;9(12):e114060.

Heldal AT, Owe JF, Gilhus NE, Romi F. Seropositive myasthenia gravis: a nationwide epidemiologic study. Neurology. 2009;73(2):150-1.

Higuchi O, Hamuro J, Motomura M, Yamanashi Y. Autoantibodies to lowdensity lipoprotein receptor-related protein 4 in myasthenia gravis. Ann Neurol. 2011;69(2):418-22.

Hoch W, McConville J, Helms S, Newsom-Davis J, Melms A, Vincent A. Autoantibodies to the receptor tyrosine kinase MuSK in patients with myasthenia gravis without acetylcholine receptor antibodies. Nat Med. 2001;7(3):365-8.

Howard FM, Lennon VA, Finley J, Matsumoto J, Elveback LR. Clinical correlations of antibodies that bind, block, or modulate human acetylcholine receptors in myasthenia gravis. Ann N Y Acad Sci. 1987;505:526-38.

Howard JF. Electrodiagnosis of disorders of neuromuscular transmission. Phys Med Rehabil Clin N Am. 2013;24(1):169-92.

Howard JF, Sanders DB. Serial single-fiber EMG studies in myasthenic patients treated with corticosteroids and plasma-exchange therapy. Muscle Nerve. $1981 ; 254$. 
Jaretzki A 3rd, Barohn RJ, Ernstoff RM, Kaminski HJ, Keesey JC, Penn AS, Sanders DB. Myasthenia gravis: recommendations for clinical research standards. Task Force of the Medical Scientific Advisory Board of the Myasthenia Gravis Foundation of America. Neurology. 2000;55(1):16-23.

Kandel E, Schwartz J. Principles of Neural Science, Fifth Edition. McGraw Hill Professional; 2013.

Kang S-Y, Oh J-H, Song SK, Lee JS, Choi JC, Kang J-H. Both binding and blocking antibodies correlate with disease severity in myasthenia gravis. Neurol Sci. 2015;36(7):1167-71.

Keesey JC. AAEE Minimonograph \#33: electrodiagnostic approach to defects of neuromuscular transmission. Muscle Nerve. 1989;12(8):613-26.

Keesey JC. Clinical evaluation and management of myasthenia gravis. Muscle Nerve. 2004;29(4):484-505.

King JC, Dumitru D, Nandedkar S. Concentric and single fiber electrode spatial recording characteristics. Muscle Nerve. 1997;20(12):1525-33.

Kokubun N, Sonoo M, Imai T, Arimura Y, Kuwabara S, Komori T, et al. Reference values for voluntary and stimulated single-fibre EMG using concentric needle electrodes: a multicentre prospective study. Clin Neurophysiol. 2012;123(3):613-20.

Konishi $T$, Nishitani $H$, Matsubara $F$, Ohta M. Myasthenia gravis: relation between jitter in single-fiber EMG and antibody to acetylcholine receptor. Neurology. 1981;31(4):386-92.

Kouyoumdjian JA, da Silva Fanani AC, Stålberg EV. Concentric needle jitter on stimulated frontalis and extensor digitorum in 20 myasthenia gravis patients. Muscle Nerve. 2011;44(6):912-8.

Kouyoumdjian JA, Stålberg E. Concentric needle jitter in stimulated frontalis in 20 healthy subjects. Muscle Nerve. 2012;45(2):276-8.

Kouyoumdjian JA, Stålberg E. Concentric needle jitter on stimulated orbicularis oculi in 50 healthy subjects. Clin Neurophysiol. 2011;122(3):617-22.

Kouyoumdjian JA, Stålberg E. Concentric needle jitter on voluntary activated frontalis in 20 healthy subjects. Muscle Nerve. 2013a;47(3):440-2.

Kouyoumdjian JA, Stålberg E. Concentric needle single fiber electromyography: normative jitter values on voluntary activated extensor digitorum communis. Arq Neuropsiquiatr. 2007;65(2B):446-9. 
Kouyoumdjian JA, Stålberg E. Concentric needle single fiber electromyography: comparative jitter on voluntary-activated and stimulated extensor digitorum communis. Clin Neurophysiol. 2008a;119(7):1614-8.

Kouyoumdjian JA, Stålberg E. Reference jitter values for concentric needle electrodes in voluntarily activated extensor digitorum communis and orbicularis oculi muscles. Muscle Nerve. 2008b;37(6):694-9.

Kouyoumdjian JA, Stålberg E. Stimulated jitter with concentric needle in 42 myasthenia gravis patients. Arq Neuropsiquiatr. 2013b;71(4):237-43.

Lagueny A, Le Masson G, Burbeaud P, Deliac P. Single fibre electromyography in multifocal motor neuropathy with persistent conduction blocks. J Neurol Neurosurg Psychiatr. 1998;65(3):357-61.

Leite MI, Jacob S, Viegas S, Cossins J, Clover L, Morgan BP, et al. IgG1 antibodies to acetylcholine receptors in "seronegative" myasthenia gravis. Brain. 2008;131(Pt 7):1940-52.

Lindstrom JM, Seybold ME, Lennon VA, Whittingham S, Duane DD. Antibody to acetylcholine-receptor in myasthenia-gravis - Prevalence, clinical correlates, and diagnostic value. Neurology. 1976;26(11):1054-9.

Marx A, Pfister F, Schalke B, Saruhan-Direskeneli G, Melms A, Ströbel P. The different roles of the thymus in the pathogenesis of the various myasthenia gravis subtypes. Autoimmun Rev. 2013;12(9):875-84.

Massey JM, Sanders DB. Single-fiber EMG demonstrates reinnervation dynamics after nerve injury. Neurology. 1991;41(7):1150-1.

Massey JM, Sanders DB. Single fiber electromyography in myasthenia gravis during pregnancy. Muscle Nerve. 1993;16(5):458-60.

Meriggioli MN, Rowin J. Single fiber EMG as an outcome measure in myasthenia gravis: results from a double-blind, placebo-controlled trial. J Clin Neurophysiol. 2003;20(5):382-5.

Meriggioli MN, Sanders DB. Advances in the diagnosis of neuromuscular junction disorders. Ame J Phys Med Rehabilit. 2005;84(8):627-38.

Mossman S, Vincent A, Newsom-Davis J. Myasthenia gravis without acetylcholine-receptor antibody: a distinct disease entity. Lancet. 1986;1(8473):116-9. 
Narayanaswami P, Pantoja-Galicia N, Betensky RA, Rutkove SB. Application of futility analysis to refine jitter recordings in myasthenia gravis. Muscle Nerve. 2012;45(4):486-91.

Nikolic A, Basta I, Stojanovic VR, Stevic Z, Lavrnic D. Electrophysiological profile of the patients with MuSK positive myasthenia gravis. Neurol Res. 2014;36(11):945-9.

Oh SJ, Eslami N, Nishihira T, Sarala PK, Kuba T, Elmore RS, et al. Electrophysiological and clinical correlation in myasthenia gravis. Ann Neurol. 1982;12(4):348-54.

Oh SJ, Hurwitz EL, Lee KW, Change CW, Cho HK. The single-fiber EMG in the Lambert-Eaton myasthenic syndrome. Muscle Nerve. 1989;12(2):159-60.

Oh SJ, Kim DE, Kuruoglu R, Bradley RJ, Dwyer D. Diagnostic sensitivity of the laboratory tests in myasthenia gravis. Muscle Nerve. 1992;15(6):720-4.

Oh SJ, Ohira M. Single-fiber EMG and clinical correlation in Lambert-Eaton myasthenic syndrome. Muscle Nerve. 2013;47(5):664-7.

Oosterhuis HJ. The natural course of myasthenia gravis: a long term follow up study. J Neurol Neurosurg Psychiatr. 1989;52(10):1121-7.

Orhan EK, Deymeer F, Oflazer P, Parman Y, Baslo MB. Jitter analysis with concentric needle electrode in the masseter muscle for the diagnosis of generalized myasthenia gravis. Clin Neurophysiol. 2013;124(11):2277-82.

Padua L, Aprile I, Monaco ML, Fenicia L. Neurophysiological assessment in the diagnosis of botulism: usefulness of single-fiber EMG. Muscle Nerve. 1999;22(10):1388-92.

Padua L, Stålberg E, LoMonaco M, Evoli A, Batocchi A, Tonali P. SFEMG in ocular myasthenia gravis diagnosis. Clin Neurophysiol. 2000;111(7):1203-7.

Padua L, Tonali P, Aprile I, Caliandro P, Bartoccioni E, Evoli A. Seronegative myasthenia gravis: comparison of neurophysiological picture in MuSK+ and MuSK- patients. Eur J Neurol. 2006;13(3):273-6.

Pascuzzi RM. The edrophonium test. Semin Neurol. 2003;23(1):83-8.

Pevzner A, Schoser B, Peters K, Cosma N-C, Karakatsani A, Schalke B, et al. Anti-LRP4 autoantibodies in AChR- and MuSK-antibody-negative myasthenia gravis. J Neurol. 2011;259(3):427-35. 
Sadeh M, River Y, Argov Z. Stimulated single-fiber electromyography in Lambert-Eaton myasthenic syndrome before and after 3, 4-diaminopyridine. Muscle Nerve. 1997;20(6):735-9.

Sanders DB. Clinical impact of single-fiber electromyography. Muscle Nerve Suppl. 2002;11(S11):S15-20.

Sanders DB, El-Salem K, Massey JM, McConville J, Vincent A. Clinical aspects of MuSK antibody positive seronegative MG. Neurology. 2003;60(12):197880.

Sanders DB, Howard JF. AAEE minimonograph \#25: Single-fiber electromyography in myasthenia gravis. Muscle Nerve. 1986;9(9):809-19.

Sanders DB, Howard JF, Johns TR. Single-fiber electromyography in myasthenia gravis. Neurology. 1979;29(1):68-76.

Sanders DB, Massey EW, Buckley EG. Botulinum toxin for blepharospasm: single-fiber EMG studies. Neurology. 1986 Apr;36(4):545-7.

Sanders DB, Stålberg E. AAEM minimonograph \#25: single-fiber electromyography. Muscle Nerve. 1996;19(9):1069-83.

Sarrigiannis PG, Kennett RP, Read S, Farrugia ME. Single-fiber EMG with a concentric needle electrode: validation in myasthenia gravis. Muscle Nerve. 2006;33(1):61-5.

Schiller HH, Stålberg E, Schwartz MS. Regional curare for the reduction of the safety factor in human motor end-plates studied with single fibre electromyography. J Neurol Neurosurg Psychiatr. 1975;38(8):805-9.

Schumm F, Stöhr M. Accessory nerve stimulation in the assessment of myasthenia gravis. Muscle Nerve. 1984;7(2):147-51.

Schwartz MS, Stålberg E. Single fibre electromyographic studies in myasthenia gravis with repetitive nerve stimulation. J Neurol Neurosurg Psychiatry. 1975;38(7):678-82.

Scuderi F, Marino M, Colonna L, Mannella F, Evoli A, Provenzano C, Bartoccioni E. Anti-P110 Autoantibodies identify a subtype of "seronegative" myasthenia gravis with prominent oculobulbar involvement. Lab Invest. 2002;82:1139-46. 
SINGLE fiber EMG reference values: a collaborative effort. Ad Hoc Committee of the AAEM Special Interest Group on Single Fiber EMG. Muscle Nerve. 1992;15(2):151-61.

Sonoo M, Uesugi H, Mochizuki A, Hatanaka Y. Single fiber EMG and repetitive nerve stimulation of the same extensor digitorum communis muscle in myasthenia gravis. Clinical Neurophysiol. 2001;112(2):300-3.

Srivastava A, Kalita J, Misra UK. A comparative study of single fiber electromyography and repetitive nerve stimulation in consecutive patients with myasthenia gravis. Electromyogr Clin Neurophysiol. 2007;47(2):93-6.

Stålberg E. Clinical electrophysiology in myasthenia gravis. J Neurol Neurosurg Psychiatr. 1980;43(7):622-33.

Stålberg E. Jitter analysis with concentric needle electrodes. Ann N Y Acad Sci. Blackwell Publishing Inc; 2012;1274(1):77-85.

Stålberg E. Propagation velocity in human muscle fibers in situ. Acta Physiol Scand Suppl. 1966;287:1-112.

Stålberg $E$. Use of single fiber EMG and macro EMG in study of reinnervation. Muscle Nerve. 1990;13(9):804-13.

Stålberg E, Ekstedt J, Broman A. Neuromuscular transmission in myasthenia gravis studied with single fiber electromyography. J Neurol Neurosurg Psychiatr. 1974;37(5):540-7.

Stålberg E, Ekstedt J, Broman A. The electromyographic jitter in normal human muscles. Electroencephalogr Clin Neurophysiol. 1971;31(5):429-38.

Stålberg E, Ekstedt J. Signs of neuropathy in distal hereditary myopathy. Electroencephalogr Clin Neurophysiol. 1969;26(3):343.

Stålberg E, Kouyoumdjian J, Sanders D. Reference values in concentric needle electrode studies. Clin Neurophysiol. 2013;124(6):1255-6.

Stålberg E, Sanders DB. Jitter recordings with concentric needle electrodes. Muscle Nerve. 2009;40(3):331-9.

Stålberg E, Sanders DB, Ali S, Cooray G, Leonardis L, Löseth S, Machado F, Maldonado A, et al. Reference values for jitter recorded by concentric needle electrodes in healthy controls: a multicenter study. Muscle Nerve. 2016;53:351-62. 
Stålberg E, Schwartz MS, Trontelj JV. Single fibre electromyography in various processes affecting the anterior horn cell. J Neurol Sci. 1975;24(4):403-15.

Stålberg E, Trontelj JV, Sanders DB. Single fiber EMG. 3rd ed. Sweden: Edshagen Publishing House Fiskebäckskil; 2010.

Stickler DE, Massey JM, Sanders DB. MuSK-antibody positive myasthenia gravis: clinical and electrodiagnostic patterns. Clin Neurophysiol. 2005;116(9):2065-8.

Trontelj JV, Khuraibet A, Mihelin M. The jitter in stimulated orbicularis oculi muscle: technique and normal values. J Neurol Neurosurg Psychiatr. 1988;51(6):814-9.

Trontelj JV, Mihelin M, Fernandez JM, Stålberg E. Axonal stimulation for endplate jitter studies. J Neurol Neurosurg Psychiatr. 1986;49(6):677-85.

Trontelj JV, Mihelin M, Khuraibet A. Safety margin at single neuromuscular junctions. Muscle Nerve Suppl. 2002;11(S11):S21-7.

Trontelj JV, Stålberg E. Jitter measurement by axonal micro-stimulation. Guidelines and technical notes. Electroencephalogr Clin Neurophysiol. 1992;85(1):30-7.

Trontelj JV, Stålberg E, Mihelin M, Khuraibet A. Jitter of the stimulated motor axon. Muscle Nerve. 1992;15(4):449-54.

Tutkavul K, Baslo MB. Reference voluntary jitter values using disposable monopolar needle electrodes in the extensor digitorum communis muscle. Clin Neurophysiol. 2010;121(6):887-9.

Tüzün E, Christadoss P. Complement associated pathogenic mechanisms in myasthenia gravis. Autoimm Rev. 2013;12(9):904-11.

Valls-Canals J, Povedano M, Montero J, Pradas J. Stimulated single-fiber EMG of the frontalis and orbicularis oculi muscles in ocular myasthenia gravis. Muscle Nerve. 2003;28(4):501-3.

Verschuuren JJGM, Huijbers MG, Plomp JJ, Niks EH, Molenaar PC, MartinezMartinez $\mathrm{P}$, et al. Pathophysiology of myasthenia gravis with antibodies to the acetylcholine receptor, muscle-specific kinase and low-density lipoprotein receptor-related protein 4. Autoimmun Rev. 2013;12(9):918-23.

Vincent A. Immunology of disorders of neuromuscular transmission. Acta Neurol Scand Suppl. 2006;183:1-7. 
Vincent A, Palace J, Hilton-Jones D. Myasthenia gravis. Lancet. 2001;357(9274):2122-8.

Wiechers D. Single fiber EMG evaluation in denervation and reinnervation. Muscle Nerve. 1990;13(9):829-32 .

Wiechers DO. Single fiber electromyography with a standard monopolar electrode. Arch Phys Med Rehabil. 1985;66(1):47-8.

Witoonpanich R, Dejthevaporn C, Sriphrapradang A, Pulkes T. Electrophysiological and immunological study in myasthenia gravis: diagnostic sensitivity and correlation. Clin Neurophysiol. 2011;122(9):1873-7.

Yannikas C, Sheean GL, King PJL. Relative sensitivities of the axillary and accessory nerves in the diagnosis of myasthenia gravis. Muscle Nerve. 1994;17:561-2.

Zambelis T, Kokotis P, Karandreas N. Repetitive Nerve Stimulation of Facial and Hypothenar Muscles: Relative Sensitivity in Different Myasthenia Gravis Subgroups. Eur Neurol. 2011;65(4):203-7.

Zisimopoulou P, Brenner T, Trakas N, Tzartos SJ. Serological diagnostics in myasthenia gravis based on novel assays and recently identified antigens. Autoimmun Rev. 2013;12(9):924-30. 

APÊNDICES 



\section{APÊNDICE 1}

\section{APROVAÇÃO DO COMITÊ DE ÉTICA DA FACULDADE DE MEDICINA DA USP}
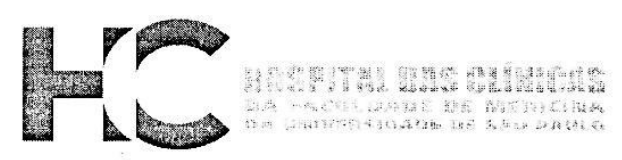

\section{APROVAÇÃO}

A Comissão de Ética para Análise de Projetos de Pesquisa CAPPesq da Diretoria Clínica do Hospital das Clínicas e da Faculdade de Medicina da Universidade de São Paulo, em sessão de 27/10/2010, APROVOU o Protocolo de Pesquisa $n^{\circ}$ 0597/10, intitulado: "ANÁlISE DO JITTER COM AGULHA CONCÊNTRICA EM PACIENTES COM FORMA OCULAR EM MIASTENIA GRAVIS" apresentado pelo Departamento de NEUROLOGIA, inclusive O Termo de Consentimento Livre e Esclarecido.

Cabe ao pesquisador elaborar e apresentar à CAPPesq, os relatórios parciais e final sobre a pesquisa (Resolução do Conselho Nacional de Saúde $n^{\circ} 196$, de 10/10/1996, inciso (X.2, letra "c").

Pesquisador (a) Responsável: Prof. Dr. Paulo. Euripedes Marchiori

Pesquisador (a) Executante: Flavia Costa Nunes Machado

CAPPesq, 29 de Outubro de 2010

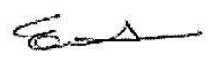

Prof. Dr. Eduardo Massad Presidente da Comissão de Ética para Análise de Projetos de Pesquisa

\footnotetext{
Comissão de Ética para Análise de Projetos de Pesquisa do HCFMUSP da Diretoria Clínica do Hospital das Clínicas da Faculdade de Medicina da Universidade de Săo Paulo Rua Ovidio Pires de Campos, 225, $5^{\circ}$ andar - CEP 05403010 - Săo Paulo - SP Fone: 01130696442 Fax: 01130696492 e-mail: cappesq@hcnet.usp.br
}

Observação: Houve mudança no título da tese, porém não foi necessário submeter novamente ao CEP pois não houve modificações no projeto. 



\section{APÊNDICE 2}

\section{APROVAÇÃO DO COMITÊ DE ÉTICA DO FLEURY MEDICINA E SAÚDE}

\section{KLEURY}

São Paulo, 22 de setembro de 2010

Parecer do projeto submetido ao Comitê de Ética em Pesquisa do Instituto Fleury, intitulado: "Análise do jitter com agulha concêntrica".

Investigador principal: Flavia Costa Nunes Machado

Parecer: aprovado

Justificativa: o projeto apresenta detalhadamente a necessidade do estudo e sua metodologia, bem como o Termo de Consentimento Livre e Esclarecido. Encontra-se, portanto, em conformidade com a resolução da CONEP 196/96 e $347 / 05$, e, por este motivo, sugiro pela aprovação do referido estudo. 



\author{
HOSPITAL DAS CLÍNICAS DA FACULDADE DE MEDICINA DA \\ UNIVERSIDADE DE SÃO PAULO - HCFMUSP
}

\title{
DADOS DE IDENTIFICAÇÃO DO SUJEITO DA PESQUISA OU RESPONSÁVEL LEGAL
}

1. NOME:

DOCUMENTO DE IDENTIDADE №: SEXO : $M \square F \square$ DATA NASCIMENTO: ENDEREÇO: ............................. BAIRRO: CIDADE: № APTO: TELEFONE: DDD ( )

2. RESPONSÁVEL LEGAL:

NATUREZA (grau de parentesco, tutor, curador etc.): DOCUMENTO DE IDENTIDADE №: SEXO : $M \square F \square$ DATA NASCIMENTO: ENDEREÇO: BAIRRO: TELEFONE: DDD ( ) CIDADE:

№ .CEP: APTO:

\section{DADOS SOBRE A PESQUISA}

1. TÍTULO DO PROTOCOLO DE PESQUISA: ANÁLISE DO JITTER COM AGULHA CONCÊNTRICA EM PACIENTES COM MIASTENIA GRAVIS AUTOIMUNE ADQUIRIDA

PESQUISADOR RESPONSÁVEL: DR. PAULO EURÍPEDES MARCHIORI

CARGO/FUNÇÃO: MÉDICO INSCRIÇÃO CONSELHO REGIONAL № CRM-SP 20.851

PESQUISADOR EXECUTANTE: FLAVIA COSTA NUNES MACHADO

INSCRIÇÃO CONSELHO REGIONAL № CRM SP 95543

CARGO/FUNÇÃO: MÉDICA

UNIDADE DO HCFMUSP: Divisão de Clínica Neurológica

2. AVALIAÇÃO DO RISCO DA PESQUISA:

$$
\begin{array}{ll}
\text { RISCO MÍNIMO } & X \\
\text { RISCO BAIXO } \quad \square & \text { RISCO MÉDIO }
\end{array}
$$

3. DURAÇÃO DA PESQUISA : DOIS ANOS 
1 - Essas informações estão sendo fornecidas para sua participação voluntária neste estudo, que visa o uso de um método chamado "análise do jitter com agulha concêntrica em pacientes com Miastenia Gravis" (JAC) para a investigação de doenças que afetam a transmissão dos impulsos do nervo para o músculo, como por exemplo a miastenia. A JAC é um método usado em todo o mundo para o diagnóstico de miastenia, porém é pouco utilizada no Brasil. 2 - A JAC constitui-se na introdução de uma agulha fina no músculo do braço e/ou da face. Em seguida você precisa realizar uma contração leve e constante do músculo que está sendo examinado, de acordo com as instruções do médico responsável. A agulha fará o registro da contração do músculo e o tempo aproximado de análise é de 50 minutos para cada músculo examinado, porém este tempo poderá ser reduzido. Se você é um participante saudável apenas um músculo será examinado. Se você estiver em uso de medicação anticolinesterásica, como por exemplo Mestinon, você deverá suspender o uso desta medicação 24 horas antes do estudo, pois o uso deste tipo de medicação prejudica a análise dos registros. Você deverá voltar a tomar a medicação normalmente no mesmo dia, após o exame.

3 - Se você tem diagnóstico ou suspeita de miastenia: será realizada coleta de sangue através de uma picada na veia do antebraço. Se você ainda não realizou um exame de eletroneuromiografia de rotina adequado, será necessária a realização deste exame para tentar confirmar o diagnóstico de miastenia e também para afastar outras doenças que possam estar comprometendo seus nervos e músculos. A primeira etapa do exame de eletroneuromiografia consiste na colocação de eletrodos na superfície da pele, como um adesivo, e na aplicação de estímulos elétricos não dolorosos sobre o nervo. Na segunda etapa o músculo é avaliado através da introdução de uma agulha fina no músculo.

4 - Os procedimentos descritos acima (itens 2 e 3) não oferecem risco para a sua saúde. É esperado um desconforto devido à introdução da agulha e durante os estímulos elétricos repetitivos. Estes estímulos elétricos não são dolorosos. Como complicação da introdução da agulha pode ficar um hematoma (roxo) no local da picada, porém como a picada é superficial, o sangramento pode ser facilmente interrompido com a compressão local e o roxo desaparece em alguns dias. O risco de infecção no local da picada é praticamente zero; será feita a limpeza da pele com álcool no local antes da picada. Se você suspender o uso da medicação anticolinesterásica 24 horas antes do exame, é possível que os sintomas de fraqueza piorem, porém habitualmente isto não ocorre ou não é percebido. Caso você apresente uma piora significativa dos sintomas, você poderá retomar o uso da medicação normalmente.

5 - Não há benefício direto se você é um participante saudável ou se você já tem um diagnóstico estabelecido, porém você estará ajudando a disponibilizar um método mais sensível para o diagnóstico de doenças que afetam a transmissão dos impulsos do nervo para o músculo, o que trará benefícios para as pessoas acometidas por estas doenças. Se você ainda não tem um diagnóstico definido para a sua fraqueza, você poderá se beneficiar diretamente deste estudo, uma vez que os exames que serão realizados auxiliam na investigação de sua doença.

6 - Garantia de acesso: em qualquer etapa do estudo, você terá acesso aos profissionais responsáveis pela pesquisa para esclarecimento de eventuais dúvidas. O principal investigador é o Dr. Paulo Eurípedes Marchiori e a executante é a Dra. FLAVIA COSTA NUNES MACHADO que poderão ser encontrados no endereço Instituto Central do Hospital das Clínicas, Av. Dr. Enéas de Carvalho Aguiar, 155, Ambulatório da Neurologia, terças-feiras das 8:00 às 11:00 horas. Telefone(s): (11) 3069-6106 ou (11) 8527-5903. Se você tiver alguma consideração ou dúvida sobre a ética da pesquisa, entre em contato com o Comitê de Ética em Pesquisa (CEP) - Rua Ovídio Pires de Campos, 225 - 5o andar - tel: 3069-6442 ramais 16, 17, 18 ou 20, FAX: 3069-6442 ramal 26 - e-mail: cappesq@hcnet.usp.br. 
7 - É garantida a liberdade da retirada de consentimento a qualquer momento e deixar de participar do estudo, sem qualquer prejuízo à continuidade de seu tratamento na Instituição;

8 - As informações obtidas serão analisadas em conjunto com outros pacientes, não sendo divulgada a identificação de nenhum paciente;

9 - Você tem o direito de ser mantido atualizado sobre os resultados que sejam do conhecimento do pesquisador;

10 - Você não terá despesas pessoais em qualquer fase do estudo, incluindo exames e consultas. Também não há compensação financeira relacionada à sua participação.

11 - Os dados e o material coletado somente serão utilizados para esta pesquisa.

Acredito ter sido suficientemente informado a respeito das informações que li ou que foram lidas para mim, descrevendo o estudo "Análise do jitter com agulha concêntrica em pacientes com forma ocular em Miastenia Gravis".

Eu discuti com a Dra. Flavia Costa Nunes Machado sobre a minha decisão em participar neste estudo. Ficaram claros para mim quais são os propósitos do estudo, os procedimentos a serem realizados, seus desconfortos e riscos, as garantias de confidencialidade e de esclarecimentos permanentes. Ficou claro também que minha participação é isenta de despesas e que tenho garantia do acesso a tratamento hospitalar quando necessário. Concordo voluntariamente em participar deste estudo e poderei retirar o meu consentimento a qualquer momento, antes ou durante o mesmo, sem penalidades ou prejuízo ou perda de qualquer benefício que eu possa ter adquirido, ou no meu atendimento neste Serviço.

Assinatura do paciente/representante legal

Data: /............................

Assinatura da testemunha

Data: .....................................

\begin{abstract}
Assinatura da testemunha
\end{abstract}
para casos de pacientes menores de 18 anos, analfabetos, semianalfabetos ou portadores de deficiência auditiva ou visual.

(Somente para o responsável do projeto)

Declaro que obtive de forma apropriada e voluntária o Consentimento Livre e Esclarecido deste paciente ou representante legal para a participação neste estudo.

Assinatura da testemunha

Data: ................................... 



\section{APÊNDICE 4}

\section{PROTOCOLO PREENCHIDO PARA O GRUPO CONTROLE}

Projeto: Análise do jitter com agulha concêntrica

Controle número

Data

\section{Dados demográficos}

Nome

DN Idade Sexo

Endereço

Cidade CEF. UF

Telefones e-mail

\begin{tabular}{|l|c|}
\hline Doenças prévias & $($ ) S ( ) N \\
\hline Diabetes & $($ ) S ( ) N \\
\hline Doenças da tireóide & $($ ) $S$ ( ) $N$ \\
\hline Neuropatia periférica & ( ) \\
\hline Neoplasia & $($ ) S ( ) N \\
\hline Outras & \\
\hline Medicações & $($ ) S ( ) N \\
\hline Bloqueadores de canal de Ca & $($ ) S ( ) N \\
\hline Betabloqueadores & $($ ) S ( ) N \\
\hline Toxina botulínica & $($ ) S ( ) N \\
\hline Exposição a agrotóxicos & $($ ) S ( ) N \\
\hline Outros &
\end{tabular}

Análise do jitter

Data

Orbicular do olho (voluntária)

Pares

Média MCD 



\section{APÊNDICE 5}

\section{PROTOCOLO PREENCHIDO PARA O GRUPO DE PACIENTES}

\section{Projeto: Análise do jitter com agulha concêntrica}

\section{Paciente número}

Data

\section{Dados demográficos}

Nome

Prontuário

DN

Idade

Sexo

Endereço

Cidade

CEF

UF

Telefones.

e-mail

( ) MG forma generalizada

( ) MG forma ocular

\section{Classificação - Myasthenia Gravis Foundation of America Traduzido do Inglês}

Pior da doença

Na data atual

Classe I. Qualquer fraqueza nos músculos oculares, possível ptose, todos os outros músculos com força normal.

Classe II. Leve fraqueza de outros músculos pode ter qualquer grau de fraqueza nos músculo oculares.

Ila. Predominantemente em membros ou músculos axiais ou ambos.

Ilb. Predominantemente músculos da orofaringe ou respiratórios ou ambos.

Classe III. Moderada fraqueza de outros músculos, pode ter qualquer grau de fraqueza nos músculo oculares.

Illa. Predominantemente em membros ou músculos axiais ou ambos.

Illb. Predominantemente músculos da orofaringe ou respiratórios ou ambos.

Classe IV. Acentuada fraqueza de outros músculos, pode ter qualquer grau de fraqueza nos músculo oculares.

IVa. Predominantemente em membros ou músculos axiais ou ambos.

$\mathrm{IVb}$. Predominantemente músculos da orofaringe ou respiratórios ou ambos; uso de sonda nasogátrica sem intubação.

Classe V. Necessidade de intubação para manutenção das vias aéreas.

Tempo doença Tempo diagnóstico 
Sinais e Sintomas

\begin{tabular}{|c|c|c|}
\hline Sinais e Sintomas & Pior & Atual \\
\hline Ptose & ( ) S ( ) N & ( ) S ( ) N \\
\hline Diplopia & $($ ) S ( ) N & ( ) S ( ) N \\
\hline Disfagia & ( ) S $\mathrm{S}($ ) $\mathrm{N}$ & $($ ) $S($ ) $N$ \\
\hline Disartria (voz anasalada) & $($ ) S ( ) N & ( ) S ( ) N \\
\hline Fraqueza pescoço & ( ) S ( ) N & ( ) S ( ) N \\
\hline Dificuldade mastigatória & ( ) S ( ) N & $($ ) $S($ ) $N$ \\
\hline Fraqueza MMSS & ( ) S ( ) N & ( ) S ( ) N \\
\hline Fraqueza MMII & ( ) S ( ) N & $($ ) $S($ ) $N$ \\
\hline Fatigabilidade generalizada & ( ) S ( ) N & ( ) S ( ) N \\
\hline Dispnéia & ( ) S ( ) N & $($ ) $S($ ) $N$ \\
\hline Respirador & $($ ) S ( ) N & ( ) S ( ) N \\
\hline Outros & ( ) S ( ) N & ( ) S $\mathrm{S}$ ( ) N \\
\hline
\end{tabular}

\begin{tabular}{|l|l|}
\hline Critério clínico: história e exame físico & \\
\hline Assimetria Ptose & $($ )S ( )N ( ) não tem ptose \\
\hline Resposta anticolinesterásico & $($ )S ( )N ( ) duvidoso \\
\hline Fatigabilidade e/ou flutuação & $($ )S ( )N ( ) duvidoso \\
\hline
\end{tabular}

\section{Critério - Investigação Prévia}

\section{Teste de Fadigabilidade - Data}

Farmacológico

Clínico

\section{ENMG}

Data Normal ( ) S ( ) N

Comentário:

\section{Dosagem de anticorpo}

Data

Qual e valores 


\section{Estudo eletrofisiológico atual - Data}

\section{Estimulação Repetitiva a $3 \mathrm{~Hz}$}

ADM

Trapézio

Orbicular do olho

\section{CNE jitter}

Suspensão do anticolinesterásico $\geq 24$ horas ( )S ( )N

Orbicular do olho (voluntária)

Pares

Média MCD

Número de pares anormais

EMG ( ) S ( ) N

Resultado:

\section{Anticorpos atual - Data}

ac-AChR

Resultado

ac-MuSK

Resultado

\section{Outras investigações}

\section{Imagem do Timo}

Técnica

Data

Conclusão

\section{Outros exames}

glicemia

( ) normal ( ).alterado

TSH

( )normal ( )alterado

T4 livre

( )normal ( )alterado 
Não ( ) Sim ( ) Data.

Histologia.

Doenças Associadas

Não ( ) Sim ( )

Medicações em uso

Anticolinesterásicos.

Corticóide.

Azatioprina

Outros 